\title{
The role of the venous system in hemodynamics during hemodialysis
}

Citation for published version (APA):

Kooman, J. P. (1992). The role of the venous system in hemodynamics during hemodialysis. [Doctoral Thesis, Maastricht University]. Datawyse / Universitaire Pers Maastricht. https://doi.org/10.26481/dis.19920604jk

Document status and date:

Published: 01/01/1992

DOI:

10.26481/dis.19920604jk

Document Version:

Publisher's PDF, also known as Version of record

\section{Please check the document version of this publication:}

- A submitted manuscript is the version of the article upon submission and before peer-review. There can be important differences between the submitted version and the official published version of record.

People interested in the research are advised to contact the author for the final version of the publication, or visit the DOI to the publisher's website.

- The final author version and the galley proof are versions of the publication after peer review.

- The final published version features the final layout of the paper including the volume, issue and page numbers.

Link to publication

\footnotetext{
General rights rights.

- You may freely distribute the URL identifying the publication in the public portal. please follow below link for the End User Agreement:

www.umlib.nl/taverne-license

Take down policy

If you believe that this document breaches copyright please contact us at:

repository@maastrichtuniversity.nl

providing details and we will investigate your claim.
}

Copyright and moral rights for the publications made accessible in the public portal are retained by the authors and/or other copyright owners and it is a condition of accessing publications that users recognise and abide by the legal requirements associated with these

- Users may download and print one copy of any publication from the public portal for the purpose of private study or research.

- You may not further distribute the material or use it for any profit-making activity or commercial gain

If the publication is distributed under the terms of Article $25 \mathrm{fa}$ of the Dutch Copyright Act, indicated by the "Taverne" license above, 


\section{The role of the venous system in hemodynamics during hemodialysis}




\section{CIP-DATA KONINKLIJKE BIBLIOTHEEK, DEN HAAG}

Kooman, Jeroen Peter

The role of the venous system in the regulation of hemodynamics during hemodialysis / Jeroen Peter Kooman ;

yill. from the author]. -Mastricht: Universitaire Pers

Maastricht. - III.

Thes is Maastricht. - With ref.

ISBN 90-5278-015-3

NUGI 742

Subject headings: hemodialysis / venous system /

hemodynamics

1992 No part of this book may be reproduced in any form, by print, photoprint, microfilm or any other means, without written permission from the author and the respective editors of the journals in which the various articles appeared in puint.

Produktie: Datawyse Maastricht, Ruud Leliveld

Druk: Krips Repro Meppel

Omslagillustratie: mevr. A. Ceha-Gerards

The studies in this thesis were made possible by financial support from Baxter"s Extramural Grant Program

Publication of this thesis was financially supported by Baxter Benelux 


\title{
The role of the venous system in hemodynamics during hemodialysis
}

\author{
PROEFSCHRIFT
}

ter verkrijging van de graad van doctor

aan de Rijksuniversiteit Limburg te Maastricht

op gezag van de Rector Magnificus, Prof. mr. M.J. Cohen, volgens het besluit van het College van Dekanen, in het openbaar te verdedigen

op donderdag, 4 juni 1992 om 16.00 uur

door

Jeroen Peter Kooman 
Promotores:

Co-promotor:

Beoordelingscommissie: prof. dr. J.P. van Hooff prof. dr. P.W. de Leeuw

dr. K.M.L. Leunissen

prof. dr. H.A.J. Struijker Boudier (voorzitter) prof. dr. J.W. Arends

prof. dr. L.W. Henderson (Crystal Lake, USA) prof. dr. R.S. Reneman prof. dr. E. Ritz (Heidelberg, Germany) 
aan mijn ouders 


\section{CONTENTS}

CHAPTER 1

Introduction to the study

CHAPTER 2

Methods used to assess venous compliance and venoconstriction

\section{CHAPTER 3}

Blood pressure measurements during the inter-dialytic period in hemodialysis patients; estimation of representative blood pressure values

\section{CHAPTER 4}

Compliance of the peripheral venous system in patients treated with chronic intermittent hemodialysis

\section{CHAPTER 5}

Morphological changes of the venous system in uremic patients

CHAPTER 6

The role of venous compliance in hemodynamics during ultrafiltration

CHAPTER 7

Reactivity of the peripheral venous system in patients treated with chronic intermittent hemodialysis

\section{CHAPTER 8}

The role of the venous system in hemodynamics during isolated ultrafiltration and bicarbonate dialysis 
CHAPTER 10

125

Samenvatting

NAWOORD

133

CURRICULUM VITAE

135 



\section{CHAPTER 1}

\section{Introduction to the study}

\section{ABSTRACT}

Hypotensive periods during hemodialysis are a frequently occurring phenomenon. In this chapter, the major pathophysiologic mechanisms behind the cardiovascular instability in hemodialysis patients are discussed, with special attention for the possible role of the venous system in this aspect.

Furthermore, the aims of this study are presented. 


\section{INTRODUCTION}

In the Netherlands, more than 2400 patients with end-stage renal failure are treated with chronic intermittent hemodialysis (1). This number will continue to rise, due to the shortage of donor kidneys available for renal allografting and because of the wider acceptance of elderly patients and patients with a dysfunction of other organs, in whom transplantation is often not possible for medical reasons.

In patients with end-stage renal failure, uremic toxins are not eliminated and the electrolyte- and acid-base status of the body will be disturbed. Furthermore, body water will increase, which may lead to hypertension and pulmonary edema (2). During chronic intermittent hemodialysis, these disturbances in the milieu interieur are corrected with the help of an artificial kidney. In this artificial kidney, blood is separated by a semipermeable membrane from the dialysate, a solution resembling normal extracellular fluid (3). Due to concentration differences between the two compartments, molecules diffuse from blood to diallysis fluid and vice versa. Thus, uremic toxins are removed and disturbances of electrolyte and acid-base status are corrected. The excess of body water is removed by ultrafiltration, i.e by convective transport generated by differences in pressure between the blood and dialysate compartment (3). Ultrafiltration can be performed with or without (isolated ultrafiltration) the presence of dialysis fluid.

In contrast to the continuous function of the human kidney, hemodialysis is usually performed intermittently in a relatively short period of time, i.e. 2-3 times weekly during 3-5 hours, which will induce profound changes in the milieu interieur of the patient. This may lead to loss of hemodynamic stability (4) during hemodialysis treatment, which is both unpleasant and potentially dangerous. That progressively more older patients and patients with cardiovascular diseases are being treated with chronic intermittent hemodialysis increases the morbidity imposed by these hypotensive periods. In this population hypotension may even lead to myocardial infarction and cerebrovascular accidents (4).

The cause of hypotensive periods during hemodialysis is multifactorial, but there are two major factors which play a role: the decrease in plasma volume and the inability of various cardiovascular regulatory mechanisms to compensate for the fall in blood pressure $(5,6)$. 


\section{PLASMA VOLUME PRESERVATION}

When fluid is removed during hemodialysis treatment, plasma volume can be partly preserved because of refill from the interstitium.

Plasma volume preservation mainly depends on the capillary Starling forces, which regulate the movement of fluid from the capillaries to the interstitial fluid or vice versa. This fluid movement is dependent on hydrostatic and oncotic forces. The hydrostatic pressure over the capillary wall is determined by the arterial blood pressure, the arteriolar versus postcapillary resistance and the tissue interstitial pressure (7). In normal circumstances, the hydrostatic pressure on the arterial side of the capillary system will move fluid into the interstitium. However, towards the venular side of the capillary system, the hydrostatic pressure decreases whereas the oncotic pressure remains equal, due to the relative impermeability of the capillary wall for proteins. This will move fluid from the interstitium back into the vascular system (6). Under normal circumstances, this interplay between hydrostatic and oncotic forces will lead to an equilibrium with virtually no netto fluid shifts (7).

However, during a large decline in plasma volume, the hydrostatic pressure at the venular side of the capillary bed decreases, which together with arteriolar constriction will result in an inward fluid shift from the interstitium to the vascular system, tending to compensate for the amount of plasma volume lost (5).

Hemodialysis treatment itself interferes directly with the capillary Starling equilibrium.

In the dialysate fluid, a buffer is present for correction of the acidosis. As buffer base, acetate or bicarbonate can be used (3). Acetate induces arteriolar vasodilation, which increases capillary hydrostatic pressure and will move fluid from the vascular system into the interstitial fluid (8). Bicarbonate, on the other hand, has less vasodilating properties, will therefore exert a more favourable effect on plasma volume preservation (5).

Several other factors related to the dialysis treatment itself can also influence plasma volume preservation. The use of a high ultrafiltration rate will lead to a rapid fall in plasma volume which can not be completely compensated for by the refill of fluid from the interstitium (5). Furthermore, the choice of the sodium concentration in the dialysate fluid can also influence the decline in plasma volume during dialysis treatment. When fluid is removed by isolated ultrafiltration, water is removed by convective transport induced by differences in hydrostatic pressure between the blood and dialysate compartment. Together with water, solutes are transported from the blood to the dialysate compartment as well. Thus, the fluid removed is isotonic with plasma and the osmolality of the blood will not change (9). When ultrafiltration is performed together with 
hemodialysis, ureum will diffuse from the blood into the dialysate compartment. The fluid removed by ultrafiltration combined with hemodialysis is hypertonic compared to plasma (9). Ureum rapidly equilibrates between the vascular system and the interstitial fluid, whereas, when ureum is removed rapidly, the transport over the cellular membrane may lag behind. Therefore, the extracellular fluid may become hypotonic to the intracellular fluid, and fluid will move into the cell. When the sodium concentration in the dialysate is high, sodium will diffuse into the blood and interstitial fluid, which can partly prevent the fall in osmolality during hemodialysis. The smaller osmotic gradient between intra- and extracellular compartments results in a smaller volume shift from the extracellular fluid into the cells, preventing a major decrease in plasma volume (10).

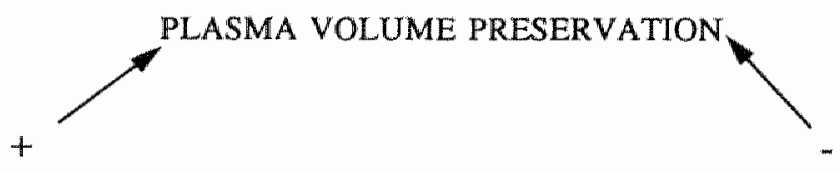

Bicarbonate dialysis

Moderate ultrafiltration rate

High sodium dialysis

Optimal fluid status
Acetate dialysis

High ultrafiltration rate Rapid fall in osmolality Hypovolemia

Figure 1. Factors influencing plasma volume preservation in hemodialysis patients

The volume status of the patient has a profound influence on the fall in plasma volume during hemodialysis. When a patient is hypervolemic, the interstitial fluid is well hydrated. Therefore, the refill of plasma volume from the interstitium will be high. When a patient is ultrafiltrated until hypovolemia, the interstitium becomes relatively dry and refill of plasma volume from the interstitium is hampered (11). Also the fact that the compliance (volume/ pressure relationship) might be higher in the hypervolemic state compared with the hypovolemic state (12) could play a role in the difference in refill of plasma volume between hyper- and hypovolemia. When the compliance of the interstitium is high, even large changes in interstitial volume will only lead to small changes in interstitial pressure, resulting in a significant refill of plasma volume from the interstitium (13). However, when a patient is ultrafiltrated until hypovolemia, the compliance of the interstitium decreases (12) and refill of plasma volume is hampered (11), leading to a rapid fall in plasma volume. 
Whatever the mechanism, it is important to estimate the exact amount of volume which has to be removed during hemodialysis by determining the optimal 'dry weight' of the patient. Dry weight is often defined as the weight at the end of dialysis below which the patient more often than not will become hypotensive (4). However, hypotensive periods can also be caused by other factors than hypovolemia (6). Because clinical and radiological parameters are notoriously inaccurate in predicting the volume status of the dialysis patient (14), a new technique was developed in our department for the objective estimation of the volume status of the patient: the echographic measurement of the inferior caval vein diameter. The inferior caval vein diameter correlates highly significantly with the right atrial pressure and with total blood volume and has proven to be a reliable and reproducible tool for the adequate assessment of post-dialytic dry weight $(15,16,17)$.

Finally, as discussed above, the postcapillary resistance is an important determinant in the regulation of the capillary Starling forces. An increase in venous pressure will tend to move fluid outward from the vascular system into the interstitial fluid, which cannot be entirely compensated for by precapillary constriction (18). The relation between venous pressure and volume is determined by the compliance (i.e. the volume/pressure relationship) of the venous system (19). A reduction in venous compliance leads to a higher venous pressure for a given amount of plasma volume and will therefore decrease the inward movement of interstitial fluid into the capillary bed (20). Therefore, a reduction in venous compliance may interfere with plasma volume preservation during hemodialysis, as will be discussed later.

\section{CARDIOVASCULAR REGULATORY MECHANISMS}

When plasma volume declines in a healthy subject, compensatory mechanisms will initially prevent a fall in blood pressure (12).

Blood pressure is determined by cardiac output and peripheral vascular resistance (12). Thus, either peripheral vascular resistance has to rise or cardiac output has to rise or remain stable to maintain hemodynamic stability. 


\section{Peripheral vascular resistance}

When blood volume is diminishing, this is first sensed by the low-pressure receptors located in the atria and pulmonary veins and later, when the hypovolemia becomes more serious also by the high-pressure receptors located in the aorta and carotid arteries (12). A decreased blood volume reduces the amount of inhibitory impulses through the glossopharyngeal and vagal nerves to the vasomotor centre in the medulla oblongata. As a result, the activity of the sympathetic system increases which constricts the resistance vessels of skin and muscle while plasma noradrenaline levels rise moderately. When the arterial pressure falls, also the number of inhibitory impulses from the pressoreceptors to the medulla oblongata decreases, leading to an increased sympathetic outflow to the splanchnic bed and a rise in plasma concentration of renin, aldosteron and vasopressin. At still higher levels of hypovolemia, the adrenal medulla releases large amounts of catecholamines (12).

In hemodialysis patients, the rise in peripheral vascular resistance is often inadequate for the amount of plasma volume lost. The following factors might be responsible for the inadequate rise of the peripheral vascular resistance during hemodialysis treatment:

1) Uremic autonomous neuropathy is present in a significant number of hemodialysis patients (21). One of the characteristics of uremic autonomous neuropathy is an abnormal reaction to the Valsalva manoeuvre, pointing towards a disturbance in the baroreceptor reflex arc (17). It is, however, still a matter of debate whether this disturbance plays a role in the pathogenesis of the impaired vascular reflexes during hemodialysis $(22,23)$.

2) In experimental uremia, an end-organ resistance for the effect of catecholamines has been reported (24). Although the concentration of catecholamines is increased in hemodialysis patients (25), the reactivity of the vascular wall towards the effect of catecholamines is reported to be diminished (26).

3) The dialysis treatment itself might interfere with the vascular reaction during a decline in plasma volume; the hemodynamic stability during isolated ultrafiltration is superior compared to ultrafiltration combined with hemodialysis. During acetate-, but also with bicarbonate dialysis, the rise in peripheral vascular resistance and the increase in catecholamines is significantly smaller than during ultrafiltration-only $(6,27,28)$. This may be due to rapid changes in electrolyte (29) or acid-base status (30) of the patient or to the washout of catecholamines through the dialysis membrane (6). Furthermore, the increase in body temperature during hemodialysis may also impair vasoconstriction during a decline in plasma volume (6). 


\section{Cardiac output}

Cardiac output depends upon myocardial contractility, heart rate and cardiac filling pressure and the afterload (12). Many hemodialysis patients have an impaired left ventricular function, resulting from atherosclerosis, hypertension or from a direct effect of uremia (31). In patients with normall cardiac function, hemodialysis treatment itself has no adverse effect on myocardial contractility (8); the influx of ionized calcium from the dialysate may even increase myocardial performance (32). However, in patients with decreased left ventricular performance, the use of acetate as dialysate buffer can seriously depress cardiac function (33).

Uremic autonomous neuropathy may blunt the heart rate increase during hypovolemia in hemodialysis patients (21). Nevertheless, when plasma volume falls substantially, heart rate will rise (33), perhaps due to the effect of catecholamines released from the adrenal medulla. The hemodynamic importance of the increased heart rate during hypovolemia in the maintenance of vascular stability during hypovolemia has recently been questioned by experimental studies (6).

Left ventricular
volume $\begin{aligned} & \text { Myocardial } \\ & \text { contractility } \\ & \text { Left ventricular compliance } \\ & \text { Venous return }\end{aligned}$

Figure 2. Factors influencing cardiac output in hemodialysis patients

One of the major determinants of cardiac output is the cardiac filling pressure (6). Especially patients with decreased left ventricular compliance, a common finding in hemodialysis patients (32), are dependent upon adequate filling pressures for maintaining an adequate cardiac output. Inadequate cardiac filling during hypovolemia may induce syncope through the Bezold-Jarisch reflex, which is a vagal reflex initiated by stimulation of cardiac mechanoreceptors in a vigorously contracting hypovolemic left ventricle (35).

Venous return is the major determinant for the cardiac filling pressure. Therefore, the venous system plays a very important role in the regulation of hemodynamics of the human body (12). However, whereas most investigations 
have been directed towards the role of the heart and resistance vessels in the induction of hemodynamic instability during hemodialysis, the venous system has received little attention so far.

The role of the venous system in the regulation of cardiovascular hemodynamics and its possible role in the induction of hypotensive periods during hemodialysis will be discussed below.

\section{THE VENOUS SYSTEM}

In 300 A.D. Galen, whose theories influenced medical thinking throughout the entire middle-ages and renaissance period, postulated that the circulatory system was the residence of the vital and animal spirits, in which the blood ebbed to and fro. He stated that the veins originated in the liver in order to conduct the blood to the heart (36). In those days, the veins were regarded as more important than the arteries in the transport of blood. Galen, however, was not the first to display an interest in the cardiovascular system. Around $350 \mathrm{~B}$.C. Aristotle advocated the importance of the vascular system in the circulation of humors, although he did not differentiate between arteries and veins (37). Some decades later, Herophilos even made the first morphological study of the arteries and veins. However, it was not until the 17 th century that William Harvey first gave a clear description of the circulatory system as a whole and, although he rather confined his interest to the arterial system, he recognized the venous system as a determinant in the return of blood to the heart (27). In the second half of the 20th century Guyton again acknowledged the major importance of venous return in the regulation of cardiac output (38).

The venous system serves as 1) a blood reservoir for that part of the blood volume that is hemodynamically inactive and 2) as a conductance system for the backflow of blood from the periphery to the heart (19); by shifting between hemodynamically active and inactive compartments the venous system can rapidly provide the blood needed to maintain cardiac output at an optimal level (39).

Therefore, whereas the precapillary vessels mainly operate locally in response to the metabolic needs of the tissue, the veins serve in the integrated cardiovascular response as a rapidly adjustable system for the control of cardiac output (39).

In the following pages, the anatomy, pharmacology and pathophysiology of the venous system will be discussed. 


\section{Anatomy}

In the embryo, veins of the body wall and of the digestive tube originate from two different structures; the former develop from mesenchymal tissue of the body wall, whereas the latter arise from the fetal visceral peritoneum. Despite some differences in their relative sensitivity towards vasoactive substances (40), their basic structure is not notably different.

Veins and venules are, like the precapillary blood vessels, composed of three different layers: intima, media and adventitia (41). However, the diameter and wall-to-lumen ratio of veins are respectively larger and smaller in veins compared to their precapillary counterparts; the wall-to-lumen ratio of veins and venules is approximately $0.1-0.2$, compared to 1.3 in arterioles (19).

The ultrastructure of the postcapillary vessels partly depends upon the distance to the heart. Like in capillaries, a large part of the wall of the collecting venules (diameter $8-50 \mu$ ), which mainly serve as exchange vessels, is formed by endothelium (42). In muscular venules (diameter: $50-100 \mu$ ) and in veins (diameter $>100 \mu$ ), which mainly serve a capacitance and conductance function, the media and adventitia become more prominent (41).

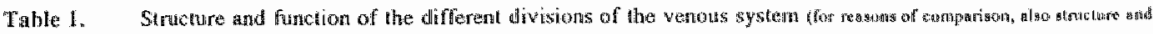
function of the precapillary vessels and capillaring ate promidentid

\begin{tabular}{|c|c|c|c|c|c|c|c|}
\hline & $\begin{array}{l}\text { Elastic } \\
\text { arteries }\end{array}$ & $\begin{array}{l}\text { MoBgcular } \\
\text { qrterties }\end{array}$ & Arterioles & Capillantum: & $\begin{array}{l}\text { Collecting } \\
\text { venules }\end{array}$ & $\begin{array}{l}\text { Musculis } \\
\text { vemules }\end{array}$ & Veins: \\
\hline Disumeter & $>200$ n.m & $150 \mu \mathrm{m}-2 \mathrm{mH}$ & $8-150 \mu m$ & $<8,8 \pi$ & $8-50 \mu=1$ & $50-1009_{\mu}$. HE & $\Rightarrow W_{\mu 11 日}$ \\
\hline Endothelium & + & +4 & +4 & $+4+4$ & $+4+4$ & +1 & + \\
\hline Meglata & $+4+$ & $4+4$ & $4-t$ & - & +1 & 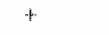 & + \\
\hline Srimorolh muscle & 4 & +40 & $+4+4$ & $*$ & $+\%$ & $4+$ & fo ti: \\
\hline Colluger & 4 & + & + & - & +4 & \# & it \\
\hline Elastin & $\#+4$ & + & -it. & - & + & 4 & + \\
\hline Function & 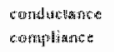 & $\begin{array}{l}\text { compliathe } \\
\text { resiptance. }\end{array}$ & ateisha!s: & exphonge & $\begin{array}{l}\text { cacharige } \\
\text { aptutituree }\end{array}$ & 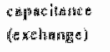 & 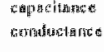 \\
\hline
\end{tabular}


Most of the superficial and deeper veins of the extremities and viscera have a diameter of 1-10 mm, whereas the large veins, (i.e. caval, portal, brachiocephalic, external iliac, renal and external jugular veins) have a diameter larger than $10 \mathrm{~mm}$. The intima of a large -or medium sized vein mostly consists of only one layer of endothelium. In most veins a lamina elastica interna is present between the intima and the media, whereas the lamina elastica externa between media and adventitia is absent. The media of the venous wall is also less pronounced compared with an arteriolar media and contains circular smooth muscle, elastin and collagen fibres, The relatively well proportioned adventitia contains collagen fibres and, in larger veins, longitudinal smooth muscle fibres (41).

Also the composition of the venous wall is related to the distance to the heart. In venules; $80 \%$ of the vessel wall is composed of collagen, whereas the vena cava contains up to $40 \%$ collagen. All veins larger than $30 \mu \mathrm{m}$ possess a relatively constant amount of smooth muscle cells, which contribute for about $30-40 \%$ to the composition of the venous wall. Elastin is absent in the smaller postcapillary venules, whereas the larger veins contain approximately $20 \%$. Thus, the composition of the venous wall also differs between veins and precapillary vessels. The relative amount of collagen is greater in veins than in arteries and arterioles, whereas the latter contain relatively more smooth muscle cells. Large arteries contain a relatively high amount of elastin and a relatively low amount of smooth muscle compared to arterioles and veins (19).

In addition to their place in the vascular tree, the localisation in the body influences the ultrastructure of the venous wall as well. The wall-to-lumen ratio of veins which have to resist hydrostatic pressure, like the deeper veins in the lower extremities, is larger, as is their relative amount of smooth muscle (43). Veins are well innervated by postganglionic unmyelinated sympathetic fibres, although to a lesser degree than the resistance vessels. The nerve terminals are situated in the adventitia or at the margin between media and adventitia, but also, in contrast to precapillary vessels, in the media itself (44). Especially the cutaneous and splanchnic veins are well innervated whereas skeletal veins hardly possess nerve terminals (45).

The adrenergic receptors on the venous smooth muscle cells are mainly of the $\alpha_{1}$ - or $\alpha_{2}$-subtype, although the functional importance of the $\alpha_{1}$-subtype seems to be greater (46). Direct stimulation of these receptors causes venous smooth muscle contraction. B-receptors are also present in the venous wall, although to a far lesser degree (43), When stimulated in a preconstricted vein, they cause venodilation (40). 


\section{Pharmacology}

The capacitance and resistance vessels differ in their response to vasoactive substances. Whereas resistance vessels exhibit an intrinsic vascular tone, the resting tone of the veins is minimal $(45,47)$. Therefore, in healthy subjects, veins have to be preconstricted to assess possible venodilating actions of a certain drug (48).

Resistance vessels consist of 'multi-unit' smooth muscle cells in which the tone is for a large part dependent upon the activity of the voltage-gated calcium channels. These stimulate the influx of extracellular calcium through the plasma membrane which results in contraction of the smooth-muscle cells. In contrast, veins, consisting of 'single-unit' smooth muscle cells, are mainly dependent upon sympathetic activity or circulating catecholamines for their contraction (45). All veins and venules larger than $40 \mu$ constrict in response to catecholamines (19). Smooth muscle contraction due to the effect of catecholamines occurs by stimulation of the $\alpha_{1}$ - and $\alpha_{2}$ adrenergic receptors. After stimulation of an $\alpha_{1}$ " adrenoceptor, a G-protein is activated. The activated $\mathrm{G}$-protein stimulates membrane-bound phospholipase-C. Phospholipase $\mathrm{C}$ induces the breakdown of the membrane lipid $\mathrm{PIP}_{2}$ into $\mathrm{IP}_{3}$, which leads to a release of intracellular calcium, resulting in contraction of the smooth muscle cell (7). This pathway is different from the one that occurs after B-receptor stimulation, which leads to activation of adenylate cyclase and of the second messenger CAMP, resulting in vasodilation (47). Vasoconstriction after $\alpha_{2}$-adrenoceptor activation results from inhibition of cAMP production through an inhibitory G-protein.

From the following it will be clear that drugs that act by blocking the voltagegated calcium channels, like calcium-entry blockers, will have little effect on the venous system (49). In contrast, drugs that selectively block the $\alpha$-adrenergic receptors will be more effective in dilating veins constricted by an increased sympathetic tone (47), because, as mentioned above, veins are dependent upon sympathetic activation for constriction.

Angiotensin II is a powerful constrictor of resistance vessels but its effect on venous tone is less clear (50). However, angiotensin converting enzyme blockers are effective venodilators (47). Probably, angiotensin III potentiates the effect of the sympathetic system on venous tone. An alternative explanation is that the veins dilate in response to the increased bradykinin levells (45) caused by blocking of the converting enzyme (51).

The organic nitrates have a predominantly venodilating action (52), which is independent from their effect on endothelium, although the same pathway is followed as in endothelium-dependent vasodilation (53); nitroglycerin is converted to nitric oxide, which is the final common pathway for endotheliumdependent vasodilatation $(54,55)$. Nitric oxide stimulates the activation of soluble 
guanylate cyclase, which leads to an increase in the intracellular c-GMP concentration (54). This, in turn, induces a fall in the intracellular calcium concentration. Moreover, the hydrolysis of phosphatidyl-inositol, a step in the noradrenaline-induced vasoconstriction, is blocked by c-GMP. This latter action would explain why veins are more responsive to the effect of organic nitrates than resistance vessels because the latter are less dependent upon a noradrenaline-mediated mechanism for constriction (47).

Atrial natriuretic peptide, a vasodilating and natriuretic substance, released in response to increased left and right atrial wall stress (16), also stimulates the release of c-GMP through activation of particulate guanylate cyclase (56).

However, its venodilating effect remains unclear. Although observed venodilation after administration of atrial natriuretic peptide (57), other authors could not reproduce their results $(58,59)$.

Endothelium-dependent venoconstriction and dilatation also play a role in the regulation of venous tone: the venodilating effects of bradykinin and acetylcholine are regulated through activation of nitric oxide (54), whereas the endothelium-dependent vasoconstrictor endothelin, whose physiological function is yet largely unknown, has a powerful venoconstricting effect (60).

\section{Pathophysiology}

Approximately $60-80 \%$ of the total blood wolume resides in the venous system, approximately $45 \%$ in the smaller veins and venules $(<100 \mu)$ and approximately $35 \%$ is located in the larger veins (19).

The venous system can conceptually be regarded both as a conductance system, which serves for the backflow of hemodynamically active ('stressed') blood from the peripheral vessels to the heart and in a blood reservoir for hemodynamically inactive ('unstressed') blood $(19,61)$.

Venous return is influenced both by the volume/pressure relationship of the stressed compartment (venous compliance) and by the translocation of blood from the blood reservoir to the hemodynamically active compartment (venoconstriction) (61).

Venous compliance, in the absence of sympathetic stimulation, is mainly determined by the morphological characteristics of the venous wall (45). As discussed above, the basic structure of the veins is similar to that of arteries. However, the wall-to-lumen ratio of veins is much smaller compared to that of precapillary vessels (19), which may explain the higher compliance of the capacitance bed (12).

Because of the large amount of blood volume stored in the venous system, the compliance of the capacitance bed is of major importance in the regulation of 
hemodynamics of the human body. When venous compliance is reduced, the venous system is more sensitive to changes in plasma volume (61). Because of the reduced volume/pressure relationship a small increase in plasma volume will lead to a rapid rise in venous pressure (62), whereas a small drop in plasma volume may lead to a steep decline in venous pressure (61).

In addition to venous compliance, the translocation of blood from unstressed to stressed compartments or vice versa is of great importance in the regulation of venous return to the heart. Unstressed blood volume is the volume present in the vascular system at zero transmural pressure. In the resting state, about $60 \%$ of the blood volume is hemodynamically inactive (61). A major part of the unstressed blood volume is probably located in blood reservoirs in the splanchnic venous system (19). However, also a significant amount is likely to be present as blood volume serving to 'prime' the venous system, i.e. to maintain a circular cross-section in the vein in order to prevent the vein from collapsing (61). With an increase in smooth muscle tone, less blood is needed to keep the vein in a circular state (63) and therefore, unstressed volume decreases.

\section{VENOUS SYSTEM}

CONDUCTANCE

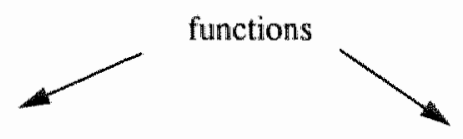

'stressed"

blood volume

(hemodynamically active)

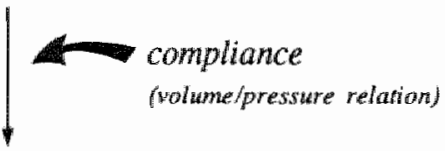

VENOUS RETURN
RESERVOIR

"unstressed"

blood volume

(hemodynamicatly

inactive)

Figure 3. The hemodynamic regulation of venous return 
During hypovolemia, unstressed blood volume can be mobilized by an increase in smooth muscle tone of the venous wall $(61,64)$. As discussed above, all larger venules and veins contain smooth muscle cells in their media (19). Venous smooth muscle constricts in response to direct sympathetic stimulation. Especially cutaneous and splanchnic veins are well innervated by sympathetic nerves. Skeletal veins do not have many nerve terminals, but constrict in response to circulating catecholamines (45). Although sympathetic stimulation may also influence the compliance of the venous system to some extent, the increase in venous smooth muscle tone mainly results in mobilization of unstressed blood volume $(19,35,64)$.

In addition to active venoconstriction, unstressed blood volume can also be mobilized by passive venoconstriction. Passive venoconstriction occurs by the deJager-Kroch phenomenon; when the flow through the compliant venous bed is reduced by constriction of the resistance vessels, the vein will collapse by passive recoil, which leads to translocation of blood from the unstressed to the stressed compartment. The opposite takes place during blood transfusion; the veins are passively dilated and blood is stored as unstressed volume (65).

Whether active or passive venoconstriction plays the largest role in the mobilization of unstressed blood volume and therefore in the regulation of venous return during a decline in plasma volume is still unknown and difficult to study. However, both mechanisms are probably of great importance in the control of cardiac output during hypovolemia (19).

In addition to their capacitance function, venules and veins also serve as resistance vessels, although to a much lesser degree compared with precapillary vessels because of their larger diameter (19). However, because the difference between pre- and postcapillary resistance is of major importance in the regulation of the capillary Starling equilibrium (see above), the resistance of the postcapillary venules plays an important role in the fluid exchange between capillaries and interstitial fluid (18).

The main site of the venous resistance is believed to be located in the venules and smaller veins. The exact site of maximal venous resistance is not well known, but probably lies upstream (i.e. closer to the capillary system) from the place where the largest a mount of blood volume is stored (19). However, also larger veins can, in a state of collapse, significantly contribute to venous resistance $(18,38)$. 


\section{POSSIBLE ROLE OF THE VENOUS SYSTEM IN THE INDUCTION OF HYPOTENSIVE PERIODS DURING HEMODIALYSIS}

\section{Venous compliance}

Venous compliance determines the basal wolume/pressure relationship of the hemodynamically active part of the venous system, in contrast to capacitance, which can be defined as the volume/pressure relationship of the entire venous system $(19,61)$. When venous compliance is reduced, a minor drop in plasma volume may, because of the reduced volume/pressure relationship, lead to a major drop in venous pressure, which in turn leads to a decline in cardiac filling pressure and, in case of inadequate compensatory mechanisms, to a decrease in cardiac output. The opposite is also true, when plasma volume increases, the concomitant rise in venous pressure is larger when venous compliance is reduced (62). Thus, a reduction in venous compliance increases the susceptibility of the venous system to changes in plasma volume.

A reduction in venous compliance may also impair the preservation of plasma volume by a change in the capillary Starling equilibrium. Because of the reduced volume/pressure relationship, the pressure in the capillary bed is higher for a given amount of plasma volume (20). This may impair the refill of plasma volume from the interstitium.

Why should venous compliance be reduced in hemodialysis patients?

As mentioned above, the diameter of the inferior caval vein is highly significantly correlated with right atrial pressure and plasma volume in hemodialysis patients (15). A similar good correlation was observed by other authors in patients with right ventricular dysfunction and in healthy controls $(66,67)$. However, when comparing the curves relating the inferior caval diameter to right atrial pressure between hemodialysis patients and healthy controls, a shift towards the pressure axis was observed in hemodialysis patients, suggesting a reduced venous volume/pressure relationship in hemodialysis patients compared to controls, which might result from structural or functional changes of the venous system.

The frequent occurrence of hypertension in hemodialysis patients (68) might play a role in the reduction of venous compliance in this group. A decreased venous compliance has been found in patients with essential hypertension $(20,62,69)$, possibly due to structural changes of the venous wall $(67,68)$. Functional changes in venous compliance might result from increased plasma levels of vasoactive substances, like catecholamines (25) and angiotensin-II (71) in hemodialysis patients. However, a reduced reactivity of the vascular wall to the effect of catecholamines has also been observed in dialysis patients (26). 
In this thesis, it was assessed whether venous compliance was reduced in hemodialysis patients compared to controls and if so, whether this reduction resulted from structural and/or functional changes. Furthermore, the hemodynamic impact of a reduction in venous compliance was studied in hemodialysis patients during isolated ultrafiltration.

\section{Venoconstriction}

As stated above, during a decline in plasma volume, hemodynamically inactive blood can be mobilized both actively by an increase in venous smooth muscle tone and by passive venoconstriction resulting from a decrease in flow through the postcapillary bed (65). Few investigators have directly observed the behaviour of the venous system during hemodialysis; Bradley et al. (72) and Nakamura et al. (73) found inadequate venoconstriction during dialysis. However, only in the former study (72), bicarbonate was used as dialysis buffer whereas in the other study (73) acetate was used, known for its vasodilatory properties (8).

An inadequate increase in venous tone in hemodialysis patients might result from uremic autonomous neuropathy, as demonstrated by an abnormal response towards the Valsalva manoeuvre (21) or by chronic end-organ resistance for the effect of catecholamines (26). Furthermore, the dialysis treatment itself may lead both to an acute decrease in catecholamine levels as well as an acute reduction in vascular reactivity (28), supported by the fact that the rise in peripheral vascular resistance is normal when fluid is removed during isolated ultrafiltration (27).

In this thesis, it was investigated whether the reactivity of the venous system to an efferent sympathetic stimulus was normal in hemodialysis patients. Moreover, because the dialysis treatment itself could influence venoconstriction, the venous response to a decline in plasma volume was assessed during isolated ultrafiltration and during ultrafiltration combined with bicarbonate dialysis. It was also assessed whether a relation existed between the response towards the Valsalva manoeuvre and the hemodynamic response during the different treatment modalities. 


\section{AIMS OF THE STUDY}

This thesis is divided into three major parts.

I. In the first part, the methods used to assess venous compliance and venoconstriction are discussed (chapter 2 ). Furthermore, because hypertension may have a strong impact on venous compliance, representative blood pressure levels are necessary to adequately assess the presence of hypertension in hemodialysis patients. However, pre-dialytic and post-dialytic blood pressure often differ and it is not known which value should be taken as a representative value for the inter-dialytic blood pressure. Therefore, ambulatory blood pressure measurements were performed during the inter-dialytic period in order to assess representative blood pressure values in hemodialysis patients (chapter 3).

II. In the second part, the basal state of the venous system (Venous compliance) and its influence on hemodynamics during isolated ultrafiltration was studied.

In chapter 4, it was studied whether venous compliance is reduced in hemodialysis patients and, if so, whether this reduction is reversible by shortterm pharmacological intervention.

In chapter 5, it was investigated whether structural abnormalities of the venous wall are present in hemodialysis patients.

In chapter 6, the hemodynamic impact of venous compliance on plasma volume preservation and on the fall in central venous pressure was assessed during isolated ultrafiltration.

III. In the third part, the active reaction of the venous system (Venoconstriction) was studied during a sympathetic stimulus, during isolated ultrafiltration and during ultrafiltration combined with bicarbonate dialysis.

In chapter 7, the reactivity of the venous system to a sympathetic stimulus was investigated in hemodialysis patients and compared to the venous reactivity of healthy controls.

In chapter 8 , it was assessed whether the response of the venous system differs when fluid is removed during bicarbonate dialysis or during isolated ultrafiltration. Furthermore, the hemodynamic reaction during the different treatment modalities was related towards the response to the Valsalva manoeuvre. 


\section{REFERENCES}

1. Tufveson $G$, Geerlings W, Brumer FP, Brynger $H$, Dijkes SR, Ehrich JHH, Fassbinder W, Gizzonil $G_{1}$, Schroedt HH, Wing $A J$. Combined report on regular dialysis and transplantation in Europe, XXI, 1990. Nephrol Dial Transpl 1991; 6 (supp 4).

2. Petersdorf RA et al (editors). Harrison"s principles of internal medicine. McGraw-Hill international book company. 10 th edition, 1983.

3. Daugirdas JT, Ing TS (ed). Handbook of dialysis. Little, Brown \& Co. 1988.

4. Henderson LW. Symptomatic hypotension during haemodialysis. Kidney Int 1980; 17:571-576.

5. Leunissen KML, Noordzij TC, van Hooff JP. Pathophysiologic aspects of plasma volume preservation, Contrib Nephrol 1990; 78:201-211.

6. Daugirdas JT. Dialysis hypotension; a hemodynamic analysis. Kidney Int 1991; 39:233246.

7. Rose BD. Clinical physiology of acid-base and electrolyte disorders. Mc-Graw Hill. 3rd Edition, 1989.

8. Leunissen KML, Cheriex EC, Janssen JHA, Teule GJ, Mooy JMV, Ramentol M, van Hooff JP. Influence of left ventricular function on changes in plasma volume during acetate and bicarbonate dialysis. Nephrol Dial Transplant 1987; 2:99-103.

9. Rodriguez M, Pederson JA, Llach F. Effect of dialysis and ultrafiltration on osmolality, colloid osmotic pressure, and vascular refilling rate. Kidney Int 1985; 28:808-813.

10. Fleming SJ, Wilkinson JS, Greenwood RN, Aldridge C, Baker LRI, Cattel WR. Effect of dialysate composition on intercompartment fluid shift. Kidney Int 1987; 32:267-273.

11. Koomans HA, Geers AB, Dorhout Mees EJ. Plasma volume recovery after ultrafiltration in patients with chronic renal failure. Kidney Int $1984 ; 26: 848-854$.

12. Guyton AC: Textbook of Medical Physiology. 7th Edition, W.B. Saunders \& Co, Philadelphia/London/Toronto, 1986.

13. Stiller $S$, Thömmes A, Königs F, Scallenberg U, Mann H. Characteristic profiles of circulating blood volume during dialysis therapy. ASAIO Trans 1989; 35:530-532.

14. Keshavia PR, Shaldon S. Hemodialysis monitors and monitoring. In: W Drukker (ed). Replacement of renal function by dialysis. Martinus Nijhoff Publishers Boston. 2nd Edition. 1983.

15. Cheriex EC, Leunissen KML, Janssen JHA, Mooy JMV, wan Hooff JP. Echography of the vena cava inferior is a simple and reliable tool for the estimation of dry weight in hemodialysis patients. Nephrol Dial Transpl 1989; 4:563-568.

16. Leunissen KML, Menheere PPCA, Cheriex EC, van den Berg BW, Noordzij TC, van Hooff JP. Plasma alpha-human atrial natriuretic peptide and dry weight in chronic hemodialysis. Nephrol Dial Transpl 1989; 4:382-386.

17. Leunissen KML, Kouw P, Kooman JP, Cheriex EC, van Hooff JP. Vena cava echography, the conducticity method and biochemical markers in the determination of fluid status in hemodialysis patients. Kidney Int (in press)

18. Renkin EM. Control of microcirculation and blood-tissue exchange. In; Handbook of Physiology, 1983. Sect 2. Cardiovascular system. Vol 4. Microcirculation. Chapt 14. American Physiological Society, Bethesda. pp 627-685. 
19. Rothe CF. Venous system: physiology of capacitance vessels. In; Handbook of Physiology, 1983, Sect 2. Cardiovascular system. Vol 3. Peripheral circulation and organ blood flow. Chapt 13. American Physiological Society, Bethesdu pp 397-452.

20. London GM, Safar ME, Levenson JA, Simon AC, Temmar MA. Renal filtration fraction, effective vascular compliance, and partition of fluid volumes in sustained essential hypertension. Kidney Int 1981; 20:97-103.

21. Bondia A, Tabernero JM, Macias JF, Martin-Luengo C. Autonomic nervous system in hemodialysis. Nephrol Dial Transpl 1988; 2:174-180.

22. Nakashima Y, Fouad FM, Nakamoto S, Textor SC, Bravo EL, Tarazi RC. Localisation of autonomic nervous system dysfunction in dialysis patients. Am J Nephrol 1987; $7: 375 \times 381$.

23. Heber ME, Lahiri A, Thompson D, Raftery EB. Baroreceptor, not left ventricular, dysfunction is the cause of hemodialysis hypotension. Clin Nephrol 1989; 32;79-86.

24. Rasher W, Schonig A, Kreye VA, Ritz E. Diminished vascular response to noradrenaline in expirimental chronic uremia. Kidney Int 1988; 21:20-27.

25. MoGrath BP, Ledingham JGG, Benedict CR. Catecholamines in peripheral venous plasma in patients on chronic hemodialysis. Clin Sci Mol Med $1978 ; 55: 89-96$.

26. Daul AE, Wang XL, Michel MC, Brodde OE. Arterial hypotension in chronic hemodialyzed patients. Kidney Int 1987; 32:728-732.

27. Baldamus CA, Ernst W, Frei UW, Koch KM. Sympathetic and hemodynamic response to volume removal during different forms of renal replacement therapy. Nephron 1982; 31: 324-332.

28. Chaignon M, Chen WT, Tarazi RC, Nakamoto S, Bravo EL. Blood pressure response to hemodialysis. Hypertension 1980; 3:333-339.

29. Henrich WL, Katz FH, Molinoff PB, Schrier RW. Competitive effects of hypokalemia and volume depletion on plasma renin activity, aldosteron and catecholamine concentrations in hemodialysis patients. Kidney Int 1977; 12:279-284.

30. Chaignon M, Chen WT, Tarazi RC, Brawo EL, Nakamoto S. Effect of hemodialysis on blood volume distribution and cardiac output. Hypertension 1981; 3:327-332.

31. Ritz E, Rambausek M, Mall G, Ruffman K, Mandelbaum A. Cardiac changes in uremia and their possible relation to cardiovascular instability on dialysis. Contrib Nephrol $1990 ; 78: 221-229$.

32. Leunissen KML, wan den Berg BW, wan Hooff JP. Ionized plasma calcium plays a pivotal role in controlling blood pressure during haemodialysis. Blood Purif 1989; 7:233-239.

33. Linzer M. Syncope 1991. Am J Med 1991; 90:1-5.

34. Leunissen KML, Hoorntje SJ, Fiers HA et al. Acetate versus bicarbonate dialysis in critically ill patients. Nephron 1986; 42:146-151.

35. Leunissen KML, van den Berg BW, Cheriex EC, Slaaf DW, Reneman RS, wan Hooff JP. The influence of fluid removal during haemodialysis on macro- and skin microcirculation. Nephron 1990; 54:162-168.

36. Lyons AC, Petrucelli RJ. Medicine, an illustrated history. Abradale Press, Harry N. Abrams Inc. New York, 1987.

37. Harris CRS. The arteries in greco-roman medicine. In: Schwartz CJ, Werthessen NT, Wolf S. Structure and function of the circulation. Vol 1. Plenum press. New York, London. 1981. 
38. Guyton AC. Circulatory physiology: cardiac output and its regulation. W.B. Saunders Company. Philadelphia/London, 1963.

39. Folkow B, Mellander S. Veins and wenous tone. Am Heart J 1964; 68:397-408.

40. Furuta $T$, Ishikawa $N$, Shigei $T$. Regional variation in the B-adrenoceptor mediated relaxation of canine veins. Blood vessels: $1986 ; 23 ; 326-245$.

41. Geneser F. Textbook of histology. Munksgaard, Copenhagen, 1986.

42. Struyker-Boudier HAJ. The arterial wall. Medicographia 1991; 13:7-9.

43. Folkow B. Structural factors: the vascular wall-consequences of treatment. Hypertension 1983:5(supp 1II):IIIS8-III62.

44. van Welsum WA. De regulatie van de contractietoestand van hel veneuze vaatbed van de benen. Ned T Geneesk 1982; 126:250-254.

45. Shepherd JT, Vanhoutte PM. Veins and their control. W.B. Saunders Company, London/Philadelphia/Toronto, 1975.

46. Appleton CP, Lee RW, Martin GV, Olajos M, Goldman S. $\alpha_{1}$ - and $\alpha_{2}$ adrenoceptor stimulation: changes in venous capacitance in intact dogs. Am I Physiol 1986; 250: H1071-H1078.

47. Robinson BF. Difference in response to dilator agents in blood vessels of different types: physiological basis for selectivity. J Hypert 1989; 7(supp 4):\$147-S151.

48. Robinson BF. Assessment of the effects of drugs on the venous system in man. $\mathrm{Br} J \mathrm{Clin}$ Pharmacol $1978 ; 6: 381-386$.

49. Gascho IA, Apollo WP. Effects of nifedipine on the venodilatory response to Nitroglycerin. Am J Cardiol 1990; 65:99-102.

50. Collier JG, Nachev C, Robinson BF. Effect of catecholamines and other vasoactive substances on superficial hand veins in man. Clin Sci $1972 ; 43: 455-467$.

51. Gillness and Goodman. The pharmacological basis of therapeutics. Pergamon press. 8th Edition. 1990.

52. Abrams J. Hemodynamic effects of nitroglycerin and long-acting nitrates. Am Heart $\mathrm{J}$ $1985 ; 110: 216-224$.

53. Kukovetz WR, Holzmann $S$, Schmidt $K$. Cellular mechanisms of action of therapeutic nitric oxide donors. Europ Heart J 1991; 12 (supp E):16-24.

54. Vallance $P$, Collier $J$, Moncada $S$. Nitric oxide synthesised from L-arginine mediates endothelium dependent dilatation in human veins in vivo. Cardiovas Res 1989;23:10521057.

55. Luscher TF. Endothelium-derived nitric oxide: the endogenous nitrovasodilator in the human cardiovascular system. Europ Heart J $1991 ; 12$ (supp E):2=11.

56. Tremblay J, Gevzer $R$, Vinay $P$, Parng $S C$. Béliveau $R$, Hamet $R$. The increase of CGMP by atrial natriuretic factor correlates with the distribution of particulate guanylate cyclase. FEBS letters 1985; 181:17-22.

57. Ebert TJ, Skelton MM, Cowley AW. Dynamic cardiovascular responses to infusions of atrial natriuretic peptide in humans. Hypertension 1988; 11:537-544.

58. Doorenbos $\mathrm{CJ}$, Blauw $\mathrm{GJ}$, van Brummelen P. Arterial and venous effects of atrial natriuretic peptide in the human forearm. Hypertension $1991 ; 4: 333-340$.

59. Groban L, Cowley AW, Ebert T. Atrial natriuretic peptide augments forearm capillay filtration in humans. Am J Physiol 1990; 259:H258-H263.

60. Pernow J, Hemsen A, Lundberg JM, Nowak J, Kaijser L. Potent vasoconstrictor effects and clearance of endothelin in the huamn forearm. Acta Physiol Scand 1991; 141:319- 
61. Greenway CV, Wayne Laurt W. Blood volume, the venous system, preload and cardiac output. Can J Physiol Pharmacol 1986; 64:383-387.

62. Safar ME, London GM, Levenson JA, Simon AC, Chau NP. Rapid dextran infusion in essential hypertension. Hypertension 1979; 1:615-623.

63. Öberg B. The relationship between active constriction and passive recoil at various distending pressures. Acta Physiol Scand 1967; 71:233-247.

64. Greenway CV, Seaman KL, Innes IR. Norepinephrine on venous compliance and unstressed volume in cat Jiver. Am J Physiol 1985; 248:H468-H476.

65. Rothe CF. Reflex control of veins and vascular capacitance. Physiol Rev 1983; 63:1281 1342.

66. Nakao S, Come PC, McKay RG, Ransil BJ. Effects of positional changes on inferior vema cava size and dynamics and correlations with right-sided cardiac pressure. Am I Cardiol $1987 ; 59: 125-132$.

67. Moreno FL, Hagan AD, Holmen JR, Pryor TA, Strickland RD, Castle CH. Evaluation of size and dynamics of the inferior vena cava as an index of rightsided cardiac function. Am J Cardiol 1984; 53:579-585.

68. Klooker P, Bommer J, Ritz E. Treatment of hypertension in dialysis patients. Blood Purif $1985 ; 3: 15-26$

69. Takeshita A, Mark AL. Decreased venous distensibility in borderline hypertension. Hypertension 1979; 1:202-206.

70. Simon G. Functional and structural compartments of reduced forearm venous distensibility. In: Safar ME (ed). Arterial and venous systems in essential hypertension. Martinus Nijhoff Publishers. Dordrecht, 1987.

71. Yamamoto T, Shimizu M, Morioka M, Kitano M, Wakabayashi J, Aizawa N. Role of angiotensin II in the pathogenesis of hyperdipsia in chronic renal failure. JAMA 1986; 256:604-608.

72. Bradley JR, Evans DB, Gore SM, Cowley AJ. Is dialysis hypotension caused by an abnormality of venous tone? $\mathrm{Br}$ Med J 1988; 296:1634-1637.

73. Nakamura Y, Ikeda T, Takata S, Yokoi H, Hirono M, Abe T, Takazakura F, Kobayashi $\mathrm{K}$. The role of peripheral resistance and capacitance vessels in hypotension following hemodialysis. Am Heart J 1991; 121: 1170-1177. 



\section{CHAPTER 2}

\section{Methods used to assess venous compliance and venoconstriction}

\section{ABSTRACT}

In this section the protocols used to assess the basal volumel pressure relationship of the venous system (venous compliance) and the active reaction of the venous system after sympathetic stimulation (venoconstriction) are discussed. Furthermore, the physiological basis of these measurements is addressed. 


\section{VENOUS COMPLIANCE}

\section{Plethysmography-introduction}

Venous compliance was measured with a strain-gauge plethysmograph. A plethysmograph is an instrument for the measurement of changes in volume of a part of the body (1). The first plethysmograph was developed in 1874 by Mosso for the recording of blood flow (1). The early types of plethysmographs estimated changes in limb volume either by recording changes in air pressure or by measuring the displacement of water (1). These devices, however, proved to be cumbersome in general use. In 1949, strain-gauge plethysmography was developed by Whitney (2). With this technique, a mercury thread is applied to the limb under study. Volume changes are estimated by recording changes in electrical resistance of the thread. The increase in resistance is directly proportional to changes in limb volume $(1,2)$.

\section{Study protocol}

Venous compliance was assessed in the forearm using a strain-gauge plethysmograph (Periflow; Janssen Scientific Instruments [Figure 1]) with direct intravenous pressure measurements. The study was done in a temperature controlled $\left(21-23^{\circ} \mathrm{C}\right)$ room. The investigation was performed in the morning in control subjects, and, in hemodialysis patients, the morning after dialysis at normovolemia. All subjects were asked to refrain from smoking, coffee, tea and coca-cola for 12 hours.

The fluid status of the patients was assessed by echographic estimation of the inferior caval vein diameter, corrected for body surface area [vena cava diameter at normovolemia $\left.=8-11,5 \mathrm{~mm} / \mathrm{m}^{2}\right](3,4)$.

Patients were in supine position with the arm at heart level. In hemodialysis patients, the mercury strain-gauge was applied to the arm contralateral to the A$V$ shunt at a distance of one-third of the forearm length from the lateral epicondyle (Figure 2).

In the same arm, a cannula (Internal diameter $1 \mathrm{~mm}$; Venflon) was inserted into an antecubital vein and connected to a pressure dome (Hewlett-Packard), positioned at right atrium height, which was considered $5 \mathrm{~cm}$ under the sternal angle. Peripheral venous pressure was measured by a Hewlett-Packard monitor and graphically displayed. Subsequently, a cuff was applied to the upperarm. The plethysmograph and pressure monitor were calibrated. After a stabilization period of 15 minutes, a basal value was obtained.

First, the upperarm cuff was inflated to a cuff pressure of $25 \mathrm{mmHg}$ and was kept that way for 3 minutes. Subsequently, the cuff was deflated for 2 minutes. 


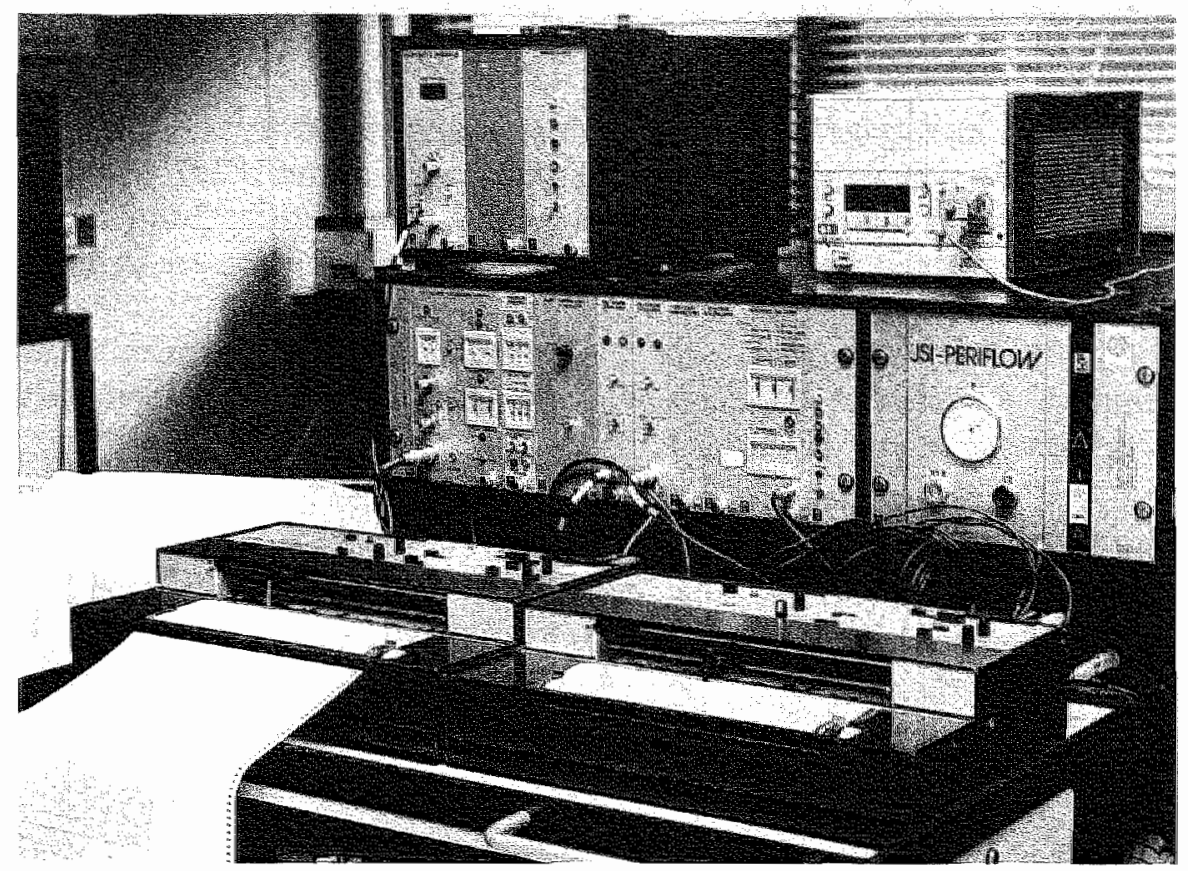

Figure 1. The Periflow strain-gauge plethysmograph

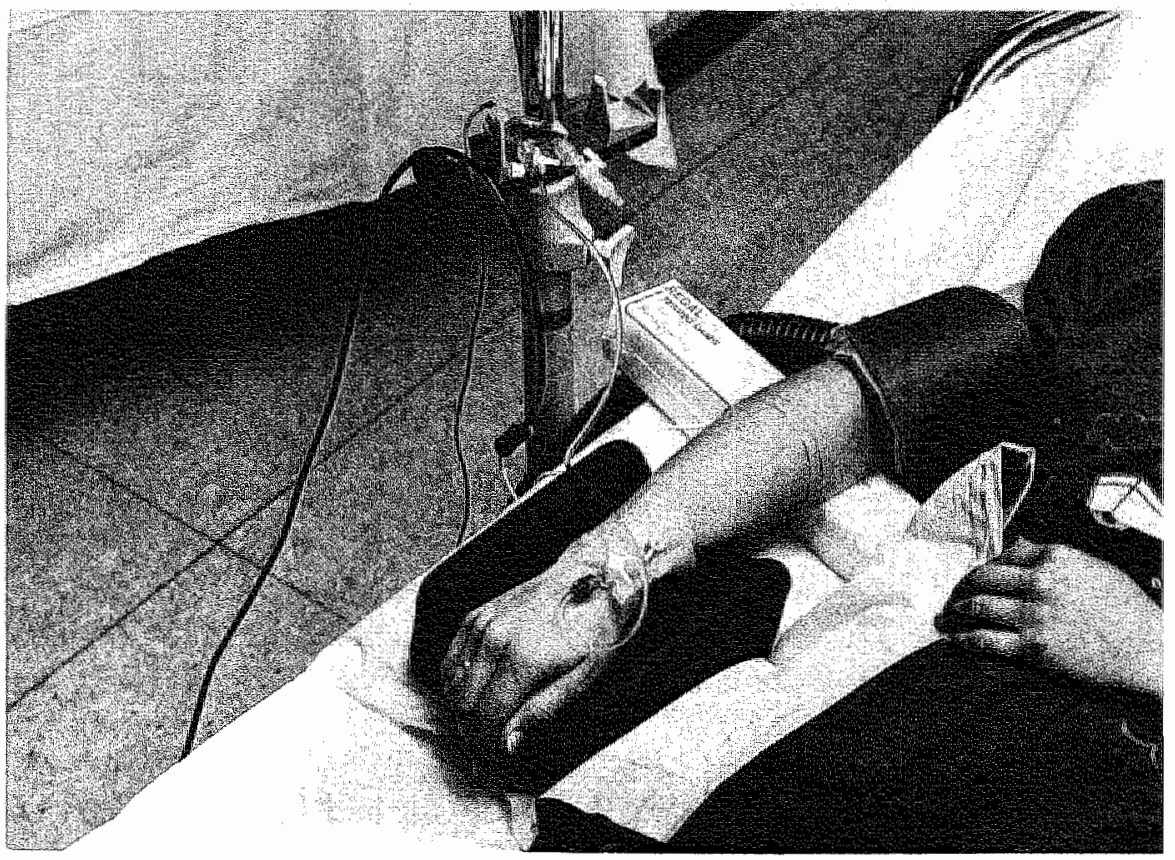

Figure 2. Application of a strain-gauge and intravenous cannula on the forearm of a patient 
The change in arm volume and intravenous pressure were both measured after cuff deflation. Subsequently, the cuff was inflated at pressures of $30,35,40$ and $45 \mathrm{mmHg}$. Again, at each cuff pressure, the cuff was inflated for 3 minutes and was deflated for 2 minutes afterwards, while the volume/pressure ratio was obtained after cuff deflation (Figure 3 ).

$V C$ was defined as the slope of the $\Delta$ venous pressure versus $\Delta$ arm volume measurements, obtained at the subsequent cuff pressures and was calculated by linear regression analysis (Figure 4).

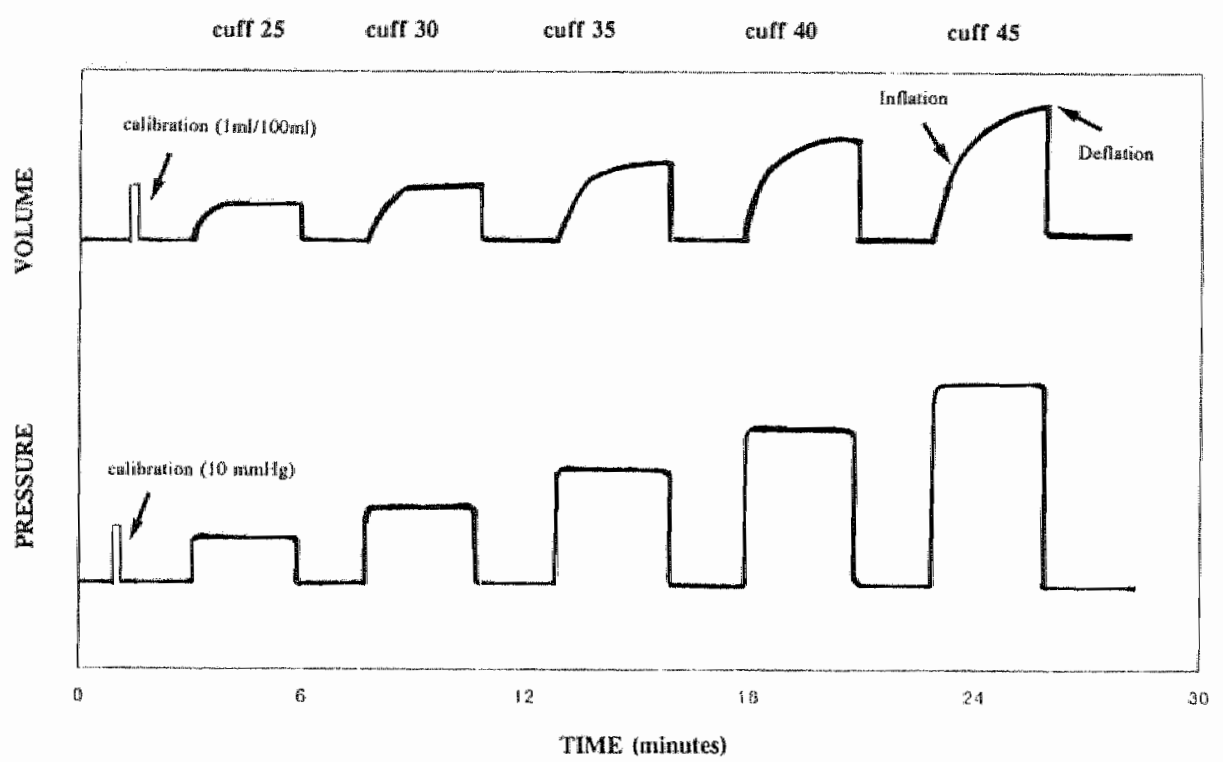

Figure 3. Venous compliance; tracing of a representative experiment

\section{Reproducibility of venous compliance measurements}

Intra-day variability of venous compliance measurements was estimated in 15 hemodialysis patients [ 10 male, 5 females] and 13 control subjects $[7$ males, 6 females). The mean age of the hemodialysis patients was $48(\mathrm{SD}=15.9)$ years, the mean age of controls was $49(S D=11.4)$ years. Measurements were performed at an interval of 1 hour. The mean intra-day coefficient of variation (CV) was $6.0(\mathrm{SD}=6.6) \%$ in hemodialysis patients and $11.0(\mathrm{SD}=8.7) \%$ in controls. 
The mean correlation coefficient of the linear pressure/volume relationship was $0.98(\mathrm{SD}=0.01)$ in hemodialysis patients and $0.98(\mathrm{SD}=0.03)$ in controls. Inter-day variability (difference between the first and second measurement 6 weeks or more) of venous compliance measurements was assessed in 11 hemodialysis patients [4 males; 7 females] and 13 control subjects [11 males; 2 females]. The mean age of the hemodialysis patients was $53.6(\mathrm{SD}=14.5)$ years and $39.3(\mathrm{SD}=10.1)$ years in controls.

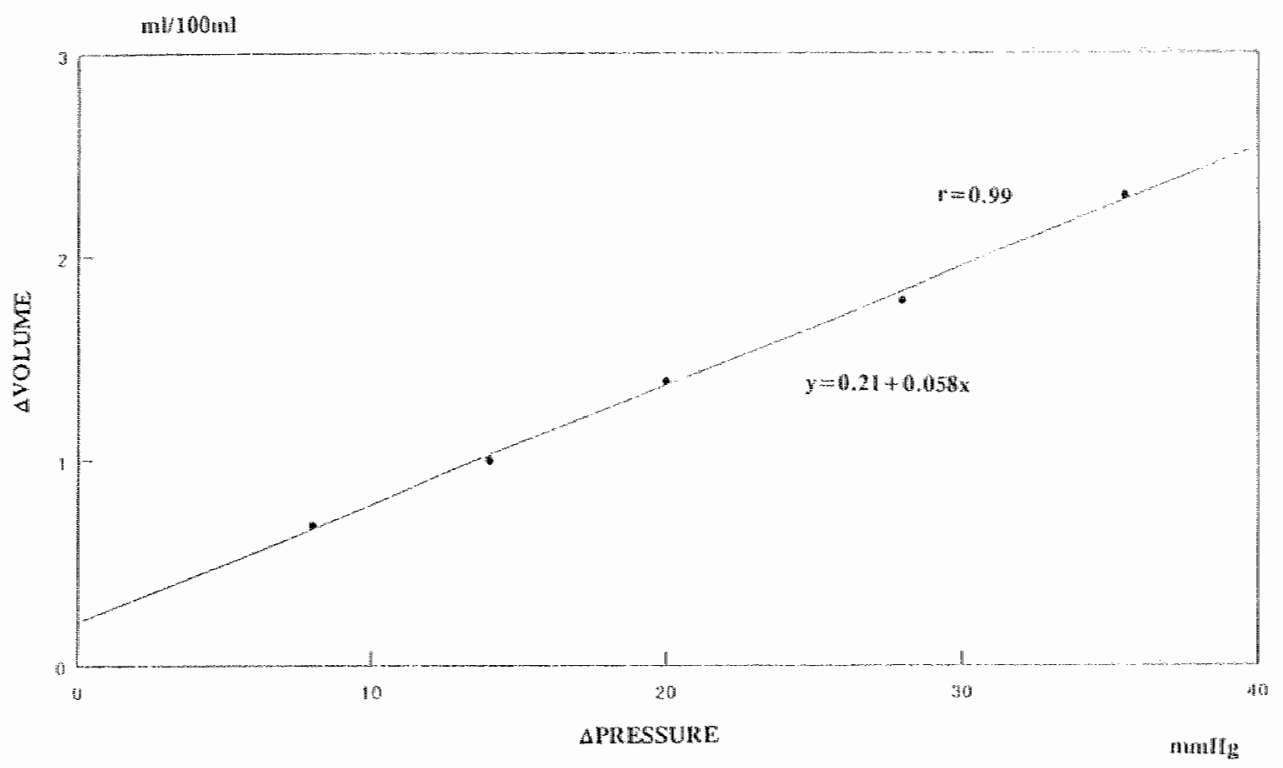

Venous Compliance $=0.058 \mathrm{~m} / \mathrm{hog} \mathrm{m} / \mathrm{mm} \mathrm{mg}$

Figure 4. Example of a calculation of venous compliance by linear regression analysis

The mean inter-day coefficient of variation was $15.8(\mathrm{SD}=12.2) \%$ in hemodialysis patients and $15.5(\mathrm{SD}=11.4) \%$ in controls.

\section{Effect of age and sex on venous compliance}

The effect of age and sex on venous compliance measurements was investigated in 17 normotensive control subjects [ 7 male, 10 female]. The mean age of the males was 46 [range 35-72] years, the mean age of the females 45 [range 26-63] years.

Venous compliance was inversely correlated with age $(r=-0.47 ; p=0.03)$. Venous compliance did not differ significantly between sexes $(p=0.10$; Mann- 
Whitney signed-rank test) but tended to be somewhat higher in males $(0.063$ $\mathrm{ml} / 100 \mathrm{ml} / \mathrm{mmHg}$; $\mathrm{SD}=.013)$ than in females $(0.055 \mathrm{ml} / 100 \mathrm{ml} / \mathrm{mmHg}$; $\mathrm{SD}=.016)$.

\section{Description of a representative venous compliance measurement (Figure 3)}

After inflation of the arm cuff, blood accumulates in the veins distal of the occlusion cuff due to arterial inflow with venous outflow obstruction (25). Intravenous pressure rises rapidly and reaches a plateau phase after approximately 20-30 seconds. The rise in arm volume is somewhat slower and reaches a plateau phase approximately $60-80$ seconds after inflation of the arm cuff. This inertia may be caused by differences in filling between different venous compartments of the forearm. This is, however, unlikely because it was shown that intravenous pressure quickly equilibrates both in cutaneous and muscle veins after venous congestion (22). More likely, the slow rise is due to stressrelaxation ('delayed compliance') of the venous wall (29). Stress-relaxation is the gradual deformation of a biological structure when tension is applied (30). It is a rapidly occurring phenomenon; Hasegawa found maximal stressrelaxation after stretch had been applied for 30 seconds to an isolated vein segment (14). It is also a rapidly reversible phenomenon: after application of a transmural pressure of $30-40 \mathrm{mmHg}$ the visco-elastic stretching of the venous wall is reversible within two minutes (31).

At higher cuff pressures, arm volume sometimes continues to rise. This could either be due to stress-relaxation or to capillary filtration $(32,33)$. The contribution of stress-relaxation in this aspect is unlikely because, as mentioned before, stress-relaxation probably reaches its maximum soon after the start of venous congestion (15). Furthermore, after deflation of the arm cuff, basal arm volume returned to higher values, probably caused by accumulation of interstitial fluid. Therefore, to correct for the effects of capillary filtration on venous compliance measurements, it is essential to measure the volume/pressure ratio after deflation of the arm cuff (8). The cuff was kept deflated for 2 nuinutes, to allow for reversion of stress-relaxation and to prevent further accumulation of interstitial fluid.

That accumulation of interstitial fluid and incomplete reversion of stressrelaxation did not interfere with venous compliance measurements in the present study is supported by the excellent linear correlation between the volume/pressure ratios assessed at lower and higher cuff pressures. 


\section{Physiological basis of venous compliance measurements}

Venous compliance of the forearm veins was assessed using strain-gauge plethysmography at multiple cuff pressures with direct intravenous pressure measurements. Venous compliance was expressed as the tangent of the regression line, constructed from changes in intravenous pressure and changes in forearm volume $(\Delta \mathrm{V} / \Delta \mathrm{P})$, measured at different cuff pressures (5). Because with plethysmography only relative changes (per $100 \mathrm{ml}$ tissue) in forearm volume are measured, the unit in which venous compliance is expressed is $\mathrm{ml} / 100 \mathrm{ml} / \mathrm{mmHg}$.

During plethysmography, virtually only the volume/pressure relationship of the skeletal and cutaneous veins is measured (6), both because the amount of blood present in arteries, arterioles and capillaries is much smaller as compared to that stored in the veins and venules (7) and because the compliance of the precapillary blood vessels is much lower compared to the compliance of the postcapillary blood vessels (7).

\section{Influence of transmural pressure on venous compliance: use of the linear part of the pressure/volume relationship}

Venous compliance was measured at cuff pressures of $25 \mathrm{mmHg}$ (intravenous pressure $\pm 15 \mathrm{mmHg}$ ) and higher. This was done because venous compliance depends upon the transmural pressure (7). The volume/pressure relationship of the venous system has a curvilinear shape $(6,8-10)$. When the transmural pressure is lower than $8-10 \mathrm{mmHg}$, veins may partly collapse and assume an elliptical configuration (8). A large increase in venous volume will only lead to a small increase in venous volume (8), thus: compliance is high. However, under these circumstances, compliance is more dependent upon the geometrical shape of the venous wall than upon its true wall characteristics (6). When transmural pressure increases, veins assume a circular configuration and the volume/pressure relationship measured at the different cuff pressures becomes linear $(8,9,10)$. Because of this linear relationship, only relative changes in arm volume and intravenous pressure are important in the assessment of venous compliance. Thus, the use of 'cuff-zero' (i.e. the cuff pressure above which the arm volume starts to rise) pressure measurements (11) is unnecessary when measuring venous compliance in this part of the pressure/volume relationship.

Venous compliance measured at higher transmural pressure is determined by the visco-elastic properties of the venous wall (12). The venous wall is mainly composed from collagen, elastin and smooth muscle cells $(13,14)$. 
Under resting circumstances, the smooth muscle tone of the venous wall is minimal (14). Venous smooth muscle is of the "multi-unit" type (15). When not sympathically stimulated, the activity of "multi-unit' smooth muscle cells is minimal, unlike the 'single-unit' type of smooth muscle cells of the resistance vessels (12). Therefore, in a comfortably warm subject, venous smooth muscle tone will hardly modify the volume/pressure relationship of the venous system (12). The absence of an important influence of venous smooth muscle tone is supported by the excellent intra- and inter-day reproducibility obtained in this and previous studies $(9,17)$. Probably, the amount and structure of the collagen fibers contributes most to the visco-elastic properties of the venous wall at higher transmural pressures $(14,16)$.

Venous compliance was found to correlate inversely with age, which is in agreement with the study of Gaschko et al. (18) but in contradiction with the study of Van den Berg et al. (19) An inverse relationship between venous compliance and age may seem somewhat contradictory, because the relative amount of collagen in the venous wall decreases with age (20). However, altered physicochemical properties of collagen might contribute to the observed inverse relationship (21).

\section{Rationale for using direct intravenous pressure measurements}

Direct intravenous pressure measurements were used in the assessment of venous compliance. After inflation of an arm cuff, blood accumulates in the veins distal to the arm cuff and pressure rapidly equilibrates in the cutaneous and skeletal veins of the forearm (22), because the valves of the forearm veins become incompetent at higher transmural pressures (23). Thus, intravenous pressure in a single antecubital vein is representative for intravenous pressure in the other parts of the forearm $(22,24)$.

When cuff pressure is used as indicator of transmural pressure, deviations from the true intravenous pressure may be found (25). We observed that intravenous pressure was generally $5-10 \mathrm{mmHg}$ lower than the cuff pressure.

Furthermore, direct intravenous pressure recordings increase the reproducibility of venous compliance measurements, a view supported by the finding of a much larger inter-day variability in the study of Boccalon et al. (26), who assessed venous compliance without direct intravenous pressure recordings.

Although the use of direct intravenous pressure measurements is more appropriate than the use of cuff pressures, extraluminal pressure, the other denominator for transmural pressure remains unknown. In normal circumstances, interstitial pressure is slightly negative (27) and is not likely to act as an important confounding factor. However, in severely fluid overloaded patients the accumulation of interstitial fluid might decrease venous compliance (28), 
although the contribution of interstitiall pressure to venous compliance will become progressively less when higher cuff pressures are used.

However, the possible interfering effect of fluid overload underlines the necessity of measuring venous compliance in hemodialysis patients at a standardized optimal fluid status. Therefore, the investigation was performed the day after dialysis at normovolemia, which was assessed by echography of the inferior caval vein $(3,4)$.

In summary, venous compliance in the linear part of the volume/pressure relationship, measured in a comfortably warm subject at normovolemia will only depend upon the morphological characteristics of the venous wall with minimal interference from smooth muscle tone (12).

\section{VENOCONSTRICTION}

\section{Study protocol}

Active venoconstriction was assessed from changes in venous tone. Changes in venous tone can be defined as changes in the pressure/volume ratio of the forearm at a given cuff pressure (25). It should be noted that venous tone is expressed in reciprocal terms $(\mathrm{mmHg} / \mathrm{ml} / 100 \mathrm{ml}$ ) compared with venous compliance $(\mathrm{ml} / 100 \mathrm{ml} / \mathrm{mmHg}$ ).

Changes in venous tone were assessed during a cold pressor test, which stimulates sympathetic activity (30) (chapter 7) and during isolated ultrafiltration and bicarbonate dialysis (chapter 8 ).

The investigation was performed in a temperature controlled room and the studied subjects had been asked to refrain from smoking, coffee, tea or cocacola for 12 hours.

Venous tone was estimated using strain-gauge plethysmography with direct intravenous pressure measurements. The strain-gauge, intravenous cannula and upperarm cuff were applied using the protocol as described above. A cuff pressure of $40 \mathrm{mmHg}$ was used. The cuff was inflated for 80 seconds, after which the cuff was deflated. The pressure/volume ratio was assessed after deflation of the arm cuff.

\section{Reproducibility}

Intra-day variability of venous tone was assessed in the same population in which intra-day variability of venous compliance was assessed. The mean 
coefficient of variation was $7.6 \%(\mathrm{SD}=4.8)$ in hemodialysis patients and $11.1 \%$ $(\mathrm{SD}=8.7)$ in controls.

\section{Physiological basis of venous tone measurements}

Active venoconstriction was assessed by recording changes in venous tone of the forearm. It is very important to distinguish between venous compliance and venoconstriction.

Venous compliance determines the volume/pressure relationship of the hemodynamically active part of the venous system $(7,35)$ in the resting state, determined by the basal visco-elastic properties of the venous wall. As discussed in the previous chapter, a reduction in venous compliance may induce a steeper fall in central venous pressure and impair plasma volume preservation.

During active venoconstriction, the tone of the smooth muscle cells in the venous wall increases, which will lead to a mobilization of hemodynamically inactive blood volume $(7,35)$. Although venous compliance might also be altered to some extent by this increase in smooth muscle tone, sympathetic stimulation mainly results in mobilization of unstressed blood volume $(7,35)$. Active venoconstriction was reflected by the change in the pressure/volume ratio measured at a cuff pressure of $40 \mathrm{mmHg}$.

The pressure/volume ratio, for reasons previously mentioned, was assessed after deflation of the arm cuff. The cuff was inflated for 80 seconds, which was shorter compared with venous compliance measurements. This was done because changes in venous tone sometimes have to be measured quickly, for instance when using the cold pressor test. At a cuff pressure of $40 \mathrm{mmHg}$, this time interval is sufficient for the arm volume to reach a stable plateau phase.

Active venoconstriction is dependent upon changes in venous smooth muscle tone. Veins are dependent upon sympathetic activity for their constriction. In the resting state, smooth muscle tone in the venous wall is minimal (12), as discussed before.

In the forearm, both cutaneous and skeletal weins are found. Whereas cutaneous veins are well innervated and can be directly stimulated by sympathetic nerves, the less innervated skeletal veins are for a major part dependent upon circulating catecholamines for constriction (12).

When assessing changes in forearm venous tone, it is not possible to distinguish between the reaction of the cutaneous or skeletal veins. It has been demonstrated that during a cold stimulus, like the cold pressor test, the main reaction arises from the cutaneous veins (36).

What happens during hypovolemia is not well known. Althowgh Brender et al. observed that cutaneous and skeletal veins, in contrast to the splanchnic venous 
system, did not respond actively to $\mathrm{a}$ decrease in carotid sinus pressure (37), an increase in forearm venous tone during hemorrhage (38) and pooling of blood in the lower limbs (39) has been observed. Cutaneous and skeletal veins may actively constrict by the effect of circulating catecholamines, released by changes in baroreceptor reflex activity (40).

Theoretically, changes in the pressure/volume ratio during increased sympathetic stimulation might also result from passive venoconstriction, i.e. passive emptying of the vein by elastic recoil due to a decreased blood flow (41). Although this is of great hemodynamic importance, it will not have played a major role in the assessment of active venoconstriction in this study. Öberg (6) found, in an animal study, that the effect of passive venoconstriction became progressively less at higher transmural pressures, whereas the effect of active venoconstriction increased at higher transmural pressures. This was confirmed in humans by Ardill et al. (42) who observed that venous tone, measured at a cuff pressure of $40 \mathrm{mmHg}$, was independent of blood flow through the forearm. At the cuff pressure used in the present study (corresponding with an intravenous pressure of approximately $30 \mathrm{mmHg}$ ), the effect of passive venoconstriction will therefore be negligible.

In summary, the change in the pressure/volume ratio at a cuff pressure of 40 $\mathrm{mmHg}$ depends upon active changes in smooth muscle tone, in contrast to venous compliance, which, when measured under resting conditions, depends upon the morphological properties of the venous wall. Thus, venous compliance and venoconstriction are two different entities with completely different hemodynamic effects (35).

\section{REFERENCES}

1. Ensink EBM, Hellige G. The rellability of venous capacity and blood flow determination by pleilhysmography (JSI-Periflow). in: Jageneau et al. Noninvasive diagnosis in the management of cardiowascular diseases. North Holland Biomedical Press. Amsterdam, New York, London, 1981.

2. Whitney $J \mathbb{R}$. The measurement of volume changes in human limbs. J Physiol London 1953; 121:1-27.

3. Cheriex EC, Leunissen KML, Janssen JHA, Mooy JMV, van Hooff JP. Echography of the vena cava inferior is a simple and reliable tool for the estimation of dry weight in hemodialysis patients. Nephrol. Dial. Transpl. 4:563-568, 1989.

4. Leunissen KML, Menheere PPCA, Cheriex EC, van den Berg BW, Noordzij TC, wan Hooff JP. Plasma alpha-human atrial natriuretic peptide and dry weight in chronic hemodialysis. Nephrol Dial Transpl 1989; 4:382-386.

5. Doorenbos CJ, Blauw GJ, wan Brummelen P. Arterial and wenous effects of atrial natriuretic peptide in the human forearm. Am J Hypert 1991; 11:333-340. 
6. Öberg B. The relationship between active constriction and passive recoil at various distending pressures. Acta Physiol Scand 1967; 71:233-247.

7. Rothe CF. Venous system: physiology of capacitance vessels. In: Handbook of Physiology, 1983. Sect 2. Cardiovascular system. Vol 3. Peripheral circulation and organ blood flow. Chapt. 13. American Physiological Society, Bethesda. pp 397-452.

8. Katz AI, Chen $Y$, Moreno AH. Flow through a collapsible tube. Experimental analysis and mathematical model. Biophys J. 1969;9:1261-1279.

9. Burki $N$, Guz A. The distensibility characteristics of the capacitance vessels of the fortarm in normal subjects. Cardiovasc Res 1970; 4:93-98.

10. Moreno AH, Katz AI, Gold LD, Reddy RV, Tech M. Mechanisms of distension of dog veins and other very thin-walled tubular structures. Circ Res 1970; 27: 1069-1080.

11. Takeshita A, Mark AL. Decreased venous distensibility in borderline hypertension. Hypertension 1979; 1:202-206.

12. Shepherd JT, Vanhoutte PM. Veins and their control. W.B. Saunders Company, London/Philadelphia/Toronto, 1975.

13. Junqueira LJ, Carneiro J. Basic Histology. Lange Medical Publications, Los Altos. 4th Edition, 1983.

14. Hasegawa M. Rheological properties and wall structures of large veins. Biorheology $1983 ; 20: 531-545$.

15. Robinson BF. Differences in response to dilator agents in blood vessels of different types: physiological bases for selectivity. J Hypert 1989 7:S147-S151.

16. Azuma $T$, Hasegawa M. Distensibility of the vein: from the architectural point of view. Biorheology $1973 ; 10: 469-479$.

17. Greenfield ADM, Patterson GC. On the capacity and distensibility of the blood vessels in the human forearm. J Physiol 1956: 131:290-306.

18. Gascho JA, Fanelli $C$, Zelis R. Aging reduces venous distensibility and the venodilatory response to nitroglycerin in normal subjects. Am J Cardiol 1989; $63: 1267-1270$.

19. van den Berg $E$, Barbey $K$. Die druckabhängige venöse kapazität in abhăngigheid von alter und geslecht in einer durchschnittsbevolkerung. Z Kardiol 1976; 65:68-80.

20. Rickenbacher $\mathbb{J}$. Zur histologische differenzierung der beinvenenwand. In: Schneider KW. Die venöse insuffizienz; pathophysiologie, klinik und therapie. Gerhard Witzstrock Gmb. 1972.

21. Comper WD, Laurent TC. Physiological function of connective tissue polysaccharides. Physiol Rev 1978; 58:255-315.

22. Bevegăd BS, Shepherd $I T$. Effects of local exercise of forearm muscles on forearm capacitance vessels. IAppl Physiol 1965; 20:968-974.

23. Brown E, Greenfield DM, Goei IS, Plassaras G. Filling and emptying of the lowpressure blood vessels of the human forearm. J Appl Physiol 1966; 21:573-582.

24. Robinson BF. Assessment of the effect of drugs on the venous system in man. Br J Clin Pharmac 1978; 6:381-386.

25. Rudofsky G. Studies on the etiology, pathophysiology, diagnostics, and therapy of venous diseases. in: Jageneau et al (ed). Noninvasive diagnosis in the management of cardiovascular diseases. North Holland Biomedical Press. Amsterdam, New York, London, 1981. 
26. Boccalon $\mathrm{H}$, Ginestet $\mathrm{MC}$, Longhi $\mathrm{R}$, Puel $\mathrm{P}$. Variations de la physiologie veineuse chez le sujet normal; êtude par plethysmographies posturale et a occlusion veineuse. J Mal Vasc. $1987 ; 12: 150$-157.

27. Guyton AC. Concept of negative interstitial pressures based on pressures in implanted perforated capsules. Circ Res $1963 ; 12: 399-414$.

28. Magrini F, Niarcho AP. Hemodynamic effects of massive peripheral edema. Am Heart J 1985; 105:90-97.

29. Alexander RS, Edwards WS, Ankeney JL. The distensibility characteristics of the portal vascular bed. Circ Res 1953; 1:271-277.

30. Milnor WR. Hemodynamics. Williams \& Wilkins. Baltimore, Hong Kong, London, Sydney. 2nd Edition, 1989.

31. Gauer OH, Thron HL. Properties of veins in vivo: integrated effects of their smooth muscle. Physiol Rev 1962; 42 (supp 5):283-303.

32. Brakkee AJM. Measurement of venous hemodynamics. in: Jageneau al (ed). Noninvasive diagnosis in the management of cardiovascular diseases. North Holland Biomedical Press. Amsterdam, New York, London, 1981.

33. Simon G. Functional and structural compartments of reduced forearm venous distensibility in human hypertension. in: Safar ME (ed). Arterial and venous systems in essential hypertension. Martinus Nijhoff Publishers. Dordrecht, 1987.

34. McLeod JG, Tuck RR. Disorders of the autonomic nervous system: Part 2. Investiga* tion and treatment. Ann Neurol 1987; 21:519-529.

35. Greenway CV, Wayne Lautt W. Blood volume, the venous system, preload and cardiac output. Can J Physiol Pharmacol 1986; 64:383-387.

36. Zelis $\mathrm{R}$, Mason DT. Comparison of the reflex reactivity of skin and muscle veins in the human forearm. J Clin Invest 1969; 48: 1870 1977.

37. Brender D, Webb-Peploe MM. Influence of carotid baroreceptors on different components of the vascular system. J Physiol 1969; 205:257-274.

38. Scharpey-Schafer EP. Venous tone. Br Med J 1961; 2:1589-1595.

39. Wood JE, Eckstein JW. A tandem forearm plethysmograph for study of acute responses of the peripheral veins of man: the effect of environmental and local temperature change and the effect of the pooling of blood in the extremities. J Clin Invest $1958 ; 37: 41-50$.

40. DiSalvo J, Parker PE, Scott JB, Haddy FJ. Carotid baroreceptor influence on total and segmental resistances in skin and muscle vasculatures. Am J Physiol 1971; 220:19701978.

41. Rothe CF. Reflex control of veins and vascular capacitance. Physiol Rev 1983; 63:1281-1342.

42. Ardill BL, Bhatnagar VM, Fentem PH. Observation of changes in volume of a congested limb as a means of studying the behaviour of capacitance vessels. I Physiol $1968 ; 194: 627-644$ 



\section{CHAPTER 3}

\section{Blood pressure during the inter-dialytic period in hemodialysis patients: estimation of representative blood pressure values.}

J.P. Kooman, U. Gladziwa' ${ }^{2}$, G. Böcker², J.A.G. Wijnen', L.M.A.B. van Bortel $^{1}$, A.J. Luik, P.W. de Leeuw, J.P. v. Hooff, K.M.L. Leunissen.

Department of Internal Medicine and 'Department of Pharmacology, University Hospital Maastricht, the Netherlands, ${ }^{2}$ Dialysis Clinic Aachen, Germany.

Nephrol Dial Transpl; in press 


\section{ABSTRACT}

Defining hypertension in hemodialysis (HD) patients is difficult for it is not known whether pre- or post-dialytic blood pressure (BP) are representative for the average inter-dialytic BP. Furthermore, the day-night BP rhythm can be disturbed in HD patients.

Therefore, in this study, BP was measured during the inter-dialytic period using non-invasive ambulatory $B P$ measurements in 4 hypotensive, 6 normotensive and 12 hypertensive HD patients. It was assessed whether pre-or post-dialytic BP was representative for the average inter-diatytic $B P$. Furthermore, the nocturnal $B P$ fall was compared between HD patients, 7 normotensive controls and 8 treated subjects with essential hypertension.

Post-diatytic BP was superior to pre-dialytic BP in predicting the average $B P$ during the inter-dialytic period. $B P$ did not differ significantly between day 1 and day 2 of the inter-dialytic period but rose rapidly the hours before dialysis. Weight gain (corrected for actual body weight) did not correlate significantly with the rise in systolic $(r=0.22 ; p=0.2)$ or diastolic $(r=-0.02 ; p=0.5) B P$ during the inter-dialytic period.

The noctumal fall in systolic BP was significantly attenuated $(p<0.001)$ in hypertensive HD patients compared with normotensive controls. The nocturnal fall in diastolic $B P$ was significantly less in hypotensive $(p<0.001)$ and normotensive $(p<0.001)$ HD patients compared with normotensive controls and in hypertensive $H D$ patients compared with normotensive $(p<0.001)$ and hypertensive $(p<0.001)$ controls.

CONCLUSION: post-dialytic BP is more representative for the average interdialytic $B P$ than pre-dialytic $B P$ and should therefore be used to define hypertension in HD patients. BP rises rapidly the hours before HD. Furthermore, the nocturnal fall in $B P$ is attenuated in HD patients, which might have consequences for the prescription of antihypertensive therapy. 


\section{INTRODUCTION}

Hypertension can have a profound infuence on venous compliance (1). Hypertension in hemodialysis patients can be caused or maintained by fluid overload, pre-existing kidney disease or structural abnormalities of the cardiovascular system (2).

It is difficult however to define hypertension in hemodialysis patients; although blood pressure is measured frequently during HD, few data exist on the blood pressure course during the inter-dialytic period. BP values measured before and after dialysis often differ and it is not known which value should be taken as basis for initiation and evaluation of antihypertensive therapy.

Pre-dialytic BP can be influenced by the rise in extracellular volume during the inter-dialytic period (3), whereas post-dialytic BP may be related to the activation of vasoactive substances during HD or by the removal of catecholamines through the dialysis membrane. Moreover, the osmolality of the dialysis fluid and the choice of dialysate buffer can play a role (3).

Another complicating factor in the regulation of BP in HD patients may be a disturbance of the day-night BP profile, as has recently been described (4). A reduced nocturnal drop in $\mathrm{BP}$ might be imporatnt for dosage and administration of antihypertensive medication.

Therefore, in this study, BP was evaluated during the inter-dialytic period and during dialysis by non-invasive ambulatory BP monitoring, while patients were dialyzed to normovolemia, in order to determine whether pre- or post-dialytic $\mathrm{BP}$ correlates best with BP during the inter-dialytic period. In addition, daynight $\mathrm{BP}$ profiles in $\mathrm{HD}$ patients were compared to those in healthy and hypertensive controls.

\section{PATIENTS}

Clinically stable HD patients were studied; controls consisted of healthy persons and subjects with essential hypertension. Exclusion criteria were: severe coronary

(NYHA II or more) or valvular heart disease, impaired left ventricular function (ejection fraction $30 \%$ or less, assessed by echocardiography) and diabetes mellitus. Twenty-two HD patients were enrolled in the study. Clinical diagnoses were chronic glomerulonephritis $(n=8)$, analgesic nephropathy $(n=5)$, hypertensive nephropathy $(n=4)$, polycystic disease $(n=2)$ and reflux nephropathy $(n=1)$; in 2 patients the cause for kidney failure was unknown. No patient was anephric. 
Four HD patients ( 1 male; 3 females) were considered hypotensive (pre-and post-dialytic BP $<90 / 60$ ). Six HD patients ( 2 males; 4 females) were considered normotensive (post-dialytic BP $>90 / 60$ and $<140 / 80$ for at least 3 months without antihypertensive medication) and $12 \mathrm{HD}$ patients ( 8 males; 4 females) were considered hypertensive (post-dialytic BP $>160 / 90$ or use of antihypertensive medication). Mean age was 62 (range 60-66) years in hypotensive HD patients, 58 (range 42-71) years in normotensive HD patients and 50 (range 20-69) years in hypertensive HD patients. Mean time on HD was 7.2 (range 2.2-17.2) years in hypotensive HD patients, 2.5 (range 1.0-5.2) years in normotensive HD patients and 7.7 (range 0.3-17.5) years in hypertensive HD patients. All hypertensive HD patients were treated with various antihypertensive agents (Calcium antagonists, ACE-inhibitors, B-sympathicolytic agents). Median number of different antihypertensive drugs used was 2 (range 1-4).

Seven patients ( 1 hypotensive, 2 normotensives and 5 hypotensives) had some residual renal function left. The mean creatinine clearance in this group was 1.8 [range $1.0-4.1] \mathrm{ml} / \mathrm{min}$, while the mean inter-dialytic diuresis was 915 [range 250-1700] ml. Fourteen patients had no diuresis.

Patients were dialyzed three times a week with a Gambro AK-100 or a Fresenius 2008 dialysis apparatus with bicarbonate as diallysate buffer. Hemophane, polysulfone or polyacrylonitrile membranes were used. Patients were ultrafiltrated to their optimal dry weight $(5,6)$.

Seven normotensive ( 6 male; 1 female) and 8 hypertensive ( 7 male; 1 female) controls were studied. Normotensive controls were healthy volunteers. Hypertensive controls were recruited from the out-patient clinic and were diagnosed as essential hypertensives after negative laboratory and angiografic investigation. Mean age was 43 (range 34-69) years in normotensive and 54 (range 27-65) years in hypertensive controls. All hypertensive controls were treated with various antihypertensive drugs (Calcium antagonists, ACEinhibitors, B-sympathicolytic agents), which were matched for the drugs used by the hypertensive dialysis patients. Median number of antihypertensive drugs used was in this group was 2 (range 1-4).

\section{METHODS}

BP was recorded non-invasively using a Spacelabs 90207 oscillometric BP monitor, which has recently been succesfully validated according to the British Hypertension Society protocol (7).

Measurements were started at the beginning of the HD session, continued during the inter-dialytic period and terminated after the start of the subsequent HD 
session. The post-dialytic BP was recorded 15 minutes following the completion of the first HD session, whereas the pre-dialytic BP was measured before the start of the following HD session. Pre-dialytic BP was measured after 15 minutes rest, before the dialysis needle was inserted.

During daytime ( 7 a.m.-11 p.m.), BP was measured every 15 minutes and during nighttime (11 p.m.-7 a.m.) every 30 minutes. Eight patients (2 hypotensives, 3 normotensives and 3 hypertensives) were dialyzed in the morning (start 8 a.m., duration 3-5 hours), whilst 14 patients ( 2 hypotensives, 3 normotensives and 9 hypertensives) were dialyzed in the afternoon (start 2 p.m., duration 3-5 hours).

The mean duration of ambulatory BP measurement was 48 hours in HD patients. Control subjects were monitored during 24 hours, the measurements being started at 8 a.m. . Patients and controls were allowed to perform their usual daily activities. Antihypertensive medication was continued in hypertensive HD patients and hypertensive controls. The increase of body weight during the inter-dialytic period was also recorded.

\section{Statistical analysis}

Values are expressed as mean $( \pm S D)$. Multivariate regression analysis with stepwise entering of variables was used to assess whether pre- or post-dialytic BP correlated best with the average BP during the entire inter-dialytic period (mean over 48 hours) and also whether pre-or post-dialytic BP was representative for the average BP during the first and second day of the inter-dialytic period. The relation between weight gain and rise in BP during the inter-dialytic period was analyzed using simple linear regression (Pearson's $r$ ). In this analysis, weight gain was expressed as percentage of the dry body weight of the patient.

Day-night differences were calculated by comparing the average $\mathrm{BP}$ and $\mathrm{HR}$ during day time $(7 \mathrm{a} . \mathrm{m} .-11 \mathrm{p} . \mathrm{m}$.$) with the average BP and heart rate (HR)$ during the night time (11 p.m.-7 a.m.) (8). The Kolmogorov-Smirnow test was used to verify whether the variables were normally distributed. The day-night difference was compared between the various groups using one-way analysis of variance [AnoVa]. The Student-Newman-Keuls test was used to assess differences between various groups. A paired. Student $t$-test was used to estimate differences in average BP and nocturnal drop in BP between day 1 and day 2 of the inter-dialytic period. Multivariate analysis (stepwise entering) was used to estimate the influence of various explanatory variables on the nocturnal drop in $\mathrm{BP}$. 


\section{RESULTS}

\section{Prediction of inter-dialytic BP}

In every subject studied, more than $85 \%$ of all BP recordings were successful. Mean values in all HD patients of the average inter-dialytic BP, the pre- and post-dialytic BP and of the average BP on the first and second day of the interdialytic period are displayed in Table 1. Systolic and diastolic BP did not differ between the first and second day of the inter-dialytic period $(p=0.2$ and $p=0.3$; resp.).

Table 1. Blood pressure (BP) characteristics in hemodialysis patients during the inter-dialytic period.

Average inter-dialytic systolic BP

Pre-dialytic systolic BP

Post-dialytic systolic BP

Systolic BP day 1

Systolic BP day 2

Average inter-dialytic diastolic BP

Pre-dialytic diastolic BP

Post-dialytic diastolic BP

Diastolic BP day 1

Diastolic BP day 2
129 (36) $\mathrm{mmHg}$

142 (42) $\mathrm{mmHg}$

124 (34) $\mathrm{mmHg}$

127 (36) mmHg

130 (36) $\mathrm{mmHg}$

72 (18) $\mathrm{mmHg}$

79 (16) $\mathrm{mmHg}$

74 (22) $\mathrm{mmH}_{\mathrm{g}}$

72 (19) mumHg

74 (16) $\mathrm{mmHg}$

Values expressed as mesn (SD)

Regression analysis showed that, both for systolic and diastolic BP, post-dialytic $B P$ measurements were superior to pre-dialytic measurements in the prediction of average inter-dialytic BP. Post-dialytic diastolic BP was also the best predictor for the average 24-hour BP both on the first and second day of the inter-dialytic period (Table 2). Post-dialytic BP was the best predictor for systolic BP on the first day of the inter-dialytic period, whereas pre-dialytic systolic BP was the best predictor for systolic BP on the second day of the interdialytic period. 
Relation between weight gain and rise in blood pressure during the interdialytic period.

In HD patients, body weight decreased with $2.7( \pm 1.9) \mathrm{kg}$ during the first dialysis session and increased by $2.8( \pm 1.4) \mathrm{kg}$ during the subsequent interdialytic period. No difference in inter-dialytic weight gain was observed between patients with and without diuresis $(2.6 \pm 1.0 \mathrm{~kg}$ and $2.4 \pm 2.1 \mathrm{~kg}$; resp.).

No significant correlation was observed between the weight gain and the rise in systolic $B P(r=0.22 ; p=0.2)$ or diastolic $B P(r=-0.02 ; p=0.5)$ during the interdialytic period.

Table 2. Prediction of inter-dialytic blood pressure (BP) by pre- and post-dialytic BP

$\begin{array}{lll}\text { Average } & \text { Average } & \text { Average } \\ \text { inter-dialytic BP } & \text { BP day 1 } & \text { BP day 2 }\end{array}$

$\begin{array}{llll}\begin{array}{l}\text { Pre-dialytic } \\ \text { systolic BP }\end{array} & \mathrm{r}=0.94 ; \mathrm{t}=2.0 & \mathrm{r}=0.93 ; \mathrm{t}=1.0 & \mathrm{r}=0.94 ; \mathrm{t}=9.3 \\ & \mathrm{p}=0.07 & \mathrm{p}<0.001 & \\ \begin{array}{l}\text { Post-dialytic } \\ \text { systolic BP }\end{array} & \mathrm{r}=0.96 ; \mathrm{t}=11.1 & \mathrm{r}=0.98 ; \mathrm{t}=15.4 & \mathrm{r}=0.93 ; \mathrm{t}=1.8 \\ & \mathrm{p}<0.001 & \mathrm{p}=0.001 & \\ \begin{array}{l}\text { Pre-dialytic } \\ \text { diastolic BP }\end{array} & \mathrm{r}=0.84 ; \mathrm{t}=1.9 & \mathrm{r}=0.82 ; \mathrm{t}=1.3 & \mathrm{r}=0.85 ; \mathrm{t}=2.3 \\ & \mathrm{p}=0.08 & \mathrm{p}=0.2 & \mathrm{p}=0.04 \\ \begin{array}{l}\text { Post-dialytic } \\ \text { diastolic BP }\end{array} & \mathrm{r}=0.90 ; \mathrm{t}=7.2 & \mathrm{r}=0.94 ; \mathrm{t}=9.4 & \mathrm{r}=0.87 ; \mathrm{t}=6.1 \\ & \mathrm{p}<0.001 & \mathrm{p}<0.001 & \mathrm{p}<0.001\end{array}$

\section{Nocturnal drop in BP and HR}

Characteristics of BP and HR in the various groups are summarized in Table 3. BP profiles of HD patients (separated for morning- or afternoon dialysis shifts) and controls are graphically displayed in Figure 1-4.

Both systolic $(p<0.001)$ and diastolic $(p<0.001)$ BP differed significantlly between the various groups, whereas HR did not $(p=0.15)$.

The nocturnal drop in systolic BP differed significantly between the various groups $(p=0.004)$ [AnoVa] and was significantly smaller in hypertensive HD patients as compared with normotensive controls $(p<0.001)$. In $11 \mathrm{HD}$ patients 
(3 normotensives, 8 hypertensives) [50\%], the nocturnal drop in systolic BP was less than $5 \mathrm{mmHg}$.

Likewise, the fall in diastolic BP during the night differed significantly $(p<0.001)$ [AnoVa] between the various groups [AnoVa] and was significantly attenuated in hypertensive $H D$ patients as compared with normotensive $(p<0.001)$ and hypertensive $(p<0.001)$ controls. Hypotensive $(p<0.001)$ and normotensive HD patients differed significantly $(p<0.001)$ from normotensive controls with respect to the nocturnal drop in diastolic BP. In 14 HD patients ( 1 hypotensive, 2 normotensives and 11 hypertensives) [63\%], the nocturnal drop in diastolic BP was less than $5 \mathrm{mmHg}$.

Also the drop in HR during the night differed significantly, although to a lesser degree $(\mathrm{p}=0.023)$ [AnoVa] between the various groups. Hypertensive HD patients displayed a significantly smaller drop in HR than normotensive controls $(p<0.001)$.

Table 3. Day night differences in blood pressure (BP) and heart rate (HR) in hemodialysis patients and controls

\begin{tabular}{|c|c|c|c|c|c|}
\hline & $\begin{array}{l}\text { Hypotenswe } \\
\text { IID patients }\end{array}$ & $\begin{array}{l}\text { Normotensive } \\
\text { MID patients }\end{array}$ & $\begin{array}{l}\text { Hypertiensiwe } \\
\text { HD patients }\end{array}$ & $\begin{array}{l}\text { Nornotensive } \\
\text { Controls }\end{array}$ & $\begin{array}{l}\text { Hypertensive } \\
\text { Controls }\end{array}$ \\
\hline Number of patients & 4 & 6 & 12 & 7 & 8 \\
\hline Average systolic $\mathrm{BP}^{0}$ (montug) & 85 (11) & $115(14)$ & $156(15)$ & $120 \%$ & 1.42 (1.4) \\
\hline Day-night difference (mumbig) & $11(0)$ & $7,6 \%$ & $3(6)$ & $18(8)$ & 119 \\
\hline Average diastolic BP (numHe) & $48(9)$ & $7110 \pi$ & $89(6)$ & $76(5)$ & 910 \\
\hline Day-night difference (numg) & $8(5)$ & 70 & $2(6)$ & $17(5)$ & $11(6)$ \\
\hline Average heant rate bimin' & $81(4)$ & $86(13)$ & $81(13)$ & $71(6)$ & $76(1.3)$ \\
\hline D.ayunght difference (b/ain) & $13(5)$ & $9(8)$ & $7(4)$ & $15(9)$ & $11(5)$ \\
\hline
\end{tabular}

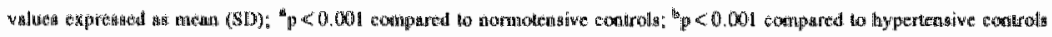

The nocturnal fall in BP in HD patients (all groups) did not differ between the first and second day of the inter-dialytic period (Fall in systolic BP: day 1: 6.5 ( \pm 8.9) $\mathrm{mmHg}$; day 2: $3.6( \pm 10.7) \mathrm{mmHg}[\mathrm{p}=0.2]$; (Fall in diastolic BP: day 1: 5.7 ( \pm 7.5$) \mathrm{mmHg}$; day $2: 4.4( \pm 8.3) \mathrm{mmHg}[\mathrm{p}=0.5]$.

Using multiple regression analysis with age, duration of $\mathrm{HD}$ treatment, mean inter-dialytic BP, number of antihypertensive drugs and the inter-dialytic weight gain (corrected for dry body weight) as independent variables and the nocturnal fall in systolic or diastolic BP as dependent variables, only the duration of HD treatment $(t=-2.4 ; p<0.05)$ and the mean inter-dialytic BP $(t=-2.2 ; p<0.05)$ 
were significantly and inversely related to the nocturnal drop in systolic BP, whereas the number of antihypertensive drugs was inversely related $(t=-2.2$; $\mathrm{p}<0.05$ ) to the nocturnal drop in diastolic BP.

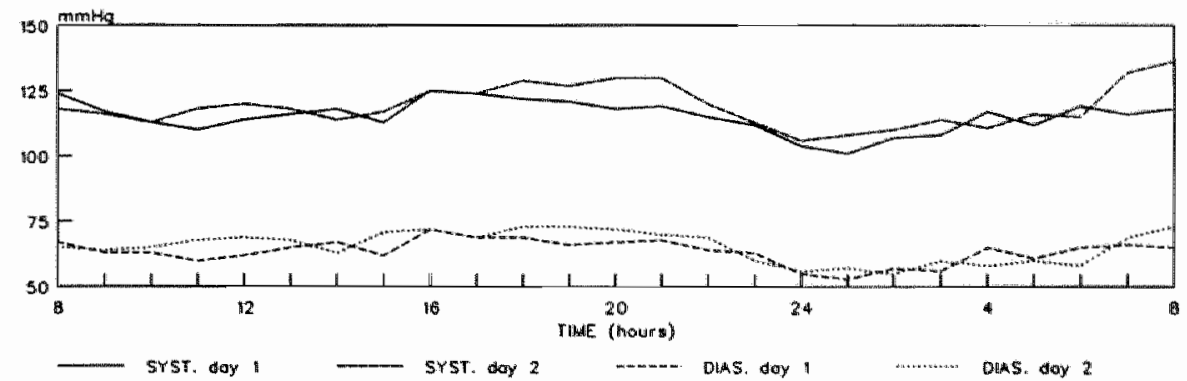

Figure 1. Blood pressure profile in hemodialysis patients (all groups) [morning session]

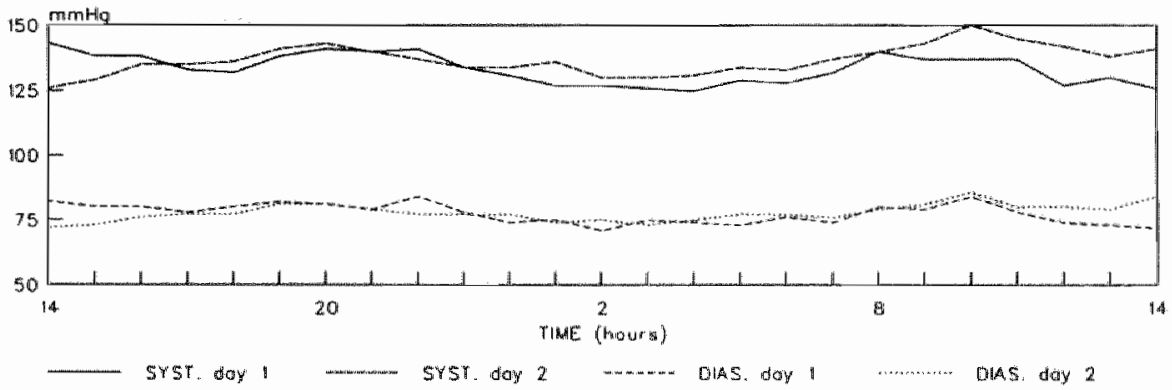

Figure 2. Blood pressure profile in hemodialysis patients (all groups) [afternoon session] 


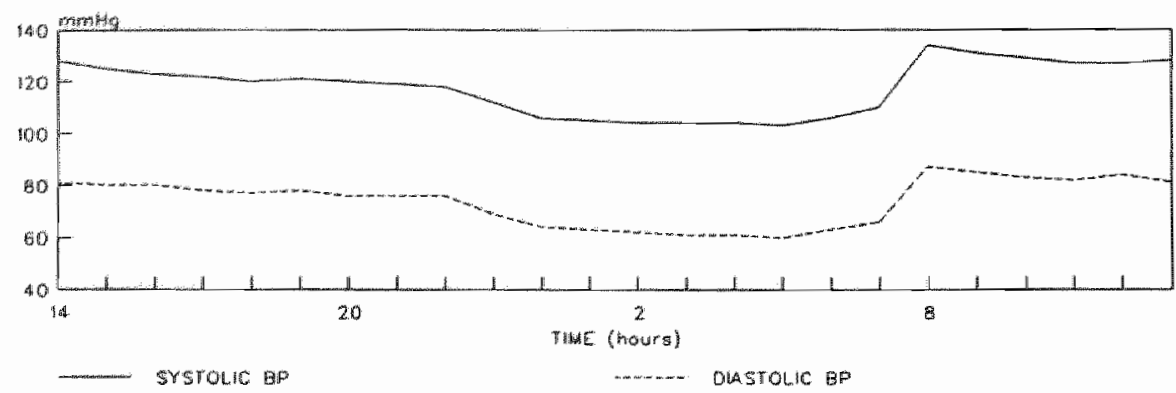

Figure 3. Blood pressure profile in normotensive controls

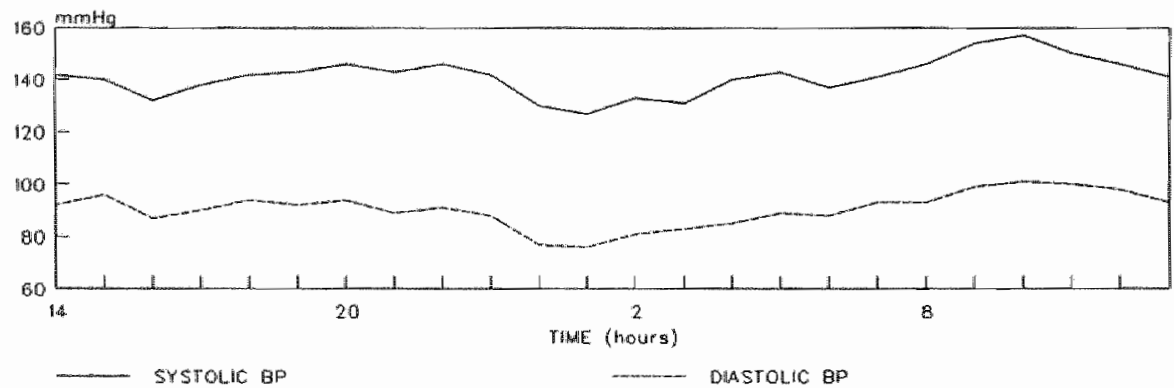

Fïgure 4. Blood pressure profile in hypertensive controls

\section{DISCUSSION}

In this study, non-invasive ambulatory BP measurements were performed in dialysis patients during the inter-dialytic period to assess whether pre- or postdialytic BP correlated best with the average BP during the entire inter-dialytic period.7 Furthermore, the nocturnal drop in BP and HR were determined in HD patients and compared with those in normotensive controls and subjects with essential hypertension.

The post-dialytic BP proved to be superior to pre-dialytic BP in predicting the average $B P$ during the entire inter-dialytic period. Also for the average diastolic $\mathrm{BP}$ on the first and second day of the inter-dialytic period, post-dialytic BP was the better determinant. Whereas post-dialytic systolic BP was the best predictor 
for the average systolic BP on the first day of the inter-dialytic period, predialytic systolic BP was most representative for the average systolic BP on the second day of the inter-dialytic period.

$\mathrm{BP}$ rose rapidly during the hours before $\mathrm{HD}$, which is in accordance with the results of Battistella et al.(9). No correlation was found between the increase in body weight and the rise in BP during the inter-dialytic period. However, the rapid pre-dialytic BP rise could be caused by volume overload, in combination with other factors, such as a reduced arterial compliance (10), which leads to an increase in systolic BP and/or a reduced venous compliance (11), which increases cardiac filling pressure and output. Also other factors, like the arousal and the increase in activity associated with the initiation of a dialysis session, may play a role in the rapid rise in BP before dialysis.

In another study in which inter-dialytic BP was measured up to 24 hours after HD, Battle et al.(12) observed a decline in BP during the hours immediately after $\mathrm{HD}$, on the postulated basis of a loss of vasopressor activity after HD. The same phenomenon was observed in the study of Battistella et al (9). We were not able to reproduce this response, neither in patients on the morning, nor in patients on the afternoon shift. The reason for this discrepancy is not clear. The vasodilating effect of acetate might last in the hours after HD in patients who slowly metabolize this substance (13). However, Battistella et al. (9) used bicarbonate as dialysate buffer, whereas in the study of Battle et al. (12), the dialysate buffer was not mentioned. Another explanation for their findings could be relative hypovolemia after $\mathrm{HD}$, leading to a decline in $\mathrm{BP}$ when the activation of vasopressor substances is attenuated. We used more reliable methods to rule out post-dialytic hypovolemia $(5,6)$.

The nocturnal drop in BP in dialysis patients was attenuated, which is in agreement with earlier studies $(4,9,14)$. A reduced day-night difference in BP may have important clinical significance, since in patients with essential hypertension, such a phenomenon is associated with an increased incidence of target-organ complications (15). Moreover, because BP remains high during the night, adjustments in dosage or frequency of administration of antihypertensive drugs might be required. The nocturnal drop in BP was most severely blunted in hypertensive HD patients. Because of the severity of hypertension in this group, antihypertensive treatment was not stopped. Although it has been well established that, apart from $\alpha$-sympathicolyic agents, antihypertensive medication does not affect the day-night BP rhythm (8), the use of multiple antihypertensive agents could have an effect on the day-night BP difference in hypertensive HD patients. This hypothesis is supported by our observation that the number of antihypertensive drugs was inversely correlated with the nocturnal drop in diastolic BP. However, the level of BP is likely to play a more important role; in our study, the severity of hypertension was related to 
the disturbance of the day-night rhythm of systolic BP, whereas Gosse et al. (16) found a relation between the $\mathrm{BP}$ elevation and the reduction of the daynight BP rhythm. Nevertheless, even when compared with essential hypertensives who were matched for the severity of hypertension and the antihypertensive drugs used, the attenuation in the nocturnal BP drop in hypertensive HD patients remained evident.

The mechanism behind the blunted day-night BP difference in HD patients remains unclear. From a theoretical point of view, an increase in plasma volume (4), the absence of diuresis, reduced daily activity, heart failure (17), autonomic failure (18), and elevated levels of catecholamines (19) could all be involwed. When an increase in plasma volume would play an important role, the nocturnal BP fall would be expected to be more severely blunted on the second day of the inter-dialytic period. However, there was no difference between the first and second day of the inter-dialytic period with respect to the day-night BP difference. Battistella et al. (9) even found a greater attenuation of the nocturnal BP drop on the first day of the inter-dialytic period.

The presence of diuresis seems to be of no influence on the day-night BP rhythm. There was no difference in the nocturnal drop of systolic BP between patients with and without diuresis, whereas the nocturnal fall in diastolic BP was even significantly more blunted in patients with diuresis, which might be explained by the relatively higher number of hypertensive patients in this group. Furthermore, in previous studies, the day-night BP rhythm was also found to be blunted in patients with chronic renal failure who had some residual renal function left (4).

The importance of reduced daily activity in our patient group is also not likely; all patients were clinically stable and able of performing normal daily activities. Furthermore, blunting of the nocturnal drop in HR was less pronounced than that of the nocturnal drop in BP in HD patients. In a recent study of Portaluppi et al. (14), in which the day-night difference in BP was assessed in hospitalized subjects with essential hypertension and in non-dialyzed patients with end-stage renal failure, the nocturnal drop in BP in patients with renal failure was also markedly reduced.

In patients with heart failure secondary to coronary artery disease, a reduced day-night difference of BP and HR has been reported (17). However, in the present study, patients with overt heart failure and coronary artery disease were excluded.

In patients with idiopathic autonomic failure a paradoxal nocturnal increase in $\mathrm{BP}$ has been described (18). Uremic autonomous neuropathy is characterized by an abnormal Valsalva ratio and normal efferent sympathetic activity (20), which points to a defect localized either in the afferent part of the baroreceptor reflex arc, the central nuclei, the heart itself or in the efferent parasympathetic nerves. 
However, the day-night difference in HR was blunted to a lesser degree than the day-night difference in $\mathrm{BP}$, which pleads against a definite role of uremic autonomic failure in the attenuation of the day-night BP differences.

The nocturnal fall in BP in healthy persons and subjects with essential hypertension is believed to originate from a reduction in sympathetic activity during the night (21). In HD patients, increased levels of catecholamines (19) as well as a reduction in the end-organ sensitivity to the effects of catecholamines have been described (22). Whether the increased catecholamine levels reflect sympathetic overactivity or serve as a compensation for a reduced endorgan sensitivity is not clear. Interestingly, Daul et al. (23) reported an inverse correlation between the increase in catecholamine levels and $\alpha_{2}$-receptor density on platelets, which was related to the duration of $\mathrm{HD}$ treatment. The relation between the reduction in the day-night difference of systolic BP and the duration of $\mathrm{HD}$ treatment observed in the present study might thus be an additional argument for a role of disturbed sympathetic activity in the attenuation of daynight $\mathrm{BP}$ differences; $\mathrm{BP}$ in HD patients might be less responsive to subtle changes in sympathetic activity. Further study is needed to support this assumption.

\section{CONCLUSION}

Post-dialytic BP is a better predictor for the average BP during the inter-dialytic period than pre-dialytic BP. Pre-dialytic BP rises rapidly during the hours before HD.

Furthermore, the day-night BP rhythm is attenuated in HD patients, both on the first and on the second day of the inter-dialytic period.

\section{REFERENCES}

1. Safar ME, London GM, Levenson JA, Simon AC, Chau NP. Rapid dextran infusion in essential hypertension. Hypertension 1979; 1:615-623.

2. Klooker $\mathrm{P}$, Bommer $\mathrm{E}$, Ritz E. Treatment of hypertension in dialysis patients. Blood Purif $1985 ; 3: 15-26$.

3. Leunissen KML, Noordzij TC, van Hooff JP. Pathophysiologic aspects of plasma volume preservation, Contrib Nephrol 1990; 78:201-211.

4. Baumgart P, Walger $\mathrm{P}$, Gemen $\mathrm{S}$, von Eiff $\mathrm{M}$, Raidt $\mathrm{H}$, Rahn $\mathrm{KH}$. Blood pressure elevation during the night in chronic renal failure, hemodialysis and after renal transplantation. Nephron 1991; 57:293-298.

5. Leunissen KML, Cheriex EC, Janssen JHA, Mooy JMV, van Hooff JP. Echography of the inferior caval vein is a simple and reliable tool for estimation of dry weight in hemodialysis patients. Nephrol Dial Transpl $1989 ; 4: 563-568$. 
6. Bonnie E, Lee WG, Stiller S, Mann H. Influence of fluid overload on vascular refilling in hacmodialysis: continuous measurements with the conductivity method. Progress in Artif Organs 1985; 135-137.

7. O'Brien E, Mee F, Atkin' N, O'Malley K. Accuracy of the Spacelabs 90207 determined by the British Hypertension Society protocol. J Hypert 1991; 9:573-574.

8. Pickering TG. Ambulatory monitoring and blood pressure variability. Science Press. London, 1991.

9. Battistella $P$, de Cornelissen $F$, de Gaudemaris $R$, Contard S, Janin G. Profil tensionnel ambulatoire de 48 heures chez l'hemodial yse chronique. Arch Mal Coeur 1990; 83:12231227.

10. Marchais S, Guerin A, Safar M, London G. Arterial compliance in uraemia. J Hypert $1989 ; 7: S 84-\$ 85$.

11. Kooman JP, Wijnen JAG, Draaijer P, van Bortel LMAB, Gladziwa U, Peltenburg HG, Struyker-Boudier HAJ, van Hooff JP, Leunissen KML. Compliance and reactivity of the peripheral venous system in patients on hemodialysis. Kidney Int 1992; 41 (in press)

12. Battle DC, von Riotte A, Lang G. Delayed hypotensive response to dialysis in hypertensive patients with end-stage renal disease. Am J Nephrol 1986; 6:14-20.

13. Vreman HJ, Assomull VM, Kaiser BA, Blaschke TF, Weiner MW. Acetate metabolism and acid-base homeostasis during hemodialysis; Influence of dialyzer efficiency and rate of acetate metabolism. Kidney Int 1980; 18 (supp 10):S62-S74.

14. Portaluppi F, Montanari L, Massari M, Di Chiara V, Capanna M. Loss of nocturnal decline of blood pressure in hypertension due to chronic renal failure. Am J Hypert $1991 ; 4: 20-26$.

15. Parati G, Pomidossi G, Albini F, Malaspina D, Mancia G. Relationship of 24-hour blood pressure mean and variability to severity of target-organ damage in hypertension. $J$ Hypertens 1987; 5:93-98.

16. Gosse P, Jullien E, Reynaud P, Dallochio $M$. Variations circadiennes de la tension artérielle; importance de la sévérité et non de la cause de l'hypertension artérielle. Arch Mal Cocur 1988; 81 (supp HTA):247-250.

17. Caruana M, Lahiri A, Cashman PMM, Altman DG, Raftery EB. Effects of chronic congestive heart failure secondary to coronary artery disease on the circadian rhythm of blood pressure and heart rate. Am J Cardiol 1988; 62:755-759.

18. Mann S, Altman $G$, Raftery EB, Bannister $E$. Circadian variation of blood pressure in autonomic failure. Circulation 1983; 68:477-483.

19. McGrath BP, Ledingham JGG, Benedict CR. Catecholamines in peripheral venous plasma in patients on chronic hemodialysis. Clin Sci Mol Med 1978; 55:89-96.

20. Campese VM, Romoff MS, Levitan D, Lane K, Massry S. Mechanisms of autonomous nervous system dysfunction in uremia. Kidney Int 1981; 20:246-253.

21. de Leeuw PW, van Leeuwen SJ, Birkenhäger WH. Effect of sleep on blood pressure and its correlates. Clin and Exper-theory and practice 1985; A7 (2\&3): 179-186.

22. Rasher W, Schonig A, Kreye VA, Ritz E. Diminished vascular response to noradrenaline in experimental chronic uremia. Kidney Int 1988; 21:20-27.

23. Daul AE, Wang XL, Michel MC, Brodde OE. Arterial hypotension in chronic hemodialyzed patienis. Kidney Int 1987; 32:728-723. 


\section{Compliance of the peripheral venous system in patients treated with chronic intermittent hemodialysis}

J.P. Kooman, J.A.G. Wijnen' ${ }^{1}$, P. Draaijer, L.M.A.B. van Bortel', U. Gladziwa ${ }^{2}$, H.G. Peltenburg, H.A.J. Struyker-Boudier ${ }^{1}$, J.P. van Hooff, K.M.L. Leunissen

Department of Internal Medicine and 'Department of Pharmacology, University Hospital Maastricht, the Netherlands. ${ }^{2}$ Dialysis Clinic, Aachen, Germany.

Kidney Int 1992; 41(4):in press 


\section{ABSTRACT}

In this chapter, it was investigated whether venous compliance $(V C)$ was reduced in hemodialysis patients. Therefore, VC was assessed in 15 normotensive and 11 hypertensive dialysis patients and in 14 normotensive and 8 hypertensive control subjects. All groups were age-matched. VC was investigated in the forearm using strain-gauge plethysmography with direct intravenous pressure measurements.

$V C$ was equal in normotensive dialysis patients and normotensive controls, but was reduced in hypertensive hemodialysis patients compared to normotensive dialysis patients $(p=0.013)$ and normotensive controls $(p=0.004)$. Hypertensive controls did not differ significantly from any group.

After one dosage with a directly acting venodilator (Nitroglycerin $5 \mathrm{mg}$ s.l.) and 3 days treatment with an $\alpha_{1}$-sympathicolytic agent (Doxazosin $2 \mathrm{mg}$ ), VC remained unaltered in hypertensive dialysis patients.

CONCLUSION: Hypertension and not renal failure causes the reduction of venous compliance in hemodialysis patients for which structural factors might be responsible. 


\section{INTRODUCTION}

Although the venous system plays a pivotal role in blood pressure regulation (1), few studies have dealt with its structure and function in hemodialysis patients. The venous system serves both as a conductance system and as a blood reservoir. In resting conditions, about $60 \%$ of total blood volume in the venous system is hemodynamically inactive ('unstressed'). Thus, only $40 \%$ is hemodynamically active ('stressed') and takes part in the regulation of the circulation (2). Compliance is defined as the volume/pressure relationship of the stressed compartment (3).

In hemodialysis patients, hypotensive periods frequently occur and are a cause of major discomfort and sometimes severe complications during dialysis (4). A reduction in venous compliance can for two reasons play a provocative role in the initiation of hypotension during hemodialysis; Firstly, a reduced venous compliance might impair plasma volume preservation during ultrafiltration and dialysis by interfering with the capillary Starling equilibrium (5). Secondly, because of the reduced volume/pressure relationship, it could also lead to a major drop in cardiac filling pressure even when plasma volume is decreased only slightly (2).

A reduction in venous compliance in hemodialysis patients was expected because the relation between the inferior caval vein diameter and right atrial pressure showed a shift to a higher atrial pressure for a given caval vein diameter in hemodialysis patients $(6,7)$ compared with healthy controls $(8,9)$. This indicates an altered pressure/volume relationship in the venous system of hemodialysis patients, possibly due to a reduction in compliance. Furthermore, given the frequent occurrence of hypertension in the dialysis population (10), specific factors related to uremia, such as increased levels of catecholamines $(11,12)$ and angiotensin II (13) might also influence the compliance of the venous system. In this study, the compliance of the peripheral venous system in hemodialysis patients was assessed using strain-gauge plethysmography the day after dialysis. In order to separate the effects of hypertension on venous compliance from the effects of renal failure, normotensive and hypertensive subjects on hemodialysis were compared with normotensive and hypertensive controls, respectively.

\section{PATIENTS}

Clinically stable patients treated with chronic intermittent hemodialysis were included. Controls consisted of healthy persons and subjects with essential hypertension. Exclusion criteria were: acute infectious diseases, diabetes mellitus, a history of shunt-operations or the insertion of a central venous 
catheter in the side contralateral to the present arterio-venous shunt (thus reducing the risk of a central venous obstruction), previous treatment with $A C E$ inhibitors, severe coronary or valvular heart disease (NYHA II or more) and a compromised left ventricular function (ejection fraction $30 \%$ or less).

Normotension was defined as a blood pressure below $140 / 80 \mathrm{mmHg}$ after hemodialysis for at least 6 consecutive months (14) (chapter 3), without the use of antihypertensive medication. Hypertension was defined as a blood pressure higher than $150 / 90 \mathrm{mmHg}$ after hemodialysis without antihypertensive medication, when patients were normovolemic. Equal limits were applied for controls. To prevent overlap between the various groups, subjects with (postdialytic) blood pressures between 140/80 and 150/90 were excluded.

Patients were dialysed three times a week at a Gambro AK-100 or a Fresenius2008 dialysis apparatus with bicarbonate as dialysate buffer.

All subjects gave informed consent. The study was approved by the Ethics Committee of the University Hospital of Maastricht.

15 normotensive (10 male, 5 female; mean age 50 [range 26-75] years) and 11 hypertensive ( 6 male, 5 female; mean age 53 [range 27-74] years) dialysis patients were studied, as were 14 normotensive ( 6 male, 8 female; mean age 47 [range 35-65] years) and 8 hypertensive ( 6 male, 2 female; mean age 47 [range 29-72] years) controls. Mean time on hemodialysis was 13 [range 3-96] months in normotensive patients and 22 [range 4-60] months in hypertensive patients. In the hypertensive groups, mean duration of hypertension was 7.2 [range 1.515] years in dialysis patients and 3.9 [range 6-7.6] years in controls. All patients had hemoglobin levels $>6.0 \mathrm{mmol} / \mathrm{l}$. Vasoactive medication was stopped at least six weeks before the investigation.

In 7 hypertensive dialysis patients ( 4 male, 3 female, mean age 56 [range 30-74] years), the effect of treatment with an $\alpha 1$-sympathicolytic agent (Doxazosin) and with a directly acting venodilator (Nitroglycerin) on venous compliance was evaluated.

\section{METHODS}

Venous compliance (VC) was measured by strain-gauge plethysmography (15) (Periflow, Janssen Scientific Instruments, Beerse, Belgium) with direct intravenous pressure measurements. The technique for the assessment of VC by strain-gauge plethysmography was discussed in detail in chapter 2 . The investigation was performed in the morning, and, in dialysis patients, the day after dialysis. Fluid status was assessed by echographic estimation of the inferior caval vein diameter, corrected for body surface area $(6,7)$ [vena cava diameter at normovolemia $\left.=8-11,5 \mathrm{~mm} / \mathrm{m}^{2}\right]$. 
Blood pressure at the day of investigation was measured in supine position after 10 minutes rest (Random-zero, Hawksley).

\section{Reversibility of a reduction in wenous compliance}

The reversibility of a reduction in $\mathrm{VC}$ was determined in two different ways: the possible role of an increased sympathetic tone was evaluated by treatment during three days with an $\alpha_{1}$-sympathicolytic agent (Doxazosin $2 \mathrm{mg}$ ). In addition, the effect of a single dose of a directly acting venodilator (Nitroglycerin ( $5 \mathrm{mg}$ sl) on VC was recorded.

The effect of Doxazosin was evaluated by comparing $\mathrm{VC}$, measured using the protocol described above, before and after Doxazosin treatment ( 3 days later). A treatment of three days was chosen because this time is necessary to obtain optimal plasma levels because of the relatively long half-life of the drug (16). Blood pressure before and during Doxazosin treatment was measured after 30 minutes rest in supine position (Random Zero, Hawksley)

The effect of Nitroglycerin on VC was assessed using a slightly different protocol because of the short duration of action of Nitroglycerin (17).

VC was measured before and after Nitroglycerin administration at cuff pressures of 30 and $35 \mathrm{mmHg}$. The cuff was inflated at the subsequent cuff pressures during 2 minutes and deflated during 1 minute after each increment in cuff pressure. Thirty seconds after Nitroglycerin administration, the first cuff inflation was started (Figure 2). The volume/pressure ratio at each cuff pressure was read after deflation of the arm cuff.

The slope of the volume/pressure curves before and after Nitroglycerin administration were compared to estimate the effect of Nitroglycerin on VC.

\section{Statistical analysis}

Values are expressed as mean $( \pm S D)$. Kruskal-Wallis analysis of variance was used to assess overall differences between the various groups. When overall differences were significant, a Mann-Whitney signed-rank test was used to evaluate differences between specific groups. Differences within groups were analysed using a Wilcoxon rank-sum test. 


\section{RESULTS (Table 1)}

The vena cava diameter index was equal in normotensive and hypertensive diallysis patients $(p=0.3)$. Mean arterial pressure (MAP) differed significantly between the various groups $(p<0.001)$ and was significantly higher in hypertensive patients and hypertensive controls than in normotensive patients $(p=0.001 ; p=0.003$, resp.) and controls $(p<0.001 ; p=0.001$, resp.). VC differed significantly between the various groups $(p=0.013)$ and was lower in hypertensive dialysis patients as compared with normotensive patients $(p=0.013)$ and controls $(\mathrm{p}=0.004)$ [Figure 1]. Peripheral venous pressure did not differ between the various groups $(p=0.22)$.

Table 1. Hemodynamic parameters in the different groups

\begin{tabular}{|c|c|c|c|c|}
\hline & $\begin{array}{l}\text { Normotensiwe } \\
\text { patients }\end{array}$ & $\begin{array}{l}\text { Hypertensive } \\
\text { patients: }\end{array}$ & $\begin{array}{l}\text { Normotensive } \\
\text { controlls }\end{array}$ & $\begin{array}{l}\text { Hypertensive } \\
\text { controls }\end{array}$ \\
\hline Number & 15 & 11 & 14 & 8 \\
\hline MAP (ntmHg) & $91(18) * * *$ & $114\{8\}$ & $96(8)$ & $112(6) * * 1$ \\
\hline $\mathrm{VC}(\mathrm{m} / / 100 \mathrm{~m} / / \mathrm{mmn} / \mathrm{lg})$ & $0.062(.021) * *$ & $0.041(.016)^{* 41 *}$ & $0.061(.012)$ & $0.051(.014)$ \\
\hline PVP (mmHg) & $7(3)$ & $7(3)$ & 5 (2) & 50 \\
\hline VCDI $\left(\mathrm{mn} / \mathrm{m}^{2}\right)$ & $8.0(1.5)$ & $8.4(1.6)$ & - & - \\
\hline
\end{tabular}

In hypertensive controls, $\mathrm{VC}$ did not differ significantly from normotensive patients $(p=0.24)$, normotensive controls $(p=0.09)$ and hypertensive patients $(p=0.13)$. VC was equal in normotensive patients and controls $(p=0.8)$.

\section{Reversibility of venous compliance in hypertensive dialysis patients}

The volume status was equal on the investigations before and after doxazosin treatment (before: $V C D I=8.0 \pm 0.9 \mathrm{~mm} / \mathrm{m} 2$ ); after: $V C D I=7.4 \pm 1.9 \mathrm{~mm} / \mathrm{m} 2$; $\mathrm{p}=0.3$ ) 
After doxazosin treatment, MAP tended to decrease: $-3.14 \pm 3.7 \mathrm{mmHg}$; $p=0.07)$. However, VC remained unaltered $(-0.003 \pm 0.02 \mathrm{ml} / 100 \mathrm{ml} / \mathrm{mmHg}$; $p=0.5$ ). After administration of Nitroglycerin, arm volume increased initially during cuff inflation. However, when the cuff was deflated, basal arm volume returned to a higher level $(0.56 \pm 0.32 \mathrm{ml} / 100 \mathrm{ml} ; \mathrm{p}=0.003)$ with no change in the volume/pressure ratio $(0.005 \pm 0.01 \mathrm{ml} / 100 \mathrm{ml} / \mathrm{mmHg} ; \mathrm{p}=0.4)$ [Figure 1]. Peripheral venous pressure remained unaltered after Nitroglycerin administration.

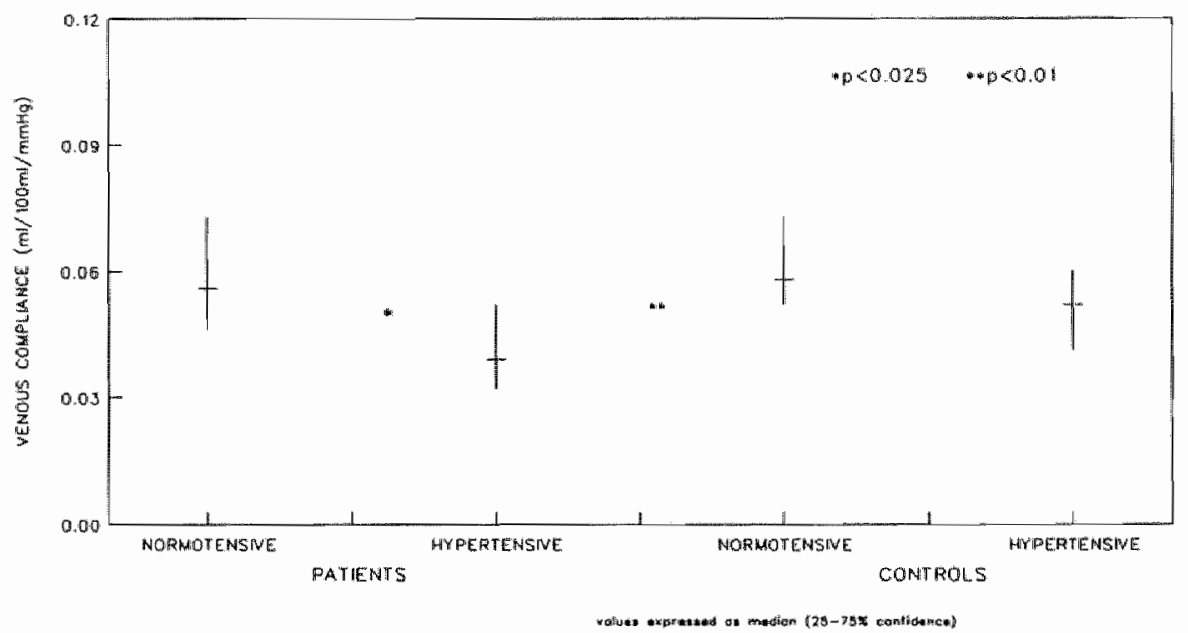

Figure 1. Venous compliance in dialysis patients and controls subjects. 


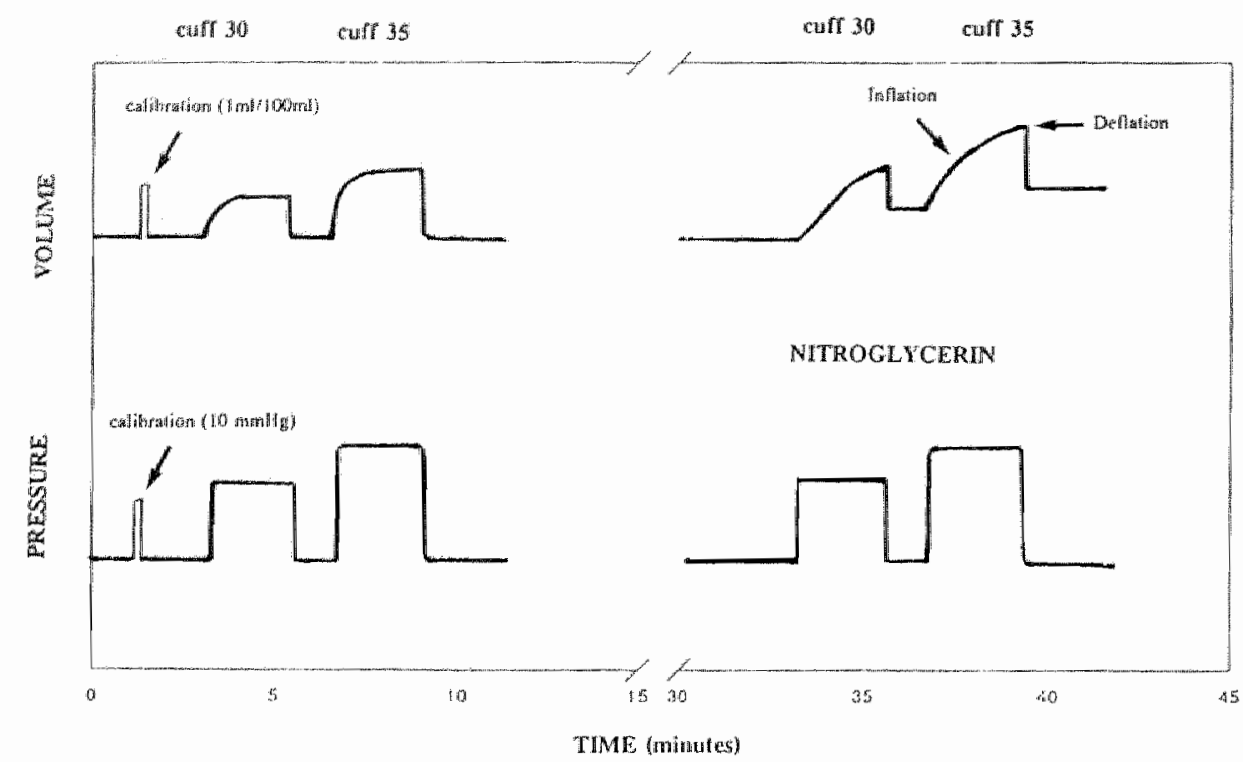

Figure 2. Effect of Nitroglycerin on venous compliance; tracing of a representative experiment

\section{DISCUSSION}

In this study the compliance of the peripheral venous system in patients treated with chronic intermittent hemodialysis was measured by strain-gauge plethysmography.

As discussed in chapter 2, a linear volume/pressure relationship was observed in our study, in contrast to the curvilinear volume/pressure relation obtained in isolated veins (18). However, the venous volume/pressure relationship is only curvilinear below a transmural pressure of $\pm 10-15 \mathrm{mmHg}$, when the crossdiameter of the vein is still elliptical (18). The minimal applied cuff pressure in the present study was $25 \mathrm{mmHg}$, reflecting an intravenous pressure of $\pm 10-15$ $\mathrm{mmHg}$. Therefore, venous compliance was only studied in the linear part of the volume/pressure relationship which is, however, considered to reflect the true compliance of the venous wall (19).

Patients and controls were divided into normotensive and hypertensive groups, respectively. In hemodialysis patients, post-dialytic blood pressure was used to distinguish between normotensive and hypertensive subjects, because we and others have shown by non-invasive inter-dialytic blood pressure measurements that the post-dialytic blood pressure is a much better predictor for inter-dialytic 
blood pressure than pre-dialytic blood pressure $(14,20)$, as discussed in chapter 3.

VC was clearly reduced in hypertensive dialysis patients, and, to a lesser degree, in hypertensive controls. No difference was observed between normotensive controls and normotensive patients. Thus, renal failure and dialysis treatment itself do not contribute to the reduction of VC in hemodialysis patients. Our data are at variance with the study of Bradley et al. (21), who found VC to be reduced in hemodialysis patients. However, they did not clearly distinguish between normotensive and hypertensive subjects, which may explain the difference. Moreover, in the present study, measurements were performed at optimal dry weight, as estimated by echographic recording of the inferior caval vein diameter $(6,7)$. Therefore, volume overload as a possible incriminating factor could virtually be excluded.

Values for VC in hypertensive controls did not differ significantly from any group, which may be related to a shorter duration of hypertension in this group as compared to hypertensive dialysis patients. Another possibility is that VC is reduced to a larger degree in patients with renal hypertension (28).

The reduced VC in hypertension has been well established $(5,23,24)$. However, the mechanism behind this reduction has not been completely elucidated. Functional (enhanced sympathetic activity) and structural factors might play a role. In animals hypertension has been found to cause structural changes of the venous wall resembling the changes found in the arterial wall. Sodium- and water logging (25), an increase in the amount of collagen and elastin and smooth muscle-cell hypertrophy (26) have all been described. The observation that VC in hypertensive dialysis patients did not change after short-term treatment with an $\alpha_{1}$-sympathicolytic agent or after one dosage with a directly acting venodilator increases the probability that structural changes are responsible for the reduction in VC in hypertensive dialysis patients. That the administered dosage of doxazosin was too low is not very likely; pharmacokinetics and effectiveness of doxazosin do not differ between healthy controls and patients with renal failure (16). Furthermore, blood pressure tended to decrease during the three day treatment.

After Nitroglycerin administration, arm volume increased during inflation of the arm cuff. However, after deflation the volume/pressure ratio remained unchanged whereas the basal arm volume returned to a higher level (Figure 2). The explanation is that Nitroglycerin theoretically could exert its action either by increasing venous compliance or by venodilatation with a consequent increase in unstressed volume. As mentioned before, unstressed blood volume is the hemodynamically inert part of the venous system that serves as a blood reservoir (3). When Nitroglycerin would have caused an increase in compliance, 
not only the arm volume after inflation of the arm cuff would have increased, but so would the volume/pressure ratio after deflation of the arm cuff. Basal arm volume would not have changed because of rapid flow of the hemodynamically active blood out of the forearm.

In contrast, with an increase in unstressed volume, the arm volume increases after inflation of the arm cuff, but, after deflation, returns to a higher basal arm volume without a change in the volume/pressure ratio. Basal arm volume increases because the hemodynamically inactive blood remains behind after release of the arm cuff. The increase in unstressed blood volume can be explained by active venodilation. Although venous smooth muscle tone is minimal in resting circumstances, some sympathetic outflow to the veins exists (22). However, this will barely influence the volume/pressure relationship of the venous wall, which is more determined by its collagen content at higher transmural pressures. After Nitroglycerin administration, the veins become entirely relaxed and hemodynamically inactive blood volume can accumulate. An increase in capillary filtration can also cause an increase in basal arm volume after cuff deflation. Increased capillary filtration after Nitroglycerin administration is, however, very unlikely (27). The dilating action of Nitroglycerin is more marked on the venous than on the arterial side of the circulation (17). Thus, it is more likely that hydrostatic pressure over the capillary wall decreases with a concomitant decrease in capillary filtration. Therefore, Nitroglycerin most likely exerts its effect by an increase in unstressed blood volume with no change in $\mathrm{VC}$, which is in accordance with the study of Manyari et al. (28).

\section{CONCLUSIONS}

Hypertension and not chronic renal insufficiency leads to a reduction in venous compliance in patients on hemodialysis. This reduction in compliance is not reversible by short-term intervention with a directly-acting venodilator or an $\alpha_{1}$ sympathicolytic agent.

The hemodynamic significance of the present findings will be discussed in chapter 6 . 


\section{REFERENCES}

1. Guyton AC: Textbook of Medical Physiology. 7th Edition, W.B. Saunders \& Co, Philadelphia/London/Toronto, 1986.

2. Greenway CV, Wayne Lautt W. Blood volume, the venous system, preload and cardiac output. Can I Physiol Pharmacol 1986; 64:383-387.

3. Rothe CF. Venous system: physiology of capacitance vessells. In: Handbook of Physiology, 1983. Sect 2. Cardiovascular system. Vol 3. Peripheral circulation and organ blood flow. Chapt 13. American Physiological Society, Bethesda. pp 397-452.

4. Henderson L. Symptomatic hypotension during hemodialysis. Kidney Int 1980; 17:571576.

5. London GM, Safar ME, Levenson JA, Simon AC, Temmar MA. Renal fillration fraction, effective vascular compliance, and partition of flud volumes in sustained essential hypertension. Kidney Int 1981; 20:97-103.

6. Cheriex EC, Leunissen KML, Janssen JHA, Mooy JMV, van Hooff JP. Echography of the vena cava inferior is a simple and reliable tool for the estimation of dry weight in hemodialysis patients. Nephrol Dial Transpl 1989; 4:563-568.

7. Leunissen KML, Menheere PPCA, Cheriex EC, van den Berg BW, Noordzij TC, van Hooff JP. Plasma alpha-human atrial natriuretic peptide and dry weight in chronic hemodialysis. Nephrol Dial Transpl 1989; 4:382-386.

8. Nakao S, Come PC, McKay RG, Ransil BJ. Effects of positional changes on inferior vena cava size and dynamics and correlations with right-sided cardiac pressure. Am I Cardiol $1987 ; 59: 125-132$.

9. Moreno FL, Hagan AD, Holmen JR, Pryor TA, Strickland RD, Castle CH. Evaluation of size and dynamics of the inferior vena cava as an index of rightsided cardiac function. Am J Cardiol 1984; 53:579-585.

10. Vincenti F, Amend WJ, Abele J, Feduska NJ, Salvatierre O. The role of hypertension in hemodialysis associated atherosclerosis. Am J Med 1980; 68:363.

11. Zucchelli P, Catizone L, Degli Esposti E, Fusaroli M, Ligabue A, Zuccala A. Influence of ultrafiltration on plasma renin activity and adrenergic system. Nephron 1978; 21:317-324.

12. McGrath BP, Ledingham JGG, Benedict $C R$. Catecholamines in peripheral venous plasma in patients on chronic hemodialysis. Clin Sci Mol Med 1978; 55:89-96.

13. Yamamoto T, Shimizu M, Morioka M, Kitano M, Wakabayashi J, Aizawa N. Role of angiotensin II in the pathogenesis of hyperdipsia in chronic renal failure. JAMA 1986 ; 256:604-608.

14. Kooman JP, Gladziwa U, Wijnen JAG, Böcker $\mathrm{G}$, van Bortel LMAB, Luik AJ, van Hooff $J P$, Leunissen KML. Non-invasive blood pressure measurements during the interdialytic period in patients on hemodialysis: assessment of representative blood pressure values. Nephrol Dial Transpl 1992 (in press)

15. Jageneau et al. Noninvasive diagnosis in the management of cardiovascular diseases. North Holland Biomedical Press. Amsterdam, New York, London, 1981.

16. Waller DG, Oliver RM. Doxazosin in renal impairment. J Human Hypertension 1990; 4 (supp 3):47-49.

17. Gillness and Goodman. The pharmacological basis of therapeutics, 8 th Edition, Pergamon press, 1990. 
18. Moreno AH, Katz AI, Gold LD, Reddy RV. Tech M. Mechanisms of distension of dog. veins and other very thin-walled tubular structures. Circ Res 1970; 28:1069-1080.

19. Oberg $\mathrm{B}$. The relationship between active constriction and passive recoil at various distending pressures. Acta Physiol Scand 1967; 71:233-247.

20. Batistella $P$, de Comelissen $F$, de Gaudemaris $R$. Ambulatory blood pressure monitoring during 48 hours in untreated hemodialysis patients. Arch Mal Coeur Vaiss 1990; $83: 1223-1227$.

21. Bradley JR, Evans DB, Cowley AJ. Abnormalities of the peripheral circulation in patients with chronic renal fallure. Nephrol Dial Transpl 1988; 3:412-416.

22. Shepherd JT, Vanhoutte PM. Veins and their control. W.B. Saunders Company, London/Philadelphid/Toronto, 1975.

23. Takeshita $A$, Mark $A L$. Decreased venous distensibility in borderline hypertension. Hypertension 1979; 1:202-206.

24. London GM, Safar ME, Safar LA, Simon AC. Blood pressure in the 'low-pressure system' and cardiac performance in essential hypertension. I Hypert $1985 ; 3: 337-342$.

25. Pamnani MB, Overbeck HW. Abnormall ion and water composition of veins and normotensive arteries in coarctation hypertension in rats. Circ Res 1986; 38:375.

26. Greenberg S, Palmer EC, Wilborn WM. Pressure-independent hypertrophy of veins and pulmonary arteries of spontaneously hypertensive rats. Characterization of function, structural and histochemical changes. Clin Sci Mol Med 1978; 55:31s-36s.

27. Ablad B, Mellander $S$. Comparative effects of hydralazine, sodium nitrite and acerylcholine on resistance and capacitance blood vessels and capillary filtration in skeletal muscle in the cat. Acta Physiol Scand 1963; 58:319-329.

28. Manyari DE, Malkinson TJ, Robinson V, Smith ER, Cooper KE. Acute changes in forearm venous volume and tone using radionuclide plethysmography. Am J Physiol 1988; 255:H947-H952. 


\section{CHAPTER 5}

\section{Morphological changes of the venous system in uremic patients}

J.P. Kooman, M.J.A.P. Daemen', R. Wijnen², M.J. Verluyten-Goessens', J.P. van Hooff, K.M.L. Leunissen

Department of Internal Medicine, 'Department of Pathology, ${ }^{2}$ Department of Surgery, University Hospital Maastricht, the Netherlands 


\section{ABSTRACT}

In this chapter, it was investigated whether structural abnormalities of the venous system are present in uremic patients. Therefore, venous samples were taken during transplantation from the common iliac vein in 12 hypertensive and 6 normotensive uremic patients (mean age 43 [range 16-62] years). Control samples were taken from the inferior caval vein and common iliac vein in 7 kidney donors and 5 autopsy patients without a history of cardiovascular disease (mean age 48 (range 14-70) years).

The thickness of the media was significantly increased in hypertensive uremic patients compared to controls $(p<0.025)$ but did not differ between normotensive patients and controls. The collagen amount of the media did not differ between the different groups.

A qualitive increase in medial smooth muscle amount was observed in 5 uremic patients (2 normotensive, 3 hypertensives), whereas almost no smooth muscle was observed in controls $(p<0.02)$. Intimal thickening was observed in uremic patients and controls.

CONCLUSION: The venous media thickness is increased in hypertensive uremic patients, which might contribute to the reduction in venous compliance observed in chapter 4 , in contrast to normotensive uremic patients, in which the media thickness is not increased. Furthermore, an increase in the amount of medial smooth muscle is present in the veins of several uremic patients, which might be due to the increased venous pressure or the effect of circulating vasoactive substances. 


\section{INTRODUCTION}

Structural changes of the cardiovascular system are common in uremic patients (1-4). Cardiac disorders as a result of atherosclerosis, hypertension or uremia $(1,2)$ can lead to arrhytmias and cardiac failure (2). Furthermore, the compliance of the left ventricle may be decreased, which impairs cardiac output during hypovolemia, leading to hypotensive periods during hemodialysis (2).

Structural changes of the arterial system can cause or maintain hypertension by the increased peripheral vascular resistance and/or the decreased arterial compliance $(3,4)$.

Still, as discussed in the previous chapters, abnormalities in structure and function of the venous system can also have important hemodynamic consequences; the major part of the total blood volume is located in the venous system, which is therefore an important determinant for the regulation of cardiac output (5).

As described in chapter 4 , the compliance (volume/pressure relation) of the venous system is reduced in hypertensive hemodialysis patients. A reduction in venous compliance can have important hemodynamic consequences. Because of the steep volume/pressure relationship, the venous system is more sensitive to changes in blood volume (6). Hence, a reduction in venous compliance will compromize the hemodynamic response during a decline in plasma volume, as may happen, for instance, during hemodialysis treatment (7).

A reduced venous compliance in hypertensive dialysis patients could either be due to functional changes of the veins, related to increased levels of catecholamines (8), or to structural changes (9).

In the previous chapter, it was shown that the decreased venous compliance was not reversible after short-term intervention with nitroglycerin or with an $\alpha_{1}$-sympathicolytic agent. These observations suggest that structural abnormalities of the venous wall are responsible for the reduction of venous compliance in hypertensive hemodialysis patients. In this study, the morphology of the venous wall in hypertensive and normotensive uremic patients was analysed and compared with that of control subjects without a history of cardiovascular disease.

\section{PATIENTS}

Samples of the common or external illiac vein were obtained from 18 uremic patients (mean age 43 [range 17-63] years), admitted for kidney transplantati- 
on, who had previously been treated with renal replacement therapy. Patients with diabetes mellitus were excluded. The original diseases of the patients were chronic glomerulonephritis $(\mathrm{n}=7)$, chronic pyelonephritis $(\mathrm{n}=5)$, polycystic disease $(n=2)$, hypertensive nephropathy $(n=1)$, IgA-nephropathy $(\mathrm{n}=1)$; the original disease was unknown in two patients.

Uremic patients were classified as normotensive or hypertensive based upon examination of the clinical records. A blood pressure above $160 / 90 \mathrm{mmHg}$, measured after hemodialysis, in the period before transplantation, or the use of antihypertensive medication were used as the parameters to define hypertension. Twelve uremic patients ( 5 males, 7 females) (mean age 44 [range 17-63] years) were classified as hypertensive whereas 6 uremic patients (5 males, 1 female) (mean age 42 [range 20-62] years) were classified as normotensive. The mean time of renal replacement therapy was 2.4 [range 0.1-6.5] years in hypertensive uremic patients and 2.6 [range 1.0-4.0] years in normotensive uremic subjects.

All hypertensive dialysis patients used antihypertensive medication. Calcium antagonists were used by 2 patients, B-sympathicolytic agents by 5 patients, diuretics by 3 patients, $\alpha$-sympathicolytic agents by 3 patients, direct vasodilators by 1 patient whereas 4 patients used angiotensin converting enzyme inhibitors. Three patients used long-acting nitrates.

Twelve age-matched normotensive controls ( 6 males, 6 females (mean age 48 [range 14-70] years) were studied. Five were autopsy patients without any history of cardiovascular disease, and 7 were kidney donors who had died from trauma. Patients with diabetes mellitus and donors dying from cardiovascular incidents were excluded. The causes of death in the autopsy patients were cancer $(n=4)$ and sepsis $(n=1)$.

The study was approved by the Ethics Committee of the University Hospital Maastricht.

\section{METHODS}

\section{Venous sampling}

In uremic patients, longitudinal samples of the common or external iliac vein were taken during kidney transplantation. In control subjects, samples were taken from the common iliac vein in autopsy patients and from the distal inferior caval vein (approximately $2 \mathrm{~cm}$ above the common iliac vein) in control subjects undergoing donor nephrectomy. Samples were fixed in ethanol $70 \%$, routinely processed and embedded in paraffin. All specimens were coded to exclude observer-bias in the interpretation of venous histology. 


\section{Analysis}

\section{Media thickness}

The media thickness of the embedded veins was measured on Elastine van Gieson stained sections using computer assisted morphometrics (MOP Videoplan; Kontron). The mean of 25 subsequent measurements in each sample was taken for calculation.

\section{Amount of medial smooth muscle}

The amount of smooth muscle in the media was assessed in a qualitative way by a trained observer (M.D.) and graded from 0 (minimal) to 2 (obvious).

\section{Collagen}

Serial sections were stained with the collagen specific dye picro-Sirius red (9). The relative amount of collagen in the media of the vein was quantified using computer assisted morphometrics (CAS-200, Becton and Dickinson [10]). The relative amount of collagen (\% collagen of tissue) was measured as the mean of 5 measurements in each sample.

\section{Statistical analysis}

Values are expressed as mean $( \pm S D)$. Overall differences in media thickness and collagen amount between controls and normotensive and hypertensive uremic patients was assessed using Kruskal-Wallis analysis of variance. When overall differences were significant $(p<0.05)$, a Mann-Whitney signed-rank test was used to assess differences between the specific groups. The difference in the (qualitive) smooth muscle amount between uremic subjects and controls was assessed using a Chi-Square test. Pearson's $r$ was used to assess the correlation between variables.

\section{RESULTS}

\section{Normal histology (Figure 1)}

Normal histology of the venous wall was established from examination of material from controls without a history of cardiovascular disease. The intima is very thin but is bounded by a distinct internal elastic lamina. The media is relatively compact and contains circular smooth muscle cells, collagen and elastic fibers. Like in other veins, the media and adventitia are not separated by an external elastic lamina. The adventititia, although larger 
than the media, is less compact and contains longitudinal smooth muscle fibers. Collagen and elastin fibres are distributed uniformly throughout the media and adventitia. The basic structure of the inferior caval vein is equal to that of the communal iliac vein.

\section{Media thickness}

The overall difference in media thickness between the various groups was significant $(p=0.03)$. Media thickness was increased in hypertensive uremic patients $(175 \pm 52 \mu \mathrm{m})(\mathrm{p}<0.025)$ but not in normotensive uremic subjects $(136 \pm 58 \mu \mathrm{m})$ as compared to normotensive controls $(p=0.9)$ [Table 1]. Media thickness in normotensive and hypertensive uremic patients did not differ significantly $(p=0.1)$. The relation between media thickness and the duration of renal replacement therapy was not significant $(r=0.03)$, nor was the relation between age and media thickness $(-0.13 ; \mathrm{p}=0.3)$ in uremic patients.

In the control group, media thickness was inversely, though not significantly correlated with age $(r=-0.43 ; p=0.08)$.

\section{Smooth muscle quantity}

The amount of medial smooth muscle in uremic patients and controls, assessed quantatively, is summarized in Table 2 . In five (28\%) of the uremic subjects (Figure 1) and none of the controls increased amounts (grade 2) of smooth muscle was found. An intermediate amount of smooth muscle was found in $12(67 \%)$ uremic patients and in 4 controls $(33 \%)$. In 8 controls, almost no smooth muscle was observed (Figure 2). The difference is in the qualitative amount of smooth muscle between uremic patients and controls was significant $(p=0.02)$.

There was no difference in media thickness between uremic patients with and without a large amount of smooth muscle (148 $\pm 58 \mu$ vs $169 \pm 44 \mu ; \mathrm{p}=0.4)$.

\section{Collagen}

The relative medial collagen amount was $44( \pm 11) \%$ in normotensive uremic patients, $41( \pm 16) \%$ in hypertensive uremic patients and $50( \pm 13) \%$ in controls respectively (Table 1). The difference between the various groups was not significant $(p=0.4)$. In uremic patients, age and relative collagen amount were not significantly related $(r=-0.29 ; p=0.1)$. However, in controls, age and relative collagen amount were significantly and inversely related $(\mathrm{r}=-0.72 ; \mathrm{p}<0.01)$. 
Table 1. Media thickness and collagen amount in uremic patients and controls

\begin{tabular}{|c|c|}
\hline $\begin{array}{l}\text { Normotensive } \\
\text { Uremic patients }\end{array}$ & $\begin{array}{l}\text { Hypertensive } \\
\text { Uremic Patients }\end{array}$ \\
\hline
\end{tabular}

$\begin{array}{lllll}\text { Number } & 6 & 12 & 12 \\ \text { Media thickness }(\mathrm{mm}) & 136(58) & 175(52) & * * & 123(32) \\ \text { Collagen amount }(\%) & 44(11) & 41(16) & 50(13)\end{array}$

$* * p<0.01$

âl valuag expressed as mean (SD)

Table 2. Amount of medial muscle, assessed qualitatively, in uremic patients and controls

Amount of smooth muscle

$\begin{array}{lll}0 & 1 & 2\end{array}$

Normotensive uremic pts

$4 \quad 2$

Hypertensive uremic pts

$1 \quad 8 \quad 3$

Controls

84 


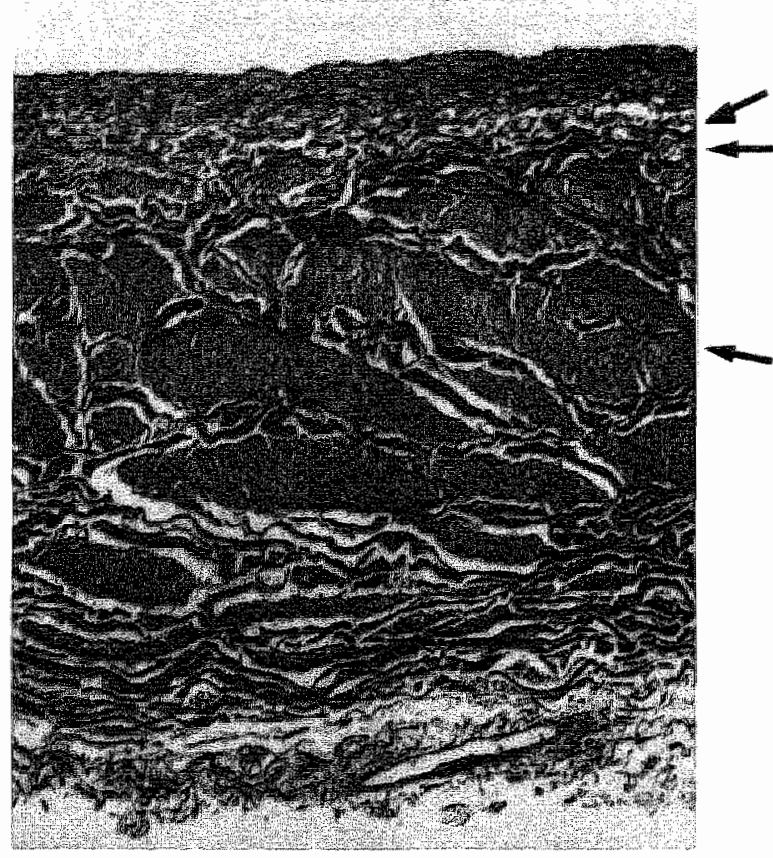

intima

media

Figure 1. Common iliac vein of a control subject without a history of cardiovascular disease (Elastine van Gieson; x100).

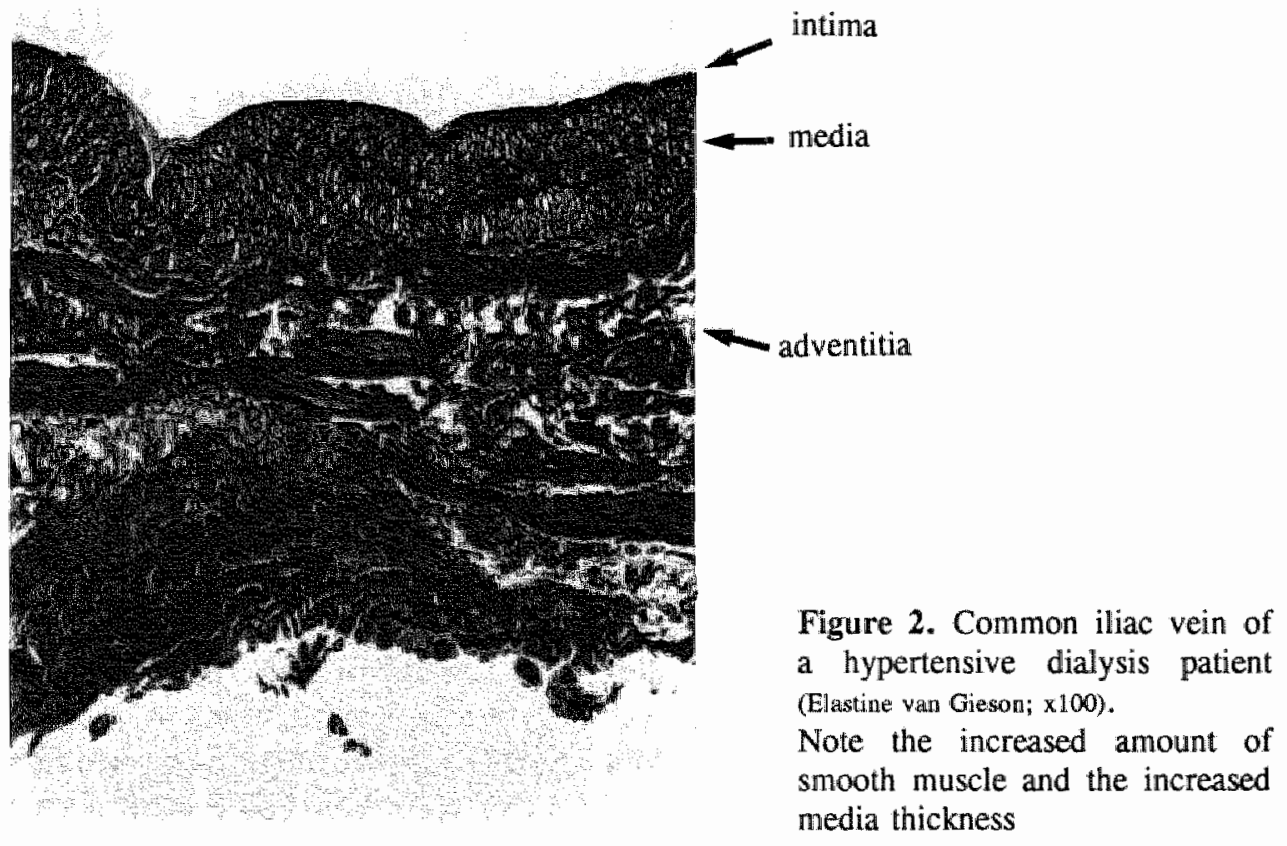




\section{DISCUSSION}

In this study, the structure of the venous wall was analyzed in normotensive and hypertensive patients with end-stage renal failure and compared to controls without a history of cardiovascular disease. Samples from uremic patients were taken from the external or common iliac vein during kidney transplantation. Veins from kidney donors or autopsy patients were used as controls. For technical reasons, venous samples in kidney donors had to be taken from the distal inferior caval vein. Though this small difference in sample location between uremic patients and kidney donors might have caused some scattering of the data, its influence on the results is probably minor: the structure of the distal vena cava is similar to that of the iliac vein (11), as was confirmed in the present study.

The media thickness was significantly increased in hypertensive uremic patients compared to controls, but did not differ between normotensive uremic patients and controls, although the scatter in individual data was large. The effect of the antihypertensive medication used by the patients is not likely to have been a confounding factor in the data, since antihypertensive treatment, if anything would have decreased the diffences between normotensive and hypertensive subjects (12).

Our data may provide an explanation for the findings of the previous chapter, in which forearm venous compliance was found to be reduced in hypertensive hemodialysis patients but normal in normotensive dialysis patients compared to healthy normotensive controls. This reduction in venous compliance in hypertensive dialysis patients could not be reversed by short-term pharmacological intervention with an $\alpha_{1}$-sympathicolytic agent or a directly acting venodilator, which is in agreement with previous studies on subjects with essential hypertension (13) and hypertensive animals (14). It should, however be noted that the veins investigated in the present study were sampled from a different vascular bed than in which venous compliance was measured. However, venous compliance measured in the forearm is for a major part determined by the volume/pressure relation of the deeper veins (15), which are impossible to obtain without major intervention.

It is unclear whether the increase in media thickness is specific for renal hypertension; whereas Sudhir et al.(16) did not find a difference in media thickness of superficial forearm veins between subjects with essential hypertension and normotensive controls, Simon et al. observed an increase in water and hexosamine content of the venous wall of hypertensive humans (17).

Furthermore, an increase in media thickness has been observed in renal hypertensive rats and dogs (18-22); Greenberg (18) observed an increase in 
mucopolysaccharides and glycoproteins in combination with media smooth muscle cell hyperplasia in veins of spontaneously hypertensive rats. Also sodium-and water logging was observed in hypertensive animals (20-22). The sodium and water content of the venous wall could not be assessed in the present study. However, the contribution of sodium and water logging to the distensibility characteristics of the venous wall is probably small (22).

In uremic patients, qualitative changes in the composition of the media were observed. Whereas the collagen amount did not differ between the various groups, an increase in smooth muscle quantity was observed in several normotensive and hypertensive uremic patients, although it should be noted that the amount of smooth muscle was only assessed in a qualitative way. An increased amount of smooth muscle might result from circulating trophic substances (23-25), like catecholamines and angiotensin 11 , which have been shown to be increased in hemodialysis patients $(8,26)$. However, a reduced end-organ sensitivity to the effect of catecholamines has been observed in hemodialysis patients as well (27). An increased quantity of smooth muscle might also result from an increase in venous pressure $(28,29)$; in hemodialysis patients, rapid changes in fluid status are common and venous pressure will be increased in fluid overloaded patients.

No obvious intimal thickening was observed in uremic patients, in contrast to the previously mentioned studies on patients with cardiac failure $(28,29)$. Intimal thickening is invariably observed in venous grafts used for coronary surgery $(30,31)$ and in arteriovenous shunts (32). However, under these circumstances, the venous wall is, apart from an increased venous pressure, also exposed to an increased shear stress, caused by a jet stream along the venous wall, which could also play a role in the development of intimal hypertrophy (32).

In controls, but not in uremic patients, the relative collagen amount and, although not significantly, media thickness were inversely related to age. However, as described in chapter 2 , venous compliance tended to decrease with advancing age, which is in accordance with the results of Gaschko et al (33). Altered physicochemical properties of the connective tissue elements in the venous wall with advancing age might play a role in a reduced venous compliance in older subjects (34).

\section{CONCLUSION}

The thickness of the media is increased in veins of hypertensive uremic patients and normal in normotensive uremic patients compared to control subjects. A qualitative increase in smooth muscle was observed in several 
normotensive and hypertensive uremic patients, in contrast to control subjects. The increase in media thickness might contribute to the reduction in venous compliance as previously observed in hypertensive dialysis patients.

\section{REFERENCES}

1. Linder A, Charra B, Sherrard DJ, Scribner BH. Accelerated atherosclerosis in prolonged maintenance hemodialysis. N Engl J Med 1972; 290:697-701.

2. Ritz E, Rambausek M, Mall G, Ruffman K, Mandelbaum A. Cardiac changes in uremia and their possible relation to cardiovascular instability on dialysis. Contrib Nephrol 1990; 78:221-229.

3. Klooker P, Bommer E, Ritz E. Treatment of hypertension in dialysis patients. Blood Purif $1985 ; 3: 15-26$.

4. Marchais S, Guerin A, Safar M, London G. Arterial compliance in uraemia. I Hypert 1989; 7:S84-S85.

5. Rothe CF. Venous system: physiology of capacitance vessels. In: Handbook of Physiology, 1983. Sect 2. Cardiovascular system. Vol 3. Peripheral circulation and organ blood flow. Chapt 13. American Physiological Society, Bethesda. pp 397-452.

6. Safar ME, London GM, Levenson JA, Simon AC, Chau NP. Rapid dextran infusion in essential hypertension. Hypertension 1979; 1:615-623.

7. Leunissen KML, Noordzij TC, van Hooff JP. Pathophysiologic aspects of plasma volume preservation, Contrib Nephrol 1990; 78:201-211.

8. MoGrath BP, Ledingham JGG, Benedict CR. Catecholamines in peripheral venous plasma in patients on chronic hemodialysis. Clin Sci Mol Med 1978; 55:89-96.

9. James J, Bosch KS, Aronson DC, Houtkooper JM. Sirius red histophotometry and spectophotometry of sections in the assessment of the collagen content of liver tissue and its application in growing rat liver. Liver 1990; 10;1-5.

10. Bacus JW, Grace LJ. An optical microscope system for stndardized cell measurement and analyses. Applied Optics 1987; 26:3280-3293.

11. Junqeira LJ, Carneiro J. Basic histology. Lange medical publications. Los Altos, 4th Edition. 1983.

12. Struyker-Boudier HAJ, van Bortel LMAB, de Mey JGR. Remodeling of the vascular tree in hypertension:drug effects. TIPS 1990; 11:240-245.

13. Takeshita A, Mark AL. Decreased venous distensibility in borderline hypertension. Hypertension 1979; 1:202-206.

14. Haraldsson B, Nilsson H, Folkow B. Structurally reduced distensibility of cardiovascular 'low pressure' compartments in primary hypertension as studied in spontaneously hypertensive rats. Acta Physiol Scand 1981; 112:473-480.

15. Burki N, Guz A. The distensibility characteristics of the capacitance vessels in the forearm in normal subjects. Cardiovas Res 1970; 4:93-98.

16. Sudhir K, Angus JA, Esler MD, Jennings GL, Lambert GW, Korner PI. Altered venous responses to vasoconstrictor agonists and nerve stimulation in human primary hypertension. J Hypertens 1990; 8:1119-1128.

17. Simon G, Conklin DJ, Altman S. Abnormal saphenous vein composition in human hypertension. Clin Exp Hypert 1981; 3:69-83. 
18. Greenberg $\mathrm{S}$, Palmer EC, Wilborn WM. Pressure-independent hypertrophy of veins and pulmonary arteries of spontaneously hypertensive rats. Characterization of function, structural and histochemical changes. Clin Sci Mol Med 1978; 55:31s-36s.

19. Greenberg $S$, Wilborn W. Functional and structural changes in veins in spontaneous hypertension. Arch Int Pharmacodyn 1982; 258:208-233.

20. Simon G, Pamnani M, Overbeck HW. Decreased venous compliance in dogs with chronic renal hypertension. Proc Soc Exp Biol Med 1976; 152:122-125.

21. Pamnani MB, Owerbeck HW. Abnormal ion and water composition of veins and normotensive arteries in coarctation hypertension in rats. Circ Res 1976; 38:375-378.

22. Simon G. Venous changes in renal hypertensive rats: the role of humoral factors. Blood vessels $1978 ; 15: 311-321$.

23. Lever AF. Slow pressor mechanisms in hypertension: a role for hypertrophy of resistance vessels. J HYpertens $1986 ; 5: 5 \rrbracket 5-524$.

24. Daemen MJAP, Lombardi DM, Bosman $\mathbb{E T}$, Schwartz SM. Angiotensin II induces smooth muscle cell proliferation in the normal and injured rat arterial wall. Circ Res $1991 ; 68: 450-456$.

25. Mulvany MJ. Pathophysiology of vascular smooth muscle in hypertension. J Hypertens 1984; 2(supp 3): $\$ 413-420$.

26. Yamanoto $T$, Shimizu $M$, Morioka $M$, Kitano $M$, Wakabayashi J, Aizawa $N$. Role of angiotensin II in the pathogenesis of hyperdipsia in chronic renal failure. JAMA $1986 ; 256: 604-608$

27. Daul AE, Wang XL, Michel MC, Brodde OE. Arterial hypotension in chronic hemodialyzed patients. Kidney Int 1987 ; $32: 728-735$.

28. Stuart M, Magarey FR. The great veins in venous hypertension. J Path Bact 1960; 79:319-323.

29. Li PL. Adaptation in veins to increased intravenous pressure with special reference to the portal system and inferior vena cava. J Path Bact 1940; 50:121-136.

30. Vlodaver $Z$, Edwards JE. Pathologic changes in aortic-coronary arterial saphenous vein grafts. Circulation $1971 ; 44: 719-728$.

31. Wesly RLR, Vaishnav RN, Fuchs JCA, Patel DJ, Greenfield JC. Static linear and nonlinear elastic properties of normal and arterialized venous tissue in dog and man. Circ Res 1975; 37:509-520.

32. Langeveld A1"M, Leunissen KML, Likelboom BC, Kitslaar PJEHM, Tordoir JHM. Duplex ultrasound detection of stenoses in newly created hemodialysis AV fistulas. In:Tordoir JHM, Kitslaar PJEHM, Kootstra G. Progress in access surgery. CIP-data koninklijke bibliotheek, Den Haag. 1990.

33. Gascho JA, Fanelli C, Zelis R. Aging reduces wenous distensibility and the venodilatory response to mitroglycerin in normal subjects. Am J Cardiol 1989; 63:1267-1270.

34. Comper WD, Laurent TC. Physiological function of connective tissue polysaccharides. Physiol Rew 1978; 58:255-315. 


\section{CHAPTER 6}

\section{The role of venous compliance in hemodynamics during ultrafiltration}

J.P. Kooman, U. Gladziwa' ${ }^{2}$, G. Böcker ${ }^{2}$, L.M.A.B. van Bortel', J.P. van Hooff, K.M.L. Leunissen

Department of Internal Medicine, 'Department of Pharmacology, University Hospital, Maastricht, the Netherlands; ${ }^{2}$ Dialysis Clinic Aachen, Germany

Kidney Int (in press) 


\section{ABSTRACT}

A reduction in venous compliance (VC) could impair plasma volume preservation by disturbing the capillary Starling equilibrium and could induce a steep fall in central venous pressure (CVP) during minor plasma volume loss because of the reduced volume/pressure relationship of the venous system.

In this chapter, the relation between $V C$, the fall in plasma volume and the decline in CVP was assessed in 12 hemodialysis patients (age 40-74 yrs) during isolated ultrafiltration (UF). Before the study, patients were $1-3 \mathrm{~kg}$ above their optimal dry weight, assessed by echography of the inferior caval vein. Patients were ultrafiltrated during 1 hour at an UF-rate of 1-1,5 l/hr. CVP was assessed directly via a subclavian catheter. The fall in plasma volume was measured using the serial hematocrit method. VC was measured at normovolemia the day after dialysis by strain-gauge plethysmography with direct $i$. v. pressure measurements.

Mean arterial pressure (MAP) and heart rate (HR) remained unaltered during UF, while plasma volume $(-10.8 \pm 4.4 \% ; p<0.001)$ and $C V P(8.0 \rightarrow 4.7 \mathrm{mmHg}$; $p<0.001)$ declined. $V C$ was inversely correlated with the fall in plasma volume $(r=-0.66 ; p<0.02)$ and with the fall in CVP Icorrected for total UF-volumel $(r=-0.62 ; p<0.02)$.

CONCLUSION: A reduction in VC impairs plasma volume preservation during $U F$ and leads to a steeper decline in CVP with a similar UF-volume. Blood pressure remained stable during UF, probably because of adequate hemodynamic compensatory mechanisms. 


\section{INTRODUCTION}

Hypotensive periods occur frequently during hemodialysis and are a major cause of morbidity in patients treated with chronic intermittent hemodialysis (1). Both impaired preservation of plasma volume and inadequate cardiovascular regulatory mechanisms contribute to the loss of blood pressure control during hemodialysis $(1,2)$.

The venous system plays an important role in the hemodynamic regulation of the human body. It serves both as a conductance system for the backflow of hemodynamically active ('stressed') blood from the peripheral vessels to the heart and as a reservoir for the hemodynamically inactive ('unstressed') blood volume (3).

During plasma volume depletion, a reduction in the volume/pressure relationship of the stressed compartment (venous compliance) can have a negative impact on hemodynamic stability during dialysis both by inducing a steep fall in central venous pressure (4) and by impairing capillary refill during a decline in plasma volume (5). In a previous study we showed that VC was reduced in hypertensive hemodialysis patients (6).

In this study the relation between $\mathrm{VC}$, the fall in central venous pressure (CVP) and the decline in plasma volume was evaluated during isolated ultrafiltration (UF) in patients treated with chronic intermittent hemodialysis.

\section{PATIENTS}

Clinically stable patients treated by chronic intermittent hemodialysis were enrolled in the study. Exclusion criteria were acute infectious diseases, diabetes mellitus, severe coronary (NYHA II or more) or valvular heart disease and compromised left ventricular function (ejection fraction $30 \%$ or less).

Prior to studies, all subjects were asked to refrain from smoking, coffee, tea and coca-cola during an overnight period. No patient was treated with vasoactive medication.

All subjects gave their informed consent. The study was approved by the Ethics Committee of the Maastricht University Hospital.

Twelve hemodialysis patients were studied [ 5 males, 7 females]. The mean age of the patients was 60 [range 40-74] years. The mean duration of hemodialysis treatment had been 1.8 [range $0.3-4.2$ ] years. The mean body surface area of the patients was 1.77 [range $1.31-2.21] \mathrm{mm} / \mathrm{m}^{2}$. The mean albumin level was 36 [range 23-45] g/l, the mean hemoglobin level 5.7 [range 4.3-6.8] $\mathrm{mmol} / \mathrm{l}$. As shown in Table 1, 7 patients were normotensive, defined as a post-dialytic blood pressure below $140 / 80$ for at least 6 consecutive months without the use 
of antihypertensive medication (chapter 3 ), whereas 5 patients were hypertensive (post-dialytic blood pressure $>150 / 90$ after dialysis).

\section{METHODS}

The patients were studied on the regular day of their dialysis scheme. The patients were 1-3 kg above their optimal dry weight, as dtermined by echography of the inferior caval vein (7). Before measurements were started, the patients had been supine and resting for 30 minutes. They were ultrafiltrated without dialysis for 1 hour at a rate of $1000-1500 \mathrm{ml} / \mathrm{hr}$. No patient was ultrafiltrated below his/her optimal dry weight. A Gambro AK 100 dialysis apparatus and hemophane membranes (GFS 12; Gambro) were used.

Blood pressure and heart rate were recorded continuously [Finapres; Ohmeda 2300; Lameris] (8).

CVP was monitored using a catheter (Permcath; Quinton; internal diameter $2 \mathrm{~mm}$ ) which was inserted through the subclavian vein and positioned in the right atrium. The location of the catheter was checked by X-ray. The catheter was connected to a pressure dome (Hewlett-Packard) positioned at the height of the right atrium, which was considered $5 \mathrm{~cm}$ under the sternal angle. CVP was recorded continuously (Hewlett-Packard $78205 \mathrm{C}$ pressure monitor).

The decline in plasma volume during UF was derived from the serial hematocrit (Ht) method and calculated according to the following formula: $\Delta$ plasma volume $=(100 / 100-$ Htbefore $) \times(100[$ Htbefore-Htafter $] /$ Htafter $)(9)$.

Both the fall in CVP and the decline in plasma volume were corrected for the total amount of ultrafiltrated volume (expressed as $\mathrm{mmHg} / 1$ and $\% / l$, respectively).

Blood samples were taken in ice-chilled tubes before and after UF for determination of noradrenaline levels (HPLC method) and plasma renin activity (RIA). Furthermore, blood samples were taken for determination of plasma colloid osmotic pressure (Wescor 4400 Colloid Osmometer) and osmolality (Wescor 5500 Vapor Pressure Osmometer).

The day after dialysis, VC was measured by strain-gauge plethysmography (10) (Periflow, Janssen Scientific Instruments) with direct intravenous pressure measurements, as described in chapter 2. In short, VC was assessed in the forearm at multiple cuff pressures $(25-45 \mathrm{mmHg})$. After each increment in cuff pressure the arm culf was deflated and a volume/pressure ratio was recorded. $V C$ was defined as the slope of the regression curve, constructed from the volume/pressure ratios obtained at the various cuff pressures (11). 
The volume status of the patients was estimated by echographic determination of the inferior caval vein diameter, corrected for body surface area (7) [vena cava diameter at normovolemia $\left.=8-11,5 \mathrm{~mm} / \mathrm{m}^{2}\right]$.

\section{Statistical analysis}

The vallues are expressed as mean $( \pm S D)$. Correlations between variables were evaluated by linear regression analysis. Stepwise multivariate regression analysis was used to assess the relative importance of factors influencing the fall in plasma volume and the decline in CVP.

\section{RESULTS}

\section{Change in hemodynamic parameters}

The individual data are presented in Table 1 , whereas the summarized data before and after UF are presented in Table 2.

Both plasma volume and CVP fell significantly during UF $(p<0.001)$. Noradrenaline levels ans plasma renin activity increased significantly $(\mathrm{p}<0.05)$, whereas blood pressure, adrenaline levels and heart rate remained stable.

Osmolality remained stable, whereas the colloid osmotic pressure increased $(\mathrm{p}<0.01)$. The rise in colloid osmotic and the decline in plasma volume were significantly related $(r=0.75 ; p<0.01)$.

\section{Correlation between VC and the decline in CVP and plasma volume}

Mean values for the vena cava diameter index and VC the day after dialysis were $8.4( \pm 3.4) \mathrm{mm} / \mathrm{m}^{2}$ and $0.049( \pm 0.021) \mathrm{ml} / 100 \mathrm{ml} / \mathrm{mmHg}$, respectively. Mean peripheral venous pressure the day after dialysis was $8.8( \pm 3.2) \mathrm{mmHg}$. VC was significantly reduced in hypertensive compared to normotensive patients $(\mathrm{p}<0.025)$. Mean peripheral venous pressure was $8.8( \pm 3.2) \mathrm{mmHg}$. CVP before dialysis and VC were inversely correlated $(r=-0.55 ; \mathrm{p}<0.05)$.

VC correlated inversely with the fall in CVP during UF $(r=-0.62 ; p<0.025)$ [Figure 1]. When multivariate regression analysis was used to assess the effect of VC, decline in plasma volume and UF-rate on the decline in CVP, only VC was significantly related to the decline in CVP $(t=-2.6 ; p<0.025)$, whereas the decline in plasma volume and the UF-rate were not. 
Table 1. Individual values for age, existence of hypertension, venous compliance (VC), and for the ultrafiltration rate (UF-rate), the decline in central venous pressure (-CVP) and plasma volume (-PV) during UF-only.

\begin{tabular}{|c|c|c|c|c|c|c|}
\hline Patient & Age & Hypertension & VC & UF-rate & CVP & -PV \\
\hline & (Yearsy) & & $(\mathrm{mi} / 10 \mathrm{ObH} / \mathrm{mm} / \mathrm{Hg})$ & (mul/hr) & $(\mathrm{mmH} / \mathrm{g} / \mathrm{l})$ & $($ 䍗/1) \\
\hline 1 & 67 & + & 0.012 & 1000 & 3.8 & 14.6 \\
\hline 2 & 61 & - & 0.072 & 1000 & 2.6 & 7.6 \\
\hline 3 & 59 & - & 0.075 & 1000 & 1.2 & 10.0 \\
\hline 4 & 71 & + & 0.030 & 1500 & 3.3 & 11.8 \\
\hline 5 & 44 & $\sim$ & 0.051 & 1000 & 2.2 & 9.9 \\
\hline 6 & 72 & - & 0.044 & 1300 & 1.5 & 8.3 \\
\hline 7 & 61 & - & 0.042 & 1300 & 1.9 & 11.4 \\
\hline 8 & 58 & + & 0.040 & 1300 & 2.8 & 8.0 \\
\hline 9 & 74 & + & 0.034 & 1000 & 4.4 & 9.5 \\
\hline 10 & 40 & + & 0.046 & 1000 & 2.6 & 9.5 \\
\hline 11 & 61 & - & 0.062 & 1000 & 2.6 & 7.0 \\
\hline 12 & 47 & ${ }^{*}$ & 0.084 & 1000 & 2.2 & 8.8 \\
\hline
\end{tabular}

Table 2. Hemodynamic parameters before and after ultrafiltration

\begin{tabular}{|c|c|c|c|}
\hline & Before & After & p \\
\hline Central venous pressure (mmHg) & $8.0(5.9)$ & $4.7(4.4)$ & $<0.001$ \\
\hline Decline in plasma volume ( & & $-11(4)$ & $<0.001$ \\
\hline Mean blood pressure (mmHig) & $96(10)$ & $94(17)$ & \\
\hline Neart rate (bents/min) & $87(12)$ & $87(18)$ & \\
\hline Noradremalline (tunolin & $4.5(4.4)$ & $6.3(5.6)$ & $<0.05$ \\
\hline Osmolality (mosmol/kg) & $291.7(12.8)$ & $293.1(12.1)$ & \\
\hline Colloid osmotic pressure (kPa) & $2.6(0.3)$ & $2.9(0.3)$ & $<0.001$ \\
\hline
\end{tabular}




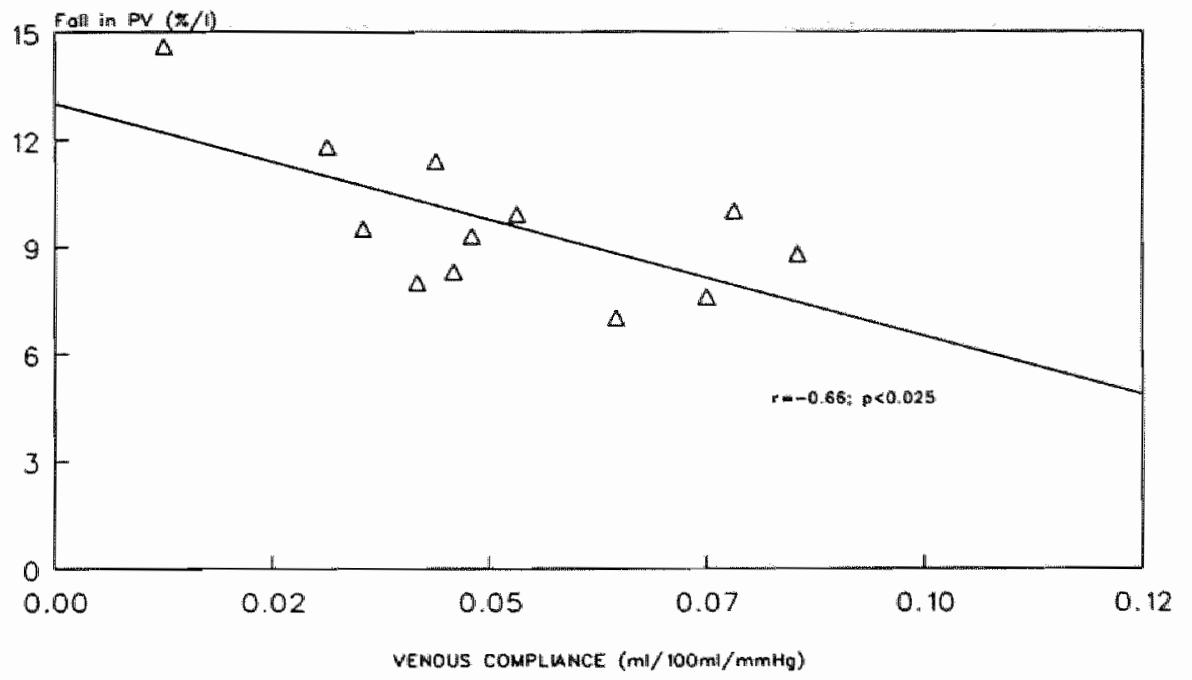

Figure 1. Relation between venous compliance and the fall in central venous pressure during ultrafiltration

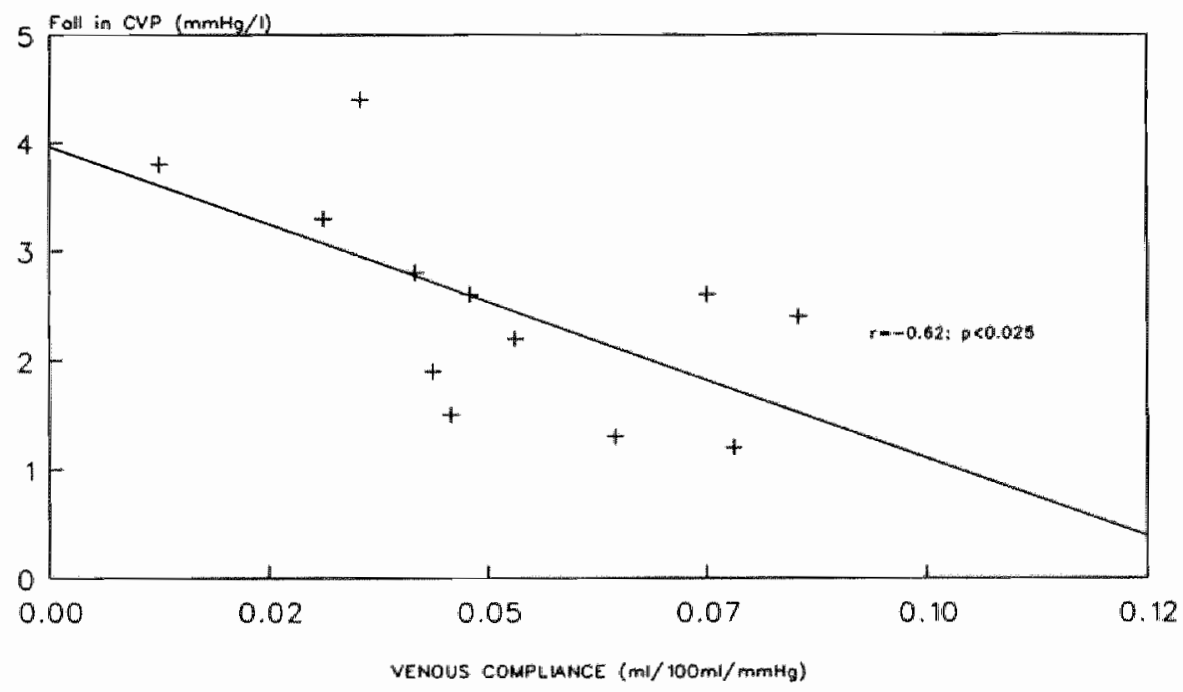

Figure 2. Relation between venous compliance and the decline in plasma volume during ultrafiltration 
VC was also inversely related to the decline in plasma volume during UF $(r=-0.66 ; p<0.025)$ [Figure 2], whereas the UF-rate $(r=0.11)$ and the colloid osmotic pressure before dialysis $(r=-0.29)$ before dialysis were not. When multivariate regression analysis was applied to assess the effect of VC, UF-rate and colloid osmotic pressure on the fall in plasma volume, only VC was significantly related to the decline in plasma volume $(t=-2.7 ; p<0.025)$, whereas the other variables were not.

\section{DISCUSSION}

In this study the effect of VC on hemodynamics during UF was evaluated.

The influence of VC on the fall in CVP and the decline in plasma volume was studied during isolated UF instead of hemodialysis because the alterations in osmolality and acid-base status during the latter may be confounding factors in the assessment of changes in CVP and preservation of plasma volume $(1,2)$. As expected, osmolality did not change during isolated UF. During the investigation, CVP and plasma volume declined whereas the colloid osmotic increased. The rise in colloid osmotic pressure was highly significantly related to the fall in plasma volume, which is in accordance with the results of Rodriquez et al.(12).

VC was measured in the forearm by strain-gauge plethysmography the day after hemodialysis at normovolemia. Under such circumstances VC reflects the true visco-elastic properties of the venous wall (13), which are mainly determined by its connective tissue elements (14). However, as will be shown in chapter 8 , venous smooth muscle tone increases during isloated ultrafiltration which can also influence VC to some extent (4). However, because an increase in smooth muscle tone merely leads to a mobilization of hemodynamically inactive blood volume (4) the hemodynamic relevance of this effect on VC will probably be minor.

In this study the compliance of the forearm veins was measured. An estimation of the compliance of the systemic circulation is possible by rapidly withdrawing $500-800 \mathrm{ml}$ of blood, while measuring the fall in central venous pressure (14). The burden thus inflicted on the often already compromised cardiovascular system of hemodialysis patients is too great to be ethically justified. As Safar et al. have shown a highly significant correlation between peripheral venous compliance and systemic compliance in healthy subjects (15) in this study only the compliance of the forearm veins was measured.

In the present study, VC was inversely related with the fall in CVP during UF. Multivariate regression analysis showed that this relation remained also persisted when corrected for the change in plasma volume. The larger fall in CVP 
associated with a decrease in VC can be explained by the reduced volume/ pressure relationship of the venous system: a minor fall in plasma volume may thus lead to a relatively large fall in CVP (4). The opposite is also true: when plasma volume increases, the concomitant rise in CVP is inversely correlated with VC (15). This view is indirectly supported by the finding that VC was inversely correlated to CVP at the beginning of the measurements. Thus, in case of a reduced $V C$, the venous system is more sensitive to changes in plasma volume. Anecdotical confirmation of the present results was found in a study of Jahn et al. (16) who, although they did not measure venous compliance directly, observed a much larger decrease in pulmonary arterial pressure in a patient with severe hypertension compared with a normotensive patient after an equal decline in body weight.

Also an inverse relation between $\mathrm{VC}$ and the decline in plasma volume was observed in the present study. A reduced VC can impair plasma volume preservation by disturbing the capillary Starling equilibrium (5). During UF, the preservation of plasma volume is highly dependent upon the refill of plasma volume from the interstitial fluid (1). A reduction in VC interferes with this mechanism because the ratio between plasma volume and interstitial volume is decreased (5). Furthermore, for a given level of plasma volume, the pressure in the postcapillary venules is higher, which increases hydrostatic pressure over the capillary wall and thus impairs refill of plasma volume from the interstitium (5).

Of course, VC is not the only factor which may influence plasma volume preservation during UF; the colloid osmotic pressure before dialysis, the ultrafiltration rate and the degree of interstitial hydration all play a role $(1,2)$. However, the colloid osmotic pressure before dialysis did not correlate with the decline in plasma volume. Possibly, the change in colloid osmotic pressure during a decline in plasma volume is of greater importance for the refill of plasma volume from the interstitium than the absolute value before dialysis (17).

The UF-rate varied only between 1000 and $1500 \mathrm{ml} / \mathrm{hr}$; moreover, when evaluated by multivariate regression analysis, the influence of the UF-rate on plasma volume preservation was small, which is in accordance with the study of Mann et al. (18). The effect of interstitial hydration on plasma volume preservation is most important when patients are ultrafiltrated below their dry weight, when the interstitial fluid volume is relatively depleted (19). Patients entered the study exceeding their dry weight by $1-3 \mathrm{~kg}$, as assessed by echography of the inferior caval vein, while great attention was paid to prevent underhydration of the patients. When patients are hyper-or normovolemic, the compliance of the interstitium is high (20); therefore, large changes in interstitial volume do not have a great impact on interstitial pressure. This means that refill 
based on this interstitial pressure is relatively independent of the fluid status in the hypervolemic period.

The deleterious effect of a reduced venous compliance on both plasma volume preservation and fall in central venous pressure may seem somewhat contradictory, because one would think that after a fall in venous pressure, hydrostatic pressure over the capillary wall would decrease, whereas after a fall in plasma volume, plasma colloid osmotic pressure would increase, both leading to an increased refill of plasma volume from the interstitium. However, as Fauchald (17) has shown, refill of plasma volume from the interstitium is low during the first part of UF, until, after 60-120 the rise in colloid osmotic pressure becomes high enough to result in a nearly steady state between fluid removal and refill of plasma volume from the interstitium. The UF-rate used in his study was approximately $1200 \mathrm{ml} / \mathrm{hr}$, comparable to the rate used in our study. Furthermore, after a fall in venous pressure, it might also take some time before the capillary hydrostatic forces reach a new equilibrium (21). Therefore, in the beginning of UF treatment, the refill of plasma volume from the interstitium will be merely dependent upon the capillary Starling equilibrium present before the start of UF, for which VC is an important determining factor.

In the present study, blood pressure and heart rate remained stable, whereas noradrenaline levels and plasma renin activity rose, which suggests that the hemodynamic reaction is adequate when ultrafiltration is performed without hemodialysis. Adrenaline levels did not rise, which can be explained by the fact that the decline in plasma volume was relatively minor. Adrenaline is released mainly from the adrenal medulla, which is only stimulated when the decline in plasma volume is very large.

\section{CONCLUSION}

A reduction in venous compliance impairs plasma volume preservation during isolated ultrafiltration and leads to a steeper decline in central venous pressure with a similar amount of ultrafiltrated volume. Blood pressure remained stable during isolated ultrafiltration, probably because of adequate hemodynamic compensatory mechanisms.

\section{REFERENCES}

1. Leunissen KML, Noordzij TC, van Hooff JP. Pathophysiologic aspects of plasma volume preservation, Contrib Nephrol 1990; 78:201-211.

2. Daugirdas IT. Dialysis hypotension; a hemodynamic analysis. Kidney Int 1991; 39:233246. 
3. Rothe CF. Reflex control of veins and vascular capicitance. Physiol Rev $1983 ; 63: 1281$ 1342.

4. Greenway CV, Wayne Lautt W. Blood volume, the venous system, preload and cardiac outpuit. Can J Physiol Pharmacol 1986; 64:383-387.

5. London GM, Safar ME, Levenson JA, Simon AC, Temmar MA. Renal filtration fraction, effective vascular compliance, and partition of fuid volumes in sustained essential hypertension. Kidney Int 1981; 20:97-103.

6. Kooman JP, Wijnen JAG, Draaijer P, van Bortel L, Gladziwa U, Peltenburg HG, Struyker-Boudier HAJ, van Hooff JP, Leunissen KML. Compliance and reactivity of the peripheral venous system in patients treated with chronic intermittent hemodialysis. Kidney Int (in press)

7. Cheriex EC, Leunissen KML, Janssen JHA, Mooy JMV, van Hooff JP. Echography of the vena cava inferior is a simple and reliable tool for the estimation of dry weight in hemodialysis patients. Nephrol Dial Transpl 1989; 4:563-568.

8. Ty Smith $\mathrm{N}$, Wesseling $\mathrm{KH}$, de Wit B. Evaluation of two prototype devices producing noninvasive, pulsatile, calibrated blood pressure measurement from a finger. I Clin Monitor 1985; 1:17-29.

9. van Beaumont $W$. Evaluation of hemoconcentration from hematocrit measurements. $J$ Appl Physiol 1972; 32:712-713.

10. Jageneau et al. Noninvasive diagnosis in the management of cardiovascular diseases. North Holland Biomedical Press. Amsterdam, New York, London, 1981.

11. Doorenbos CJ, Blauw GJ, van Brummelen P. Arterial and venous effects of atrail natriuretic peptide in the human forearm. Am J Hypert 1991; 11:333-340.

12. Rodriguez M, Pederson JA, Llach F. Effect of dialysis and ultrafiltration on osmolality, colloid osmotic pressure, and vascular refilling rate. Kidney Int 1985; 28:808-813.

13. Shepherd JT, Vanhoutte PM. Veins and their control. W.B. Saunders Company, London/Philadelphia/Toronto, 1975.

14. Simon G. Functional and structural components of reduced forearm venous distensibility in human hypertension. In: Safar ME (ed). Arterial and venous systems in essential hypertension. Martinus Nijhoff. Dordrecht/Boston/Lancaster. 1987.

15. Safar ME, London GM, Levenson JA, Simon AC, Chau NP. Rapid dextran infusion in essential hypertension. Hypertension $1979 ; 1: 615-623$.

16. Jahn $H$, Schohn $D$, Schmitt $\mathbb{R}$. Hemodynamic modifications induced by fluid removal and treatment modalities in chronic hemodialysis patients. Blood Purif 1983; 1:80-89.

17. Fauchald P. Effect of ultrafiltration on body fluid volumes and transcapillary colloid osmotic gradient in hemodialysis patients. Contrib Nephrol 1989; 74: 170-175.

18. Mann H, Ernst E, Gladziwa U, Schallenberg U, Stiller S. Changes in blood volume during dialysis are dependent upon the rate and amount of ultrafiltrate. Trans Am Soc Artif Intern Organs 1989; 35: 250-252.

19. Koomans HA, Geers AB, Dorhout Mees EJ. Plasma volume recovery after ultrafiltration in patients with chronic renal failure. Kidney Int 1984; 26: 848-854.

20. Guyton AC. Textbook of medical physiology. Sixth Edition. W.B. Saunders Company. Philadelphia/London, 1981.

21. Guyton AC. Circulatory physiology: cardiac output and its regulation; W. B. Saunders Company. Philadelphia/London, 1963 ; page 264. 



\section{CHAPTER 7}

\section{Reactivity of the peripheral venous system in patients treated with chronic intermittent hemodialysis.}

J.P. Kooman, J.A.G. Wijnen', P. Draaijer, L.M.A.B. van Bortel ${ }^{1}$, U. Gladziwa ${ }^{2}$, H.G. Peltenburg, H. A. J. Struyker-Boudier ${ }^{1}$, J.P. van Hooff, K.M.L. Leunissen

Department of Internal Medicine and 'Department of Pharmacology, University Hospital Maastricht, the Netherlands. ${ }^{2}$ Dialysis Clinic, Aachen, Germany.

Kidney Int 1992; 41(4): in press 


\section{ABSTRACT}

In hemodialysis patients, active venoconstriction during a sympathetic stimulus could be impaired because of a lesion in the baroreceptor reflex arc, caused by uremic autonomous neuropathy, or because of a reduced end-organ sensitivity to the effect of catecholamines.

Therefore, the active reaction of the venous system during a sympathetic stimulus was investigated in hemodialysis patients. Active venoconstriction was assessed by estimating the increase in forearm venous tone (VT) during a cold pressor test ( 90 seconds immersion). The change in VT was recorded using strain-gauge plethysmography of the forearm with direct intravenous pressure measurements. Seven normotensive hemodialysis patients (age 32-66 years), 7 hypertensive hemodialysis patients (age 36-74 years) and 7 normotensive controls (age 36-60 years) were studied. Also the rise in mean arterial pressure (MAP) and noradrenaline levels (NA) during the cold pressor test were measured. As index for the intactness of the baroreceptor reflex arc, a Valsalva manoeuvre was used. Measurements were performed the day after hemodialysis at an optimal fluid status, assessed by echography of the inferior caval vein.

The Valsalva ratio was reduced in normotensive and hypertensive hemodialysis patients when compared to controls $(p=0.02$ and $p=0.03$; resp.). During the cold pressor test, VT, MAP and NA increased significantly in hemodialysis patients and controls $(p<0.001)$. The change in VT, MAP and NA did not differ significantly between the various groups. The relationship between the results of the Valsalva manoeuvre and the change in VT, MAP and NA during the cold pressor test was not significant.

CONCLUSION: Despite a pathological response to the Valsalva manoeuvre, active venoconstriction during sympathetic stimulation is intact in hemodialysis patients. Thus, the sympathetic part of the baroreceptor reflex arc is intact in hemodialysis patients. The existence of reduced end-organ sensitivity in hemodialysis patients is unlikely. 


\section{INTRODUCTION}

The venous system contains a major part of the total blood volume (1), the majority of which is hemodynamically inactive (1). This hemodynamically inactive blood volume can be mobilized by an increase in venous smooth muscle tone (2) in case of a decline in plasma volume. Venous smooth muscle contracts in response to direct sympathetic stimulation or to circulating catecholamines (3).

Several factors, however, may interfere with the responsiveness of the venous system when plasma volume falls during hemodialysis. Although catecholamines are increased in hemodialysis patients (4), a reduced end-organ reactivity to catecholamines has been described (5). Moreover, many hemodialysis patients suffer from uremic autonomous neuropathy $(6,7)$. Uremic neuropathy is, among others, characterized by a disturbed reaction to the Valsalva manoeuvre, which points towards a disturbance in the baroreceptor reflex arc $(6,7)$. The hemodialysis treatment itself may also impair vascular reactivity (8).

In this chapter, venous reactivity during sympathetic stimulation was assessed in hemodialysis patients and controls and related with the degree of autonomic neuropathy. The investigations were performed on the day after dialysis at normovolemia, in order to exclude an effect of the dialysis treatment itself. Venous reactivity during hemodialysis will be discussed in the next chapter.

\section{PATIENTS}

Clinically stable patients treated with chronic intermittent hemodialysis were included. Controls consisted of healthy persons and subjects with essential hypertension. Exclusion criteria were: acute infectious diseases, diabetes mellitus, previous treatment with ACE-inhibitors, severe coronary or valvular heart disease (NYHA II or more) and a compromised left ventricular function (ejection fraction $30 \%$ or less).

Seven normotensive ( 4 male, 3 female; mean age 51.6 [range 32-66] years), 7 hypertensive ( 2 male, 5 female; mean age 51.1 [range 36-74] years) diallysis patients and 7 normotensive ( 5 male, 2 female; mean age 43.1 [range 36-60 years]) controls were studied. Mean time on hemodialysis was 43 [range 8-96] months in normotensive patients and 35 [range 6-94] months in hypertensive patients. All patients had hemoglobin levels $>6.0 \mathrm{mmol} / 1$. Two hypertensive patients were treated with a calcium antagonist (Nifedipine) and one with a Breceptor antagonist (Metoprolol), which were stopped 14 days before the study. Normotension was defined as a blood pressure below 140/80 $\mathrm{mmHg}$ after hemodialysis for at least 6 consecutive months (9) (chapter 3), without the use 
of antihypertensive medication. Hypertension was defined as a blood pressure higher than $150 / 90 \mathrm{mmHg}$ after hemodialysis without antihypertensive medication, when patients were normovolemic. Equal limits were applied for controls. To prevent overlap between the various groups, subjects with (postdialytic) blood pressures between $140 / 80$ and 150/90 were excluded.

Patients were dialysed three times a week at a Gambro AK-100 or a Fresenius2008 dialysis apparatus with bicarbonate as dialysate buffer.

All subjects gave informed consent. The study was approved by the Ethics Committee of the University Hospital of Maastricht.

\section{METHODS}

The investigation was performed in the morning, and, in dialysis patients, the day after dialysis at normovolemia. Volume status of the patients was assessed by echographic estimation of the inferior caval vein diameter, corrected for body surface area $(10,11)$ [vena cava diameter at normovolemia $=8-11,5$ $\left.\mathrm{mm} / \mathrm{m}^{2}\right]$ All subjects were asked to refrain from smoking, coffee, tea and cocacola during an overnight period.

Reactivity of the peripheral venous system was assessed by means of straingauge plethysmography with direct intravenous pressure measurements together with a cold pressor test, which stimulates sympathetic activity (12). Venoconstriction was expressed as the relative increase in venous tone (VT) (i.e. the pressure/volume ratio) (13) after the cold pressor test.

The technique of strain-gauge plethysmography was discussed extensively in chapter 2.

After the intravenous cannula had been inserted, patients were supine and resting for $40 \mathrm{~min}$. Hereafter, blood samples for the determination of adrenaline and noradrenaline (HPLC method were taken through the intravenous cannula. Subsequently, the arm cuff was inflated at a pressure of $40 \mathrm{mmHg}$ during 80 seconds, after which the cuff was deflated again and the pressure/volume ratio obtained. After 15 minutes the cuff was inflated again and the arm with the A-V shunt was immersed in ice-cold water during 90 seconds (Figure 1). After 80 seconds of immersion, the cuff was deflated and again a pressure/ volume ratio was obtained. Blood pressure was recorded continuously (Finapress, Ohmeda 2300; Lameris [14]) at the arm contralateral to the A-V shunt.

Because the hemodynamic effects of the cold pressor test last shortly (15) and because the cold pressor test is painful, the cuff was inflated for 80 seconds only, which is sufficient for arm volume to reach a stable plateau.

The relative increase in VT was expressed as (increase in VT during the cold pressor test/VT before the cold pressor test). 


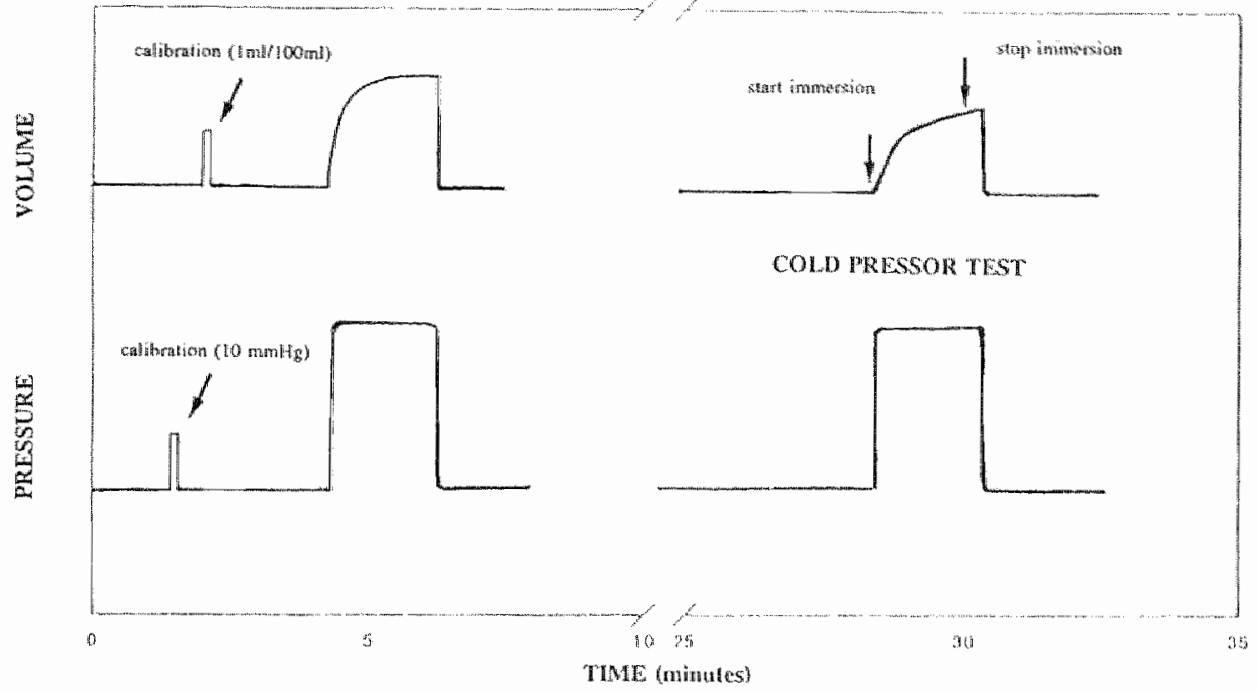

Figure 1. Effect of the cold pressor test on venous tone; tracing of a representative experiment

To estimate total integrity (afferent, central + efferent part) of the baroreceptor reflex arc, heart rate was recorded during an after a Valsalva manoeuvre (12), which was performed by forced expiration against a pressure of $40 \mathrm{mmHg}$ for 15 seconds. The response to this manoeuvre was expressed as the ratio between the longest $R-R$ interval during the release phase to the shortest $R-R$ interval during the strain phase (Valsalva ratio).

\section{Statistical analysis}

Values are expressed as mean $( \pm S D)$. Linear regression analysis was used to assess correlations between variables. Kruskal-Wallis analysis of variance was applied to assess overall differences between the various groups. When overall differences were significant, a Mann-Whitney signed-rank test was used to evaluate differences between specific groups. Differences within groups were evaluated using a Wilcoxon rank-sum test. Normal values $(90 \%$ confidence limits) for the Valsalva manoeuvre as given by O'Brien et al. (16) were used to define autonomic neuropathy. 
According to the echography of the inferior caval vein, patients were normovolemic on the day of investigation. Mean arterial pressure was significantly higher in hypertensive dialysis patients as compared to normotensive dialysis patients and control subjects.

Basal levels of noradrenaline and adrenaline differed significantly between the various groups and were significantly higher in dialysis patients than in control subjects $(p=0.03$ and $p=0.04$; resp.). Basal levels of noradrenaline displayed an inverse relationship with the duration of hemodialysis treatment, which tended to significance $(r=-0.49 ; p<0.06)$, whereas no relation was observed between the duration of hemodiallysis treatment and basal levels of adrenaline $(\mathrm{r}=-0.29)$.

During the cold pressor test, VT increased significantly $(p<0.001)$ in all groups. The increase in VT was due to a decrease in arm volume, because venous pressure remained unaltered.

Although the relative increase in VT did not differ significantly between the various groups $(p=0.10)$, it tended to be more pronounced in hypertensive dialysis patients.

Mean arterial pressure rose significantly in all groups during the cold pressor test $(p<0.001)$. The rise in mean arterial pressure $(\triangle M A P)$ did not differ significantly between the various groups.

Also noradrenaline levels rose in dialysis patients $(p=0.02)$ and in controls $(p=0.03)$ during the cold pressor test, while adrenaline levels remained stable $(\triangle A)$ in all groups $(p=0.7)$.

The rise in noradrenaline ( $\triangle \mathrm{NA}$ ) did not differ between the various groups, but also tended to be more pronounced in hypertensive dialysis patients.

In hemodialysis patients, no relation was observed between the relative increase in VT and $\triangle N A$ during the cold pressor test. Also no relation was found between $\triangle \mathrm{MAP}$ and $\triangle \mathrm{NA}(\mathrm{r}=0.04 ; \mathrm{p}=0.5)$.

The Valsalva ratio differed significantly between the various groups and was significantly lower in normotensive $(p=0.02)$ and hypertensive $(p=0.03)$ dialysis patients compared with controls. Six of the 14 dialysis patients (43\%) had abnormal Valsalva ratios (corrected for age[11]). In controls ratios were normal. Duration of hemodialysis treatment and the Valsalva ratio were not significantly related $(r=0.23, p=0.3)$.

In hemodialysis patients, a weak, but not significant, relationship was found between the Valsalva ratio and the relative increase in VT during the cold pressor test $(r=0.45 ; p=0.06)$. Relationship between the Valsalva ratio and MAP $(r=-0.23 ; p=0.2)$ or $\triangle N A(r=0.19 ; p=0.3)$ were also not significant in hemodialysis patients. The duration of hemodialysis treatment was inversely, 
albeit weakly, related to the relative increase in VT during the cold pressor test $(r=-0.43 ; p=0.07)$.

Table 1. Hemodynamic parameters in the different groups

$\begin{array}{lll}\text { Normotensive } & \text { Hypertensive } & \text { Normotensive } \\ \text { patients } & \text { patients } & \text { controls }\end{array}$

\begin{tabular}{|c|c|c|c|c|c|}
\hline Number & 7 & & 7 & & 7 \\
\hline $\begin{array}{l}\text { MAP } \\
(\mathrm{mmH} g)\end{array}$ & $81(23)$ & $* *$ & $110(5)$ & $* * *$ & $90(6)$ \\
\hline $\begin{array}{l}\text { VCDI } \\
\left(\mathrm{mm} / \mathrm{m}^{3}\right)\end{array}$ & $7.8(1.9)$ & & $8.11(1.6)$ & & - \\
\hline Valsalva Ratio & $1.23(.1)$ & & $1.25(.2)$ & $*$ & $1.67(.5)^{*}$ \\
\hline $\begin{array}{l}\text { NA } \\
\text { (nmolity) }\end{array}$ & $3.5(1.1)$ & & $3.7(1.8)$ & * & $1.9(0.5) *$ \\
\hline $\begin{array}{l}\text { A } \\
\text { (nmolid) }\end{array}$ & $0.7(.4)$ & & $0.9(.7)$ & $*$ & $0.3_{(.2)} * 1$ \\
\hline $\begin{array}{l}\underset{(\mathrm{MAP}}{\mathrm{MAnHg})} \\
.\end{array}$ & $21(16)$ & & $21(10)$ & & $17(12)$ \\
\hline $\begin{array}{l}\Delta \mathrm{VT} \% \\
(\mathrm{~W})\end{array}$ & $38(38)$ & & $77(43)$ & & $30(21)$ \\
\hline$\frac{\Delta \mathrm{NA}}{(\mathrm{nmol} / \mathrm{l})}$ & $0.5(1.0)$ & & $2.1(2.2)$ & & $0.5(0.5)$ \\
\hline$\underset{(\text { (nimol/1) }}{\Delta \mathrm{A}}$ & $0.1(0.6)$ & & $0.1(0.8)$ & & $0.02(0.2)$ \\
\hline
\end{tabular}

$M A P=$ Mean Arterial Pressure; $\triangle M A P=$ change of MAP during cold pressor lest; $\Delta$ VT $\%=$ relative change of ViT during

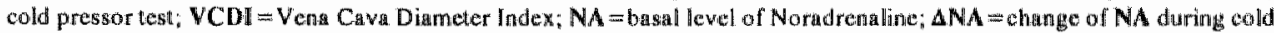
pressor test; $A=b a s a l$ level of adrenaline;

$\Delta A=$ change af A during cold pressor test

\section{DISCUSSION}

In this study the reactivity of the peripheral venous system during sympathetic stimulation was assessed by means of strain-gauge plethysmography in normotensive control subjects and normotensive and hypertensive hemodialysis patients at normovolemia. 
Venoconstriction was determined at a cuff pressure of $40 \mathrm{mmHg}$, because changes in the pressure/volume ratio at higher transmural pressures are independent of alterations in flow; thus only active and not passive venoconstriction is measured (chapter 2) $[17,18]$.

Changes in venous tone were evaluated during the cold pressor test, which elicites a response mediated by afferent pain- and temperature neurons and efferent sympathetic vasoconstrictor fibers (12), resulting in constriction of the blood vessels and a rise in blood pressure.

The integrity of the complete baroreceptor reflex arc was assessed using the Valsalva manoeuvre (12).

During the cold pressor test, venous tone increased significantly in hemodialysis patients and in normotensive controls. In addition, blood pressure and noradrenaline levels also increased significantly. Adrenaline levels remained stable because the cold pressor test does not have a stimulatory effect on the adrenal medulla, the main production site of adrenaline (12).

Although the relative increase in venous tone did not differ significantly between the various groups, the reaction tended to be more pronounced in hypertensive hemodialysis patients. The same trend was observed when considering the rise in noradrenaline during the cold pressor test, suggesting sympathetic overactivity in hemodialysis patients. However, the rise in blood pressure was equal in normotensive and hypertensive hemodialysis patients and in controls. Therefore, it remains unsettled whether sympathetic overactivity is really present in hypertensive hemodialysis patients, as has been suggested by McGrath et al. (19).

In hemodialysis patients, no relation was observed between the rise in blood pressure, the absolute and relative increase in VT and the rise in noradrenaline during the cold pressor test. However, noradrenaline levels are only an indirect measure of sympathetic activity, because they only indicate the amount that is spilled over out of the synaptic cleft into the blood (20). Thus, plasma levels of catecholamines do not necessarily correlate with the local concentration at the nerve terminal.

The normal blood pressure response during the cold pressor test strongly suggests that the sympathetic nerves are intact in hemodialysis patients, which is in accordance with previous reports $(21,22)$.

In contrast, the Valsalva ratio was significantly lower both in normotensive and hypertensive dialysis patients compared to control subjects. $43 \%$ of the dialysis patients demonstrated an abnormal reaction to the Valsalva manoeuvre, according to age-matched reference values (16).

The abnormal response to the Valsalva manoeuvre in the face of the normal responsiveness during the cold pressor test suggests that the uremic autonomic 
defect is located either in the afferent part of the baroreptor reflex arc, the central nuclei, the efferent parasympathetic nerves or the heart itself (23).

Basal catecholamine levels were increased in normotensive and hypertensive dialysis patients compared to controls, which is in agreement with other studies $(4,24)$. Basal noradrenaline and adrenaline levels did not differ between normotensive and hypertensive dialysis patients, which is in contrast with the study of Mc Grath et al. (4), but in agreement with the study of Schohn et al. (25).

The increase in catecholamines might be due to a reduced end-organ sensitivity to the effect of catecholamines (5), as suggested by Daul et al. (26) who observed an inverse correlation between the number of adrenoreceptors on human platelets and catecholamine levels. In their study, the adrenoreceptor density was also inversely correlated to the duration of hemodialysis treatment. Howver, in the present study, basal levels of catecholamines and the duration of hemodialysis treatment were even inversely related, albeit weakly. Although the increase in VT and the duration of hemodialysis treatment were inversely correlated, this relation was rather weak. Furthermore, the rise in blood pressure and in catecholamine levels during the cold pressor test also were not related to the duration of hemodialysis treatment. Thus, the results of the present study do not lend support to the hypothesis that end-organ sensitivity to the effect of catecholamines is reduced in haemodialysis patients.

\section{CONCLUSIONS}

Despite a pathological response towards the Valsalva manoeuvre, the existence of autonomic neuropathy in hemodialysis patients, active venoconstriction and the rise in mean arterial pressure during a cold pressor test are not impaired in hemodialysis patients at normovolemia compared to control subjects. Therefore, the sympathetic part of the baroreceptor reflex arc is intact in hemodialysis patients.

\section{REFERENCES}

1. Greenway CV, Wayne Lautt W. Blood volume, the venous system, preload and cardiac output. Can J Physiol Pharmacol 1986; 64:383-387.

2. Rothe CF. Reflex control of veins and vascular capacitance. Physiol Rev 1983; 63:1281-1342.

3. Shepherd IT, Vanhoutte PM. Veins and their control. W.B. Saunders Company, London/Philadelphia/Toronto, 1975. 
4. MCOrath BP, Ledingham JGG, Benedict CR. Catecholamines in peripheral venous plasma in patients on chronic hemodialysis. Clin Sci Mol Med 1978; 55:89-96.

5. Rasher W, Schonig $A$, Kreye $V A_{*}$ Ritz $E$. Diminished vascular response to nofadrenaline in experimental chronic uremia. Kidney Int 1988; $21: 20-27$.

6. Bondia A, Tabemero JM, Macias JF, Martin-Luengo C. Autonomic nervous system in hemodialysis. Nephrol Dial Transplant 1988; 2:174-180.

7. Campese VM, Romoff MS, Levitan D, Lane $K$, Massry DG. Mechanisms of autonomic nervous system dysfunction in uremia. Kidney Int 1981;20:246-253.

8. Baldamus CA, Emst W, Frei UW, Koch KM. Sympathetic and hemodynamic response to volume removal during different forms of renal replacement therapy. Nephron $1982 ; 31: 324 \times 332$.

9. Kooman JP, Gladziwa U, Wijnen JAG, Böcker $G$, wan Bortel LMAB, Luik AJ, van Hooff $J P_{y}$, Leunissen $\mathrm{KML}$. Non-invasive blood pressure measurements during the inter-dialytic period in patients on hemodialysis: assessment of representative blood pressure values. Nephrol Dial Transpl 1992 (in press)

10. Cheriex EC, Leunissen KML, Janssen JHA, Mooy JMV, van Hooff JP. Echography of the vena cava inferior is a simple and reliable tool for the estimation of dry weight in hemodialysis patients. Nephrol Dial Transpl 1989; 4:563-568.

11. Leunissen KML, Menheere PPCA, Cheriex EC, wan den Berg BW, Noordzij TC, van Hooff JP. Plasma alpha-human atrial natriuretic peptide and dry weight in chronic hemodialysis. Nephrol Dial Transpl 1989; 4:382-386.

12. McLeod JG, Tuck RR. Disorders of the autonomic nervous system: Part 2 . Investigation and treatment. Ann Neurology 1987; 21:519-529.

13. Rudofsky G. Studies on the etiology, pathophysiology, diagnostics, and therapy of venous diseases. in: Jageneau et al (ed). Noninvasive diagnosis in the management of cardiovascular diseases. North Holland Biomedical Press. Amsterdam, New York, London, 1981.

14. Ty Smith N, Wesseling $\mathrm{KH}$, de Wit B. Evaluation of two prototype devices producing noninvasive, pulsatile, calibrated blood pressure measurement from a finger. J Clin Monitor 1985 1:17-29.

15. Greene MA, Boltax AJ, Lustig GA, Rogow E. Circulatory dynamics during the cold pressor test. Am J Card 1965; 16:54-60.

16. O'Brien IAD, O'Hare, Corrall RJM. Heart rate variability in heal thy subjects: effects of age and the derivation of normal ranges for tests of autonomic function. Br Heart J $1986 ; 55: 348-354$.

17. Oberg B. The relationship between active constriction and passive recoil at various distending pressures. Acta Physiol Scand 1967; 71:233-247.

18. Ardill BL, Bhatnagar VM, Fentem PH. Observation of changes in volume of a congested limb as a means of studying the behaviour of capacitance vessels. I Physiol $1968 ; 194: 627-644$

19. McGrath BP, Tiller DJ, Bune A, Chalmers JP, Korner PI, Uther JB. Autonomic blockade and the Valsalva maneuver in patients on maintenance hemodialysis: a hemodynamic study. Kidney Int 1977; 12:294-302.

20. Esler $M$, Leonard $P$, O'Dea $K$, Jackman $G$, Jennings $G$, Korner $P$. Biochemical quantification of sympathetic nerwous activity in humans using radiotracer methodology: Fallibility of plasma noradrenaline measurements. J Cardiovasc Pharmacol 1982; 4:SI52-S157. 
21. Naik RB, Mathias CJ, Wilson CA, Reid JL, Warren DJ. Cardiovascular and autonomic reflexes in hemodiallysis patients. Clin Sci 1981; 60: 165-170.

22. Henrich WL. Autonomic insufficiency. Arch Intern Med $1982 ; 339-344$.

23. Nakashima Y, Fouad FM, Nakamoto S, Textor SC, Bravo EL, Tarazi RC. Localization of autonomic nervous dysfunction in dialysis patients. Am J Nephrol $1987 ; 7: 375-381$.

24. Zucchelli $\mathrm{P}$, Catizone L, Degli Esposti E, Fusaroli M, Ligabue A, Zuccala A. Influence of ultrafiltration on plasma renin activity and adrenergic system. Nephron 1978; 21:317-324.

25. Schohn D, Weidmann P, Jahn H, Beretta-Piccoli C. Norepinephrine-related mechanism in hypertension accompanying renal failure. Kidney Int 1985; 28:814-822.

26. Daul $\mathrm{AE}$, Wang $\mathrm{XL}$, Michel $\mathrm{MC}$, Brodde $\mathrm{OE}$. Arterial hypotension in chronic hemodialyzed patients. Kidney Int $1987 ; 32 ; 728-735$. 



\section{The role of the venous system in hemodynamics during isolated ultrafiltration and bicarbonate dialysis}

J.P. Kooman, U. Gladziwa², G. Böcker ${ }^{2}$, L.M.A.B. van Bortel', J.P. van Hooff, K.M.L. Leunissen

Department of Internal medicine and ${ }^{1}$ Department of Pharmacology, University Hospital Maastricht, the Netherlands, ${ }^{2}$ Dialysis Clinic Aachen, Germany

Kidney Int (in press) 


\section{ABSTRACT}

Insufficient active constriction of veins and resistance vessels during plasma volume depletion could play a causative role in the occurrence of hypotensive periods during hemodialysis (HD). An impaired vascular reaction could result from a dysfunction of the baroreceptor reflex arc or from the effect of the hemodialysis treatment itself.

The constriction of veins and resistance vessels was assessed sequentially during isolated ultrafiltration (UF-only) and during ultrafiltration combined with bicarbonate HD (UF+HD) by measuring the change in venous tone (VT) and vascular resistance (FVR) of the forearm. Twelve HD patients were studied (age 30-64 years). VT and FVR were measured using strain-gauge plethysmography with direct intravenous pressure measurements. The UF-rate was equal during $U F$-only and $U F+H D(1 \mathrm{l} / \mathrm{hr})$. In 6 patients, the measurements were started with $U F$-only and in 6 patients with UF+HD [total study time: 90 minutes]. The intactness of the baroreceptor reflex arc was assessed by a Valsalva manoeuvre. The fall in plasma wolume was equal during UF-only and $U F+H D(-5.7 \pm 4.9 \%$ and $-7.2 \pm 2.7 \%$; resp.). In all patients, VT and FVR increased during UF-only $(p<0.005)$, but remained stable during $U F+H D$. No significant correlation was observed between the Valsalva ratio and the vascular reaction during UF-only and $U F+H D$.

CONCLUSION: During UF-only, venous and arterial constriction during a decline in plasma volume are pronounced despite an abnormal response to the Valsalva manoeuvre in several patients. During UF+HD, the constriction of veins and resistance vessels is significantly reduced compared to the vascular reaction during UF-only; this may play an important role in the occurrence of hypotension during $H D$. 


\section{INTRODUCTION}

The venous system can be viewed upon as a two-compartment system. One compartment contains the hemodynamically active ('stressed") blood volume and serves as a conductance system for the backflow of blood from the periphery to the heart; the other compartment serves as a reservoir for the hemodynamically inactive ('unstressed') blood volume (1). In resting circumstances, nearly $60 \%$ of the total blood volume is hemodynamically inactive (2).

Thus, together with a reduction in venous compliance, as discussed in the previous chapters, the mobilization of unstressed blood volume is of the utmost. importance in the regulation of hemodynamics during a decline in plasma volume. Mobilization of unstressed blood volume can be achieved by active and passive venoconstriction (1). Whereas passive venoconstriction results from elastic recoil of the collapsing venous wall following a decrease in blood flow through the postcapillary bed, active venoconstriction is accomplished by an increase in venular smooth muscle tone (1).

During a fall in plasma volume, active venoconstriction is enhanced by increased sympathetic outflow, which is mediated by baroreceptor reflex activation, which in turn is initiated by reduced stimulation of the baroreceptors in the aorta and carotid arteries (3).

In hemodialysis patients, various factors may interfere with the responsiveness of the venous system during a decline in plasma volume, such as a disturbance in the baroreceptor reflex, secondary to uremic autonomic neuropathy (4), a reduced reactivity of the vascular wall to catecholamines (5) or by an acute reduction in vascular reactivity induced by the hemodialysis treatment itself (6). The latter assumption is supported by notion that hemodynamic stability is better maintained when fluid is removed by isolated ultrafiltration (UF-only) (6).

Although it was shown in the previous chapter that venoconstriction during a sympathetic stimulus was normal in hemodialysis patients, both a lesion in the baroreceptor reflex arc or an acutely impaired vascular reactivity during hemodialysis might result in inadequate active venoconstriction with an ensuing decrease in venous return. In addition, insufficient constriction of the resistance vessels impairs the passive mobilization of unstressed blood volume (7).

Therefore, the response of veins and resistance vessels to a decline in plasma volume was assessed both during UF-only and during ultrafiltration (UF) combined with bicarbonate dialysis, results from related to the response towards the Valsalva manoeuvre. 


\section{PATIENTS}

Clinically stable patients treated by chronic intermittent hemodialysis were enrolled in the study. Exclusion criteria were acute infectious diseases, diabetes mellitus, severe coronary (NYHA II or more) or valvular heart disease and compromised left ventricular function (ejection fraction $30 \%$ or less).

Prior to studies, all subjects were asked to refrain from smoking, coffee, tea and coca-cola for 12 hours. Three patients (nr. 1,6 and 8 [Table 1]) were treated with calcium entry blockers, which were stopped 48 hours before the study. All subjects gave their informed consent. The study was approved by the Ethics Committee of the Maastricht University Hospital.

Twelve hemodialysis patients were investigated [ 7 males, 5 females]. The mean age of the patients in this group was 47 [range 30-64] years. The mean time on hemodialysis had been 3.7 [range $0.2-14.0$ ] years. The mean hemoglobin level was 6.7 [range $4.0-8.7$ ] $\mathrm{mmol} / 1$, the mean albumin level 39 [range $27-47$ ] $\mathrm{g} / \mathrm{l}$.

\section{METHODS}

The patients were studied on the regular day of their dialysis scheme. Before any measurements were started, patients had been supine and resting for 30 minutes.

Both UF-only and UF combined with dialysis were performed for 45 minutes. The UF rate was $1000 \mathrm{ml} / \mathrm{hr}$ during UF-only as well as during UF combined with hemodialysis.

UF-only and UF + HD were performed sequentially; six patients were treated with UF-only, followed by UF combined with dialysis (sequential UF-dialysis) while in the other 6 patients the study was started with UF combined with dialysis, followed by UF-only (sequential dialysis-UF).

A Gambro AK-100 dialysis apparatus and hemophane membranes (GFS 12; Gambro) were used. The composition of the dialysate fluid was: Sodium 141 mmol/l, Potassium 2,0 mmol/1, Bicarbonate $34 \mathrm{mmol} / \mathrm{l}$, Acetate $3 \mathrm{mmol} / \mathrm{l}$, Calcium 1,75 $\mathrm{mmol} / 1$, Magnesium 0,5 $\mathrm{mmol} / 1$, Chloride $108 \mathrm{mmol} / \mathrm{l}$. The temperature of the dialysate was $37,5^{\circ} \mathrm{C}$.

Blood pressure and heart rate were recorded continuously during the study [Finapres; Ohmeda 2300; Lameris] (8).

Active venoconstriction was estimated in terms of an increase in venous tone (pressure/volume ratio). Venous tone and forearm blood flow were assessed by strain-gauge plethysmography. The arm cuff, strain-gauge and intravenous catheter were applied as described in chapter 2 . For the estimation of venous 
tone, the pressure/volume ratio was recorded at a cuff pressure of $40 \mathrm{mmHg}$ and after deflation of the arm cuff.

To measure forearm blood flow, a cuff pressure of $50 \mathrm{mmHg}$ was applied. The hand circulation was not occluded because of the presence of the Finapress device at the ipsilateral finger. The cuff was inflated $5 \mathrm{msec}$ after the R-top of the electrocardiogram. An inflation/ deflation ratio of 3:2 heart beats was used. Flow was estimated using a computerized integrator (9). Venous tone and forearm blood flow were recorded every 15 minutes during the study. Forearm vasular resistance (FVR) was calculated by dividing mean arterial pressure by forearm blood flow. Blood samples for determination of osmolality, colloid osmotic pressure, ionized calcium, noradrenaline (HPLC method) and hematocrit were obtained before the study, after UF-only and after UF combined with dialysis. The fall in plasma volume was calculated using the serial hematocrit method (10). Furthermore, the potassium and sodium concentration was determined before the investigation and after UF combined with dialysis.

To assess the integrity of the baroreceptor reflex arc, a Valsalva manoeuvre was performed by expiration against a pressure of $40 \mathrm{mmHg}$ for 15 seconds with simultaneous ECG recording (11). The Valsalva ratio was expressed as the ratio between the longest $R-R$ interval during the release phase to the shortest $R-R$ interval during the strain phase.

\section{Statistical analysis}

The values are expressed as mean $( \pm S D)$. Correlations between variables were evaluated by linear regression analysis. Friedman's analysis of variance was used to assess overall differences in the obtained parameters between the basal state and the subsequent treatment modes. When overall differences were significant, Wilcoxon's signed-rank test was used to analyze specific differences between the basal state and the different treatment modes.

\section{RESULTS}

The individual data are presented in Table 1, whereas the summarized data are presented in Table 2. Blood pressure was significantly higher during UF-only than during UF combined with dialysis $(p<0.05)$. Heart rate remained stable during the different treatment modes. Plasma osmolality after UF-only did not differ significantly from osmolality before the investigation, whereas the plasma osmolality after UF combined with dialysis was significantly lower compared to the values before the investigation $(p<0.05)$ and after UF-only. Plasma 
colloid osmotic pressure significantly increased both during UF and during UF combined with dialysis. Also the decline in plasma volume was comparable during UF-only $(-7.2 \pm 2.7 \%)$ and UF combined with dialysis $(-5.7 \pm 4.9 \%)$. Potassium was $5.2( \pm 0.5) \mathrm{mmol} / \mathrm{l}$ before the investigation and $4.3( \pm 0.3)$ mmol/l after UF combined with dialysis $(p<0.005)$. Sodium was $138.6( \pm 3.3)$ $\mathrm{mmol} / \mathrm{l}$ before the investigation and $140.4( \pm 2.2) \mathrm{mmol} / \mathrm{l}$ after UF combined with dialysis $(p=0.07)$.

Venous tone and FVR differed significantly $(p<0.001)$ between the various treatment modes and were significantly higher during UF-only $(p<0.005)$ compared to basal values and to UF combined with dialysis. FVR and venous tone during UF combined with dialysis did not differ significantly compared to the basal state. In Figure 1 a representative measurement of venous tone in a patient treated with sequential UF-dialysis is demonstrated.

Figure 2 illustrates the vascular response of patients treated with sequential UFdialysis. Venous tone and FVR increased gradually $(\mathrm{p}<0.05)$ during UF-only and decreased gradually when hemodialysis was started.

In Figure 3, the vascular response of patients treated with sequential dialysis-UF is shown. Both venous tone and FVR remained stable during UF combined with dialysis but rose significantly $(\mathrm{p}<0.05)$ when UF-only was performed.

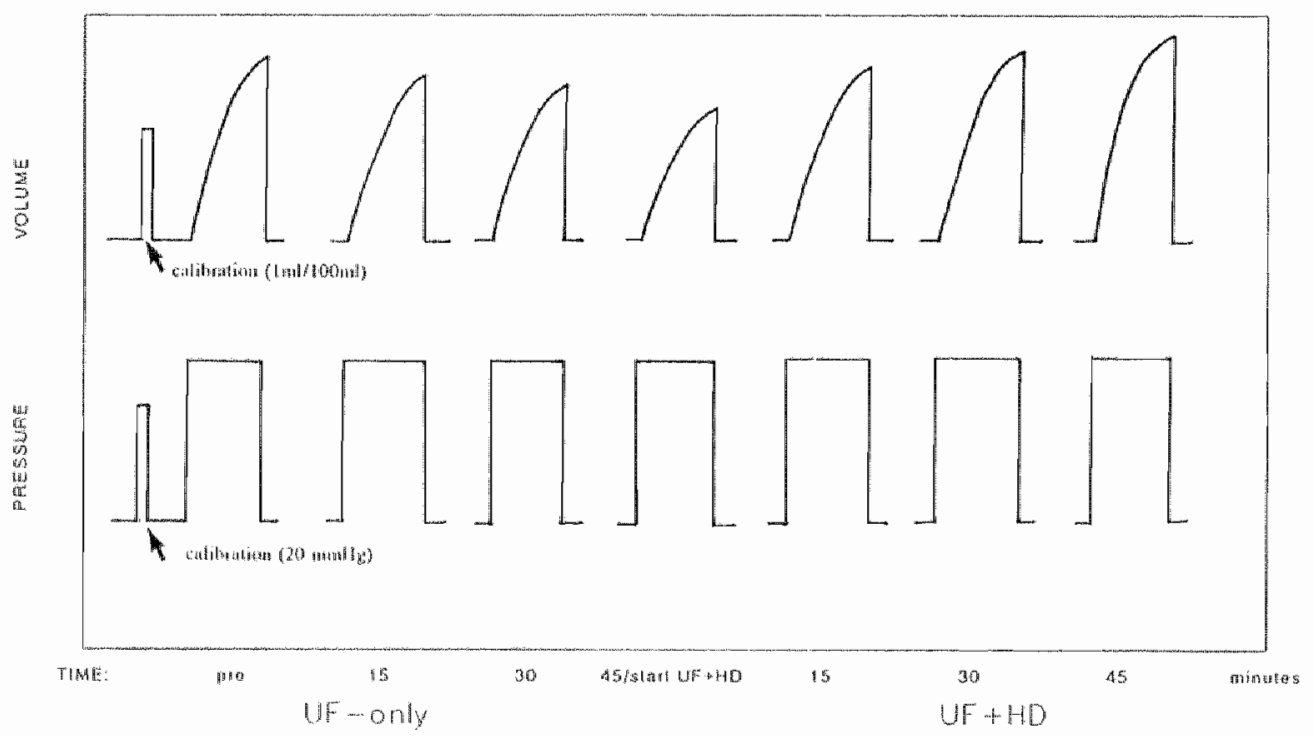

Figure 1. Representative measurement of venous tone during isolated ultrafiltration and ultrafiltration combined with hemodialysis 
Table 1.Individual values for age, Valsalva ratio (VR) and the change in wenous tone $(\Delta V T)$ and forearm vascular resistance $(\triangle F V R)$ during the different treatment modes

\begin{tabular}{|c|c|c|c|c|c|c|c|}
\hline \multicolumn{2}{|c|}{ Patient } & Age & $\begin{array}{l}\text { WR } \\
\text { (years) }\end{array}$ & \multicolumn{2}{|c|}{ 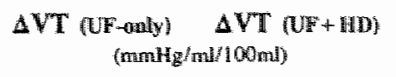 } & $\begin{array}{l}\triangle \text { FVR (UF-only) } \\
\text { (minuHg/mi }\end{array}$ & 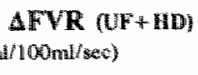 \\
\hline 1 & $4 *$ & 43 & 1.13 & -2.0 & -7.9 & 1251 & 14 \\
\hline 2 & * & 61 & 1.16 & 9.5 & 2.5 & 4640 & 1856 \\
\hline 3 & $*$ & 56 & 1.60 & 7.7 & -0.8 & $\mathbb{1 1 3}$ & -1656 \\
\hline 4 & * & 34 & 1.35 & 7.7 & -6.8 & 7332 & -200 \\
\hline 5 & $*$ & 53 & 1.15 & 10.0 & 0.5 & 2580 & 102 \\
\hline 6 & $*$ & 64 & - & 10.7 & -3.7 & 2425 & -276 \\
\hline 7 & * & 41 & 1.13 & 7.0 & -5.2 & 620 & -124 \\
\hline 8 & $*$ & 30 & 1.25 & 1.6 & -5.6 & 558 & 275 \\
\hline 9 & $* *$ & 36 & 1.28 & 28.3 & 5.3 & 7560 & 1828 \\
\hline 10 & $*$ & 46 & 1.40 & 6.0 & 2.4 & 5175 & 1705 \\
\hline 11 & $*$ & 43 & 1.57 & 14.5 & 2.2 & 2094 & -172 \\
\hline 12 & $*$ & 53 & 1.60 & 7.1 & 0.0 & 6624 & 1383 \\
\hline \multicolumn{8}{|c|}{ * putients treated with UF-only, sequentially followed by UF + dialysis (UF+HD) } \\
\hline \multicolumn{8}{|c|}{ 'Valsalwa ratio could not be obtained due to atrial fibrillation } \\
\hline
\end{tabular}

Table 2. Hemodynamic parameters during isolated ultrafiltration (UF-only) and during UF combined with hemodialysis.

\begin{tabular}{|c|c|c|c|c|}
\hline & Pretreatinent & UF-only & UF + dialysis & p [AnoVa] \\
\hline $\begin{array}{l}\text { Mean arterial pressure } \\
\text { (mumflg) }\end{array}$ & $106(12)$ & $115(16)^{2}$ & $108(13)$ & $<0.05$ \\
\hline $\begin{array}{l}\text { Heart rate } \\
\text { (beals/ming) }\end{array}$ & $70(7)$ & 70 & $69(8)$ & 0.8 \\
\hline 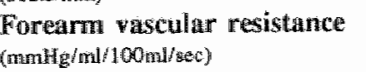 & $3428(1249)$ & $6842(3108)^{\text {ed }}$ & $3823(1606)$ & $<0.001$ \\
\hline $\begin{array}{l}\text { Venous tone } \\
\text { (numHig/mi/100/n) }\end{array}$ & $20.14 .8)$ & $29.0(9.2)^{2 \times d}$ & $18.7(5.2)$ & $<0.001$ \\
\hline $\begin{array}{l}\text { Noradrenaline } \\
\text { (nmolib) }\end{array}$ & $2.1(1.8)$ & $2.5(2.2)$ & $11.9(0.3)$ & 0.4 \\
\hline $\begin{array}{l}\text { Ionized Calcium } \\
\text { (mmol/l) }\end{array}$ & $1.25(0.11)$ & $1.30(0.11)^{8}$ & $1.33(0.10)^{64}$ & $<0.01$ \\
\hline $\begin{array}{l}\text { Osmolality } \\
\text { (mosmol/kg) }\end{array}$ & $312.6(13.3)$ & $316.9(12.4)^{e}$ & $304.5(7.6)^{\mathrm{b}}$ & $<0.05$ \\
\hline $\begin{array}{l}\text { Colloid osmotic pressure } \\
(\mathrm{kPa})\end{array}$ & $2.7(0.3)$ & $3.3(0.5)^{d}$ & $3.2(0.3)^{\mathrm{h}}$ & $<0.025$ \\
\hline $\begin{array}{l}\text { Declime in pllasma volume } \\
\text { (w) }\end{array}$ & & $-7.3(2.8)^{\mathrm{d}}$ & $-6.0(5.4)^{d}$ & \\
\hline \multicolumn{5}{|c|}{ 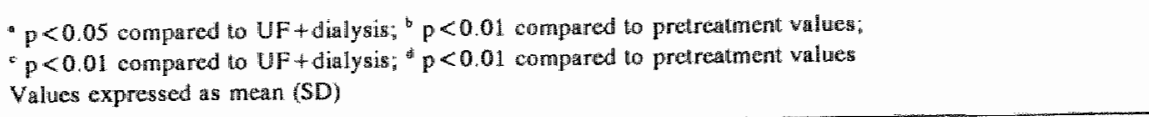 } \\
\hline
\end{tabular}




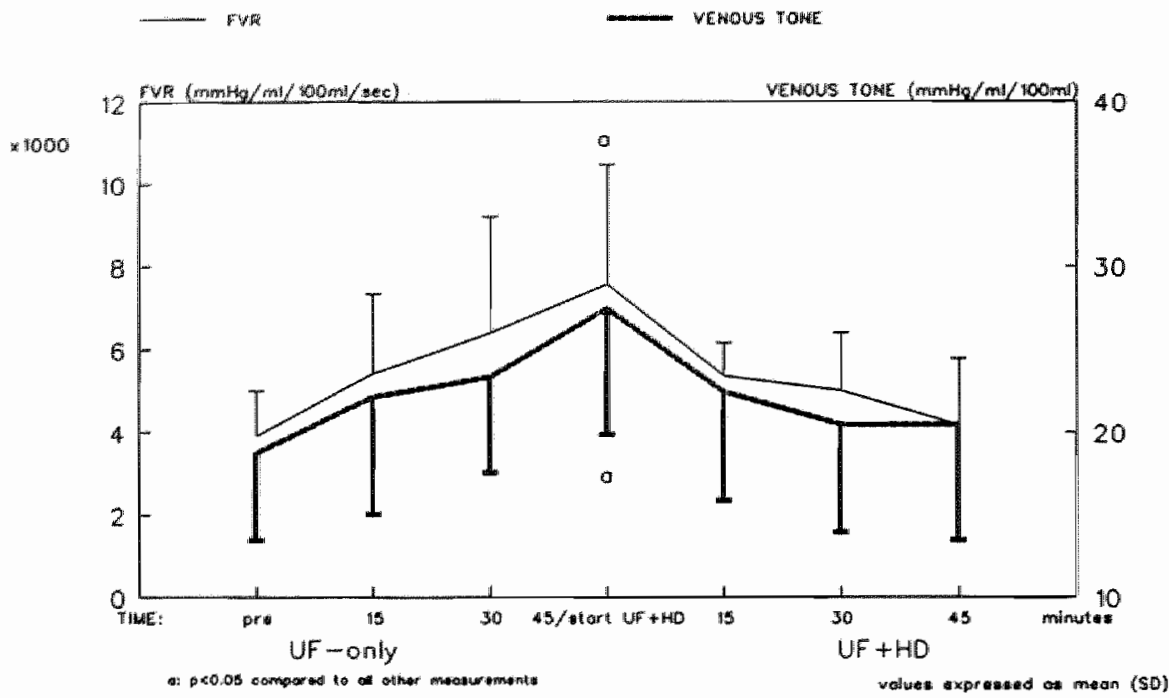

Figure 2. Reaction of the veins and resistance vessels during sequential UF-dialysis UF - anly =isolated ultrafiltration $\mathbf{U F}+\mathbf{H D}=$ ultrafiltration combined with hemodialysis

Noradrenaline levels did not differ significantly between the various treatment modes $(p=0.4)$ due to the large variability. Still, noradrenaline levels tended to rise during UF-only and to decrease during UF combined with dialysis. Ionized calcium differed significantly during the basal state and the different treatment modes $(\mathrm{p}<0.01)$ and was significantly higher during UF-only $(p<0.05)$ or during UF combined with dialysis $(p<0.05)$ compared to the basal state.

The mean Valsalva ratio of the patients was $1.28( \pm 0.18)$. The Valsalva ratio was not significantly related to the change in venous tone and FVR during UFonly $(r=-0.47 ; p=0.08$ and $r=-0.31$; resp.) and during UF combined with dialysis $(r=-0.23$ and $r=0.01$; resp.). 


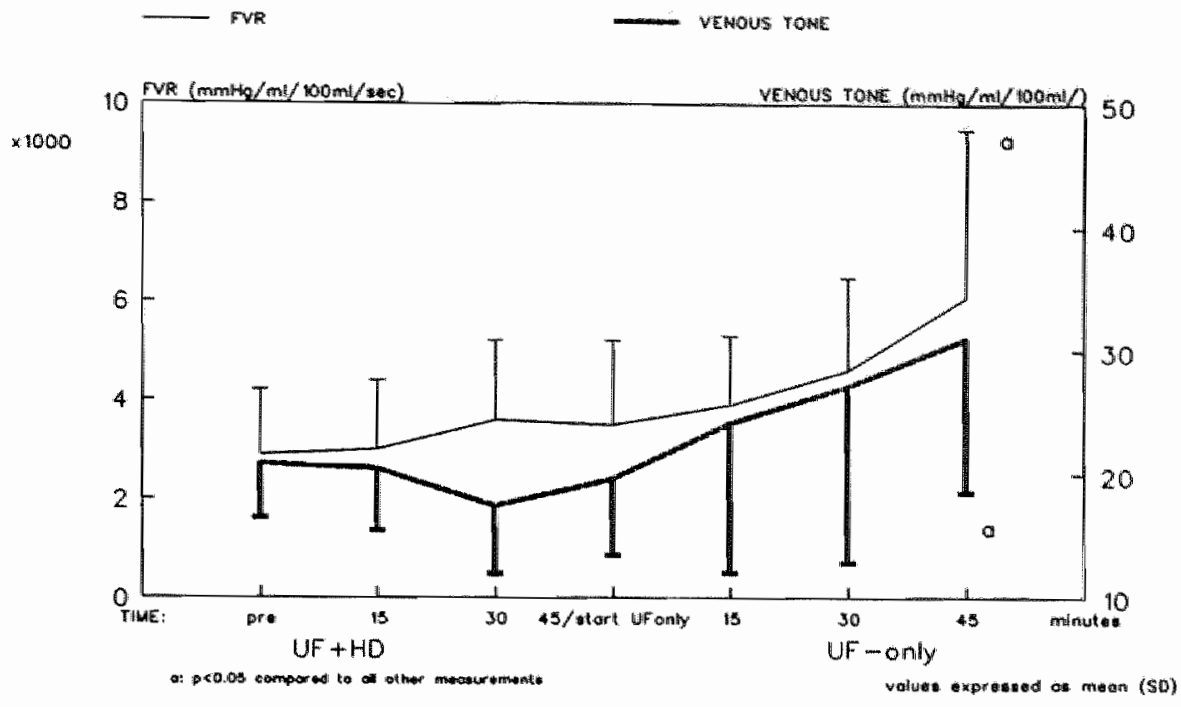

Figure 3. Reaction of the veins and resistance vessels during sequential dialysis-ur UF-only = isolated ultrafiltration

$\mathrm{UF}+\mathrm{HD}=$ ultratiltration combined with hemodialysis

\section{DISCUSSION}

In this study, the response of the venous system and resistance vessels was evaluated during isolated UF and during UF combined with bicarbonate dialysis. A semi cross-over design was used to ensure that a difference in vascular response between the two treatment modalities would not arise from large differences in plasma volume. Antihypertensive medication was stopped 48 hours before the investigation. However, the drugs used have little effect on the venous system. Furthermore, because the vascular reaction did not differ between treated and untreated patients the use of antihypertensive medication is not likely to have been a disturbing factor (12).

Whereas osmolality was significantly lower after UF combined with dialysis compared to the pretreatment values and the values after isolated UF, the rise in colloid osmotic pressure and the decline in plasma volume were equal after both procedures, which is in accordance with the study of Rodriguez et al. (13) However, irrespective of the sequence of treatments, venous tone and FVR were significantly higher during isolated UF compared to UF combined with dialysis, although the decline in plasma volume was comparable during both procedures. This is in accordance with earlier studies $(14,15)$. However, only in the present study and in that of Bradley et al. (15) bicarbonate was used as dialysate buffer. 
In addition to active venoconstriction, the mobilization of unstressed blood volume by passive venoconstriction is also very important in the regulation of venous return in case of a decrease in plasma volume. Passive venoconstriction occurs by the de Jager-Kroch phenomenon (1); i.e. when blood flow through a compliant vascular bed decreases, its capacity decreases due to passive elastic recoil. Blood flow through the postcapillary vascular bed declines when precapillary resistance rises. Therefore, the increase of FVR during isolated UF not only leads to the maintenance of blood pressure at the precapillary side of the circulation but also helps to maintain venous return to the heart by passive mobilization of the unstressed blood volume.

Thus, both active and passive venoconstriction are significantly less pronounced during UF combined with dialysis compared to isolated UF. The cause for the diminished vascular response during bicarbonate dialysis is still unresolved. Decreased catecholamine levels (16), an acute reduction of vascular sensitivity to the effect of catecholamines (6), rapid electrolyte shifts (17) and a rise in core temperature (2) may be involved in the pathogenesis of the decreased sympathetic and vascular response during hemodialysis. In the present study, although not significantly, noradrenaline levels tended to rise during isolated UF but to decrease during the subsequent dialysis. However, noradrenaline levels are a poor marker of sympathetic activity, because only the amount flowing over from the synaptic cleft into the blood is measured (18) and not the concentration present at the nerve terminal itself.

Reduced reactivity of the vascular wall to sympathetic stimulation during bicarbonate dialysis might be caused by a decrease in ionized calcium due to rapid changes in the acid-base status of the patient (19). Ionized calcium is a crucial element for the contraction of vascular smooth muscle cells (20). However, in the present study, ionized calcium increased significantly both during isolated UF, due to plasma volume contraction and during UF combined with dialysis, which in the latter case is also due to calcium influx from the dialysate.

Rapid changes in electrolyte status may also influence sympathetic activity during hemodialysis. Henrich et al.(17) observed a decline in catecholamine levels when plasma potassium decreased whereas catecholamine levels remained stable when plasma potassium was kept constant. In our study, potasssium levels decreased only moderately whereas no patient was hypokalemic after the investigation. Finally, rapid changes in the acid-base status of the patient may also impair active vasoconstriction (21).

That temperature may play a role in the inadequate vascular reaction during dialysis is supported by studies in which greater hemodynamic stability was observed during dialysis with cooled dialysate $(22,23)$. This theory clearly needs further investigation. 
The Valsalva ratio was not related to the increase in venous tone or to the rise in FVR, neither during isolated UF, nor during UF combined with dialysis. This and the excellent vascular stability during isolated UF, observed in previous studies (16), are arguments against a localization of the autonomic defect either in the afferent segment or in the efferent sympathetic part of the baroreceptor reflex arc. The autonomous defect is most likely located either in the sinus node itself, the central nuclei or in the efferent parasympathetic fibers to the heart (24).

\section{CONCLUSION}

During hemodialysis, the response of the veins as well as that of the resistance vessels is significantly reduced compared to the vascular reaction during isolated UF. If the decline in plasma volume is not too large and if the cardiac function of the patients is not impaired, the diminished vascular reaction does not always lead to hemodynamic instability, as shown in the present study. However, in patients with severe cardiac impairment or in those with decreased left ventricular compliance, who are highly dependent upon adequate cardiac filling pressures (25), the inadequate vascular reaction during hemodialysis is likely to be an important contributing factor to the induction of hypotensive periods during hemodialysis.

\section{REFERENCES}

1. Rothe CF. Venous system: physiology of capacitance vessels. In: Handbook of Physiology, 1983. Sect 2. Cardiovascular system. Vol 3: Peripheral circulation and organ blood flow. Chapt 13. American Physiological Society, Bethesda. pp 397-452.

2. Greenway CV, Wayne Lautt W. Blood volume, the venous system, preload and cardiac output. Can J Physiol Pharmacol 1986; 64:383-387.

3. Shepherd JT, Vanhoutte PM. Veins and their control. W.B. Saunders Company, London/Philadelphia/Toronto, 1975.

4. Daul AE, Wang XL, Michel MC, Brodde OE. Arterial hypotension in chronic hemodialyzed patients. Kidney Int 1987; 32:728-732.

5. Bondia A, Tabernero JM, Macias JF, Martin-Luengo C. Autonomous nervous system in hemodialysis. Nephrol Dial Transplant 1988; 2:174-180.

6. Baldamus CA, Ernst W, Frei UW, Koch KM. Sympathetic and hemodynamic response to volume removal during different forms of renal replacement therapy. Nephron 1982; 31:324-332.

7. Daugirdas JT. Dialysis hypotension; a hemodynamic analysis. Kidney Int 1991; 39:233246.

8. Ty Smith $\mathrm{N}$, Wesseling $\mathrm{KH}$, de Wit B. Evaluation of two prototype devices producing noninvasive, pulsatile, calibrated blood pressure measurement from a finger. J Clin Monitor $1985 ; 1: 17-29$. 
9. Jageneau et al. Noninvasive diagnosis in the management of cardiovascular diseases. North Holland Biomedical Press. Amsterdam, New York, London, 1981.

10. van Beaumont $W$. Evaluation of hemoconcentration from hematocrit measurements. I Appl Physiol 1972; 32"712-713.

11. Mc Leod JG, Tuck RR. Disorders of the autonomic nervous system: Part 2. Investigation and treatment. Ann Neurology 1987; 21:519-529.

12. Robinson BF. Differences in response to dilator agents in blood vessels of different types: physiological bases for selectiwity. I Hypertens 1989; 7 (supp 4):S147-S151.

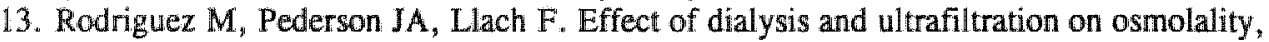
colloid osmotic pressure, and vascular refilling rate. Kidney Int 1985; 28: 808-813.

14. Bradley JR, Evans DB, Gore SM, Cowley AJ. Is dialysis hypotension caused by an abnormality of venous tone? Br Med J 1988; 296:1634-1637.

15. Nakamura Y, Ikeda T, Takata S, Yokoi H, Hirono M, Abe T, Takazakura F, Kobayashi $\mathrm{K}$. The role of peripheral resistance and capacitance vessels in hypotension following hemodialysis. Am Heart J 1991; 121: 1170-1177.

16. Zuchelli P, Catizone L, Degli Esposti E, Fusaroli M, Ligabue A, Zuccalà A. Influence of ultrafiltration on plasma renin activity and adrenergic system. Nephron 1978; $21: 317$ 324.

17. Henrich WL, Katz FH, Molinoff PB, Schrier RW. Competitive effects of hypokalemia and volume depletion on plasma renin activity, aldosteron and catecholamine concentrations in hemodialysis patients. Kidney Int $1977 ; 12: 279-284$.

18. Esler $M$, Leonard $P$, O'Dea $K$, Jackman $G$, Jennings $G$, Korner P. Biochemical quantification of sympathetic nervous activity in humans using radiotracer methodology: Fallability of plasma noradrenaline measurements. J Cardiovase Pharmacol 1982; 2:S152-S157.

19. Leunissen KML, van den Berg BW, van Hooff JP. Ionized calcium plays a pivotal role in controlling blood pressure during hemodialysis. Blood Purif 1989; 7:233-239.

20. Vlachakis ND, Frederics R, Velasquez $M$, Alexander $N$, Singer $F$, Maronde RF. Sympathetic system function and vascular reactivity in hypercalcemic patients. Hypertension $1982 ; 19: 452-458$.

21. Scharpey-Schafer EP, Semple SJG, Halls RW, Howarth S. Venous constriction after exercise; its relation to acid-base changes in venous blood. Clin Sci 1965; 29:397

22. Maggiore Q, Pizarelli F, Sisca S. Blood temperature and vascular stability during hemodialysis and hemofiltration. Trans Am Soc Artif Int Organs 1982; 28:523-527.

23. Orofino L, Marcén R, Quereda C, Villafruela JJ, Sabater J, Matesanz R, Pascual J, Ortuño J. Epidemiology of symptomatic hypotension in hemodialysis: is cool dialysate benificial for all patients? Am J Nephroll 1990; 10:177-180.

24. Nakashima Y, Fouad FM, Nakamoto S, Textor SC, Bravo EL, Tarazi RC. Localization of autonomous nervous dysfunction in dialysis patients. Am J Nephrol 1987; 7:375-381.

25. Ritz E, Rambausek M, Mall G, Ruffman K, Mandelbaum A. Cardiac changes to uremia and their possible relation to cardiovascular instability on dialysis. Contrib Nephrol 1990; $78: 221-229$. 
CHAPTER 9

\section{Summary and conclusions}


In the Netherlands, more than 2400 patients are treated with chronic intermittent hemodialysis, which is therefore the most frequently used technique in the treatment of patients with end-stage renal failure. This number will continue to increase, due to a shortage of donor kidneys and to a wider acceptance of elderly patients and patients with a dysfunction of other organs, in whom, for medical reasons, transplantation is often not possible. During chronic intermittent hemodialysis, uremic toxins are removed and disturbances of electrolyte and acid-base status are corrected by bringing the blood in contact with dialysate in an artificial kidney. The excess of body water is removed by ultrafilltration, i.e by convective transport generated by differences in pressure between the blood and dialysate compartment. Ultrafiltration can be performed with and without concomitant hemodialysis.

In contrast to the continuous function of the human kidney, hemodialysis and ultrafiltration are performed intermittently during a relatively short period of time, i.e 2-3 times weekly during 3-5 hours. This induces rapid changes in the fluid status of the patient, which may lead to a loss of hemodynamic stability.

Hypotensive periods frequently occur during hemodialysis treatment, which is a major cause of morbidity in the dialysis population. Two mechanisms are of importance in the maintenance of hemodynamic stability during dialysis: The first is the preservation of plasma volume, which depends upon the velocity of fluid withdrawal during hemodialysis and ultrafiltration and upon the refill of plasma volume from the interstitium, the second is the integrity of cardiovascular regulation mechanisms during a decline in plasma volume.

The venous system is an important factor in the regulation of cardiovascular hemodynamics because it contains $60-80 \%$ of the total blood volume.

The venous system can be viewed upon as a two-compartment model. One compartment consists of the hemodynamically active ('stressed') blood volume which takes an active part in the backflow of blood from the periphery to the heart.

The other part of the venous system contains hemodynamically inactive ('unstressed') blood volume, mainly serving as a reservoir for blood volume. In resting circumstances, only $40 \%$ of the total blood volume is hemodynamically active.

Two mechanisms are of importance in the regulation of venous hemodynamics; the first is venous compliance, the volume/pressure relationship of the stressed compartment, which in healthy subjects is mainly determined by the passive visco-elastic properties of the venous wall with minimal interference of smooth muscle tone; the second is venoconstriction, either passive or active, which serves to translocate unstressed blood volume to the hemodyna- 
mically active compartment; passive venoconstriction results from passive elastic recoil of the venous wall due to changes in flow; active venoconstriction results from an increase in smooth muscle tone.

A reduction in venous compliance can impair hemodynamics during hemodialysis by impairing the preservation of plasma volume, due to a disturbed Starling equilibrium over the capillary wall. Furthermore, because of the reduced volume/pressure relation, a minor fall in plasma volume may lead to a steep decline in central venous pressure. A reduction in venous compliance in hemodialysis patients may result from the existence of hypertension in hemodialysis patients or from increased circulating levels of vasoactive substances, like noradrenaline or angiotensin II.

In addition to a reduction in venous compliance, venoconstriction can be impaired as well in hemodialysis patients, because of the presence of autonomic neuropathy or because of a reduced end-organ sensitivity towards catecholamines. Moreover, the hemodialysis treatment itself might lead to an acute impairment in the vascular response during hemodialysis, a view supported by the superior hemodynamic observed when fluid is removed during isolated ultrafilltration.

The present study was divided into three major parts; in the first part, the methods used in this thesis were described (chapter 2 and 3 ). In the second part (chapter 4-6) the passive properties of the venous system (venous compliance) and its hemodynamic consequences was studied in hemodialysis patients. In the second part (chapter 7 and 8), the active reaction (venoconstriction) of the venous system was assessed.

In chapter 2, the methods used to estimate venous compliance and active venoconstriction were discussed. Venous compliance and active venoconstriction were assessed in the forearm by strain-gauge plethysmography with direct intravenous pressure measurements. Although the pressure/volume relationship of the venous system is curvilinear, venous compliance was only assessed in the linear part of the pressure/volume relationship, because under these circumstances, venous compliance is only determined by the true viscoelastic properties of the venous wall, in contrast to venous compliance assessed in the curvilinear part of the pressure/volume relationship, which is mostly determined by the geometric shape of the partly collapsed venous wall.

Venoconstriction was expressed by means of changes in venous tone (pressure/volume ratio). Venous tone was assessed at a cuff pressure of $40 \mathrm{mmHg}$, because at higher transmural pressures, the measured venoconstriction is 
independent from changes in flow; thus: only active venoconstriction is measured.

Venous compliance in dialysis patients can be influenced by the existence of hypertension. It is however, difficult to define the presence of hypertension in hemodialysis patients, because it is unknown whether blood pressure measured before or after hemodialysis is representative for the average blood pressure during the inter-dialytic period. Pre-dialytic blood pressure can be influenced by the rise in plasma volume during the inter-diallytic period and by the arousal associated with the start of a dialysis procedure, whereas postdialytic blood pressure can be influenced by factors specifically related to the dialysis treatment itself, like the fall in plasma volume and the activation or removal of vasoactive substances. Therefore, as described in chapter $\mathbf{3}$, noninvasive ambulatory blood pressure measurements during the inter-dialytic period were used to evaluate whether pre-or post-dialytic blood pressure is representative for the average inter-dialytic blood pressure. It was shown that post-dialytic blood pressure was a better predictor for the average interdialytic blood pressure than pre-dialytic blood pressure and therefore should be taken as guideline for the existence and evaluation of hypertension in a dialysis population. Furthermore, the day-night blood pressure rhythm was blunted in hemodialysis patients compared with controls.

In chapter 4 , it was evaluated whether venous compliance was reduced in hemodialysis patients and if so, if this reduction could be reversed by shortterm pharmacological intervention with a directly acting venodilator (Nitroglycerin) and after a three-day period of oral treatment with an $\alpha 1$-sympathicolytic agent (Doxazosin). Venous compliance was equal in normotensive dialysis patients and normotensive non-uremic controls, but was reduced in hypertensive hemodialysis patients compared to normotensive controls and dialysis patients. Venous compliance in hypertensive controls was intermediate between hypertensive dialysis patients and the normotensive groups.

The reduced venous compliance in hypertensive hemodialysis patients was not reversible after administration of Nitroglycerin and Doxazosine, suggesting that structural factors may contribute to the reduction in venous compliance.

Therefore, in chapter 5, the morphology of the venous wall was studied in normotensive and hypertensive uremic patients and compared with controls without a history of cardiovascular disease. The medial thickness did not differ between normotensive uremic patients and controls, but was significantly increased in hypertensive dialysis patients, which might contribute to 
the decrease in venous compliance in this group. Furthermore, a qualitative increase in smooth muscle was observed in several normotensive and hypertensive uremic patients, possibly caused by an increase in venous pressure or by the effect of circullating trophic substances.

In chapter 6 , the hemodynamic significance of a reduction in venous compliance was assessed in hemodialysis patients during isolated ultrafiltration. Venous compliance correlated inversely with the decline in central venous pressure and the decline in plasma volume during ultrafiltration. The larger decline in central venous pressure in patients with a reduced venous compliance probably results from the reduced volume/pressure relationship of the venous system, whereas the larger decline in plasma volume is probably due to an impaired refill of plasma volume from the interstitium, resulting from an altered relationship between plasma volume and interstitial volume caused by a disturbance in the capillary Starling equilibrium.

Mean arterial pressure and heart rate remained unaltered in all patients, probably due to the adequate activation of cardiovascular compensatory mechanisms during isolated ultrafiltration.

In chapter 7, it was studied whether the active reaction of the venous system towards a sympathetic stimulus was intact in normotensive and hypertensive hemodialysis patients. The study was performed the day after dialysis at normovolemia. Sympathetic stimulation was accomplished by using a cold pressor test, whereas the intactness of the entire baroreceptor reflex arc was assessed by a Valsalva manoeuvre. Despite a pathological response towards the Valsalva manoeuvre, both normotensive and hypertensive dialysis patients responded with an active increase in venous tone and with a rise in mean arterial pressure during the cold pressor test. Therefore, the autonomic defect in hemodialysis patients is not located in the efferent sympathetic part of the baroreceptor reflex arc, whereas a reduced end-organ sensitivity towards the effect of catecholamines is unlikely.

In chapter 8, it was studied whether the hemodialysis treatment itself could impair the vascular reaction during a decline in plasma volume. Therefore, venous tone and forearm vascular resistance were measured during isolated ultrafiltration and during ultrafiltration combined with bicarbonate hemodialysis. Although the decline in plasma volume was equal during isolated ultrafiltration and during ultrafiltration combined with hemodialysis, forearm vascular resistance and venous tone increased significantly during isolated ultrafiltration but remained stable during ultrafiltration combined with hemodialysis. The Valsalva ratio was not related to the vascular reaction, 
neither during isolated ultrafiltration nor during ultrafiltration combined with hemodialysis. Thus, the hemodialysis treatment itself impairs the vascular reaction during hemodialysis, whereas test studying heart rate responses in hemodialysis patients are not predictive for the vascular reaction during a decline in plasma volume

Concluding, the venous system contributes in two ways to the impaired hemodynamic regulation of hemodialysis patients, first by a reduction of venous compliance in hypertensive hemodialysis patients, which impairs plasma volume preservation and induces a steeper decline in central venous pressure during ultrafiltration. Furthermore, in dialysis patients, the mobilization of hemodynamically inactive blood volume is impaired when ultrafiltration is combined with dialysis, which leads to pooling of plasma volume. All these abnormalities can impair venous return and hence, induce a decline in cardiac output (Figure 1).

When cardiovascular regulation mechanisms are intact, for instance when fluid is removed during isolated ultrafiltration, or when the cardiac function of the patients is not impaired, abnormalities of the venous system do not necessarily lead to a decline in blood pressure, as was shown in the previous studies. However, in patients with a reduced left ventricular compliance or an otherwise compromised left ventricular function, who are highly dependent upon adequate venous return for the maintenance of cardiac output, abnormalities of the venous systems can play a pivotal role in the induction of hypotensive periods during hemodialysis. In these patients, fluid has to be removed either during isolated ultrafiltration or during hemodialysis at a low ultrafiltration rate.

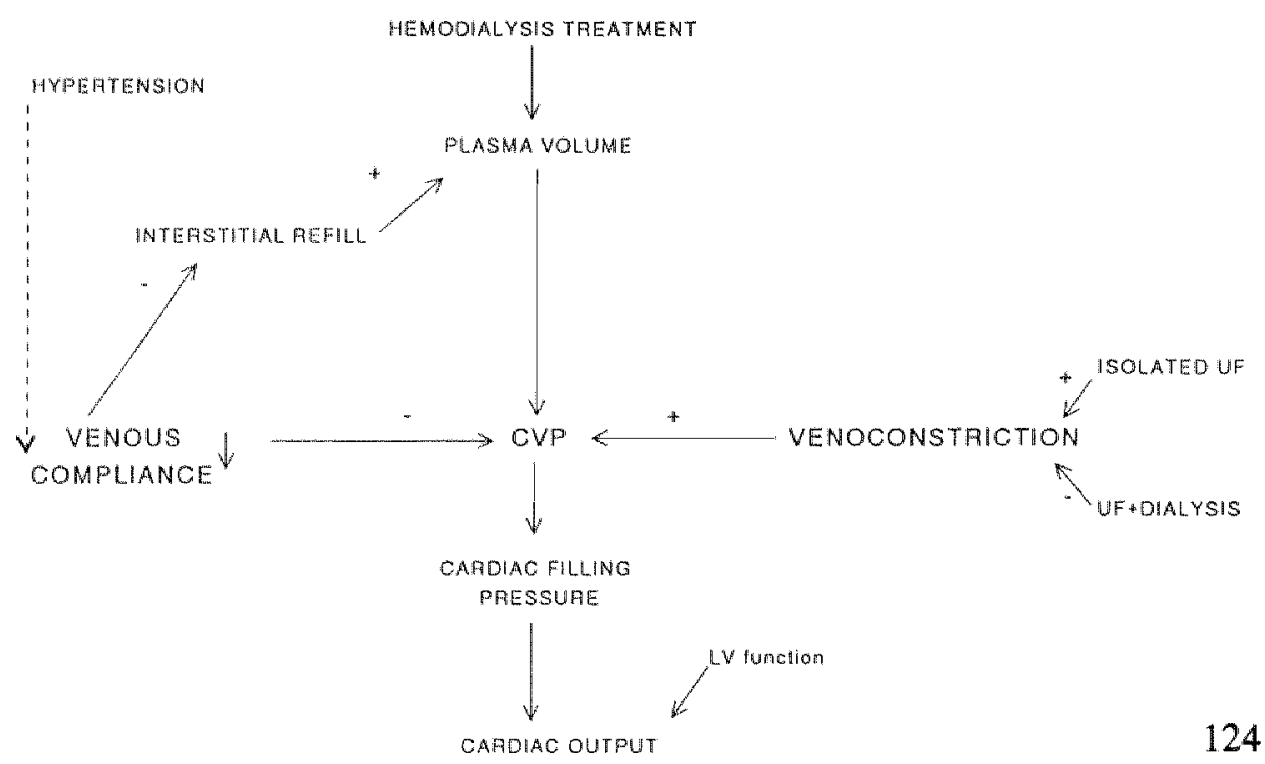


CHAPTER 10

\section{Samenvatting}


In Nederland worden meer dan 2400 patiënten behandeld met chronische intermitterende hemodialyse, hetgeen daarmee de meest gebruikte techniek is bij de behandeling van patiënten met terminale nierinsufficiëntie. Het aantal dialysepatienten zall blijven stijgen, gezien het tekort aan donornieren en het toegenomen aanbod van oudere patiënten en patiënten met bijkomende ziekten, die vanwege medische redenen niet getransplanteerd kunnen worden. Gedurende chronische intermitterende hemodialyse worden uremische toxines verwijderd en worden afwijkingen in het electrolyt- en zuur-base evenwicht gecorrigeerd door diffusief transport (d.w.z. transport gebaseerd op concentratieverschillen van opgeloste stoffen) door het bloed van de patiënt in een kunstnier in contact te brengen met dialysaat (vloeistof die qua electrolytconcentratie lijkt op normale extracellulaire vloeistof). Het overschot aan lichaamswater wordt daarentegen verwijderd door convectief transport (ultrafiltratie), dat berust op drukverschillen tussen het bloed- en dialysaatcompartiment. Ultrafiltratie kan worden verricht met of zonder bijkomende hemodialyse.

In tegenstelling tot de continue functie van de menselijke nier, worden hemodialyse en ultrafiltratie intermitterend verricht gedurende een relatief korte tijd, gemiddeld 2-3 maal per week gedurende 3-5 uur. Dit induceert snelle wisselingen in de vochtstatus en het milieu interieur van de patiënt, hetgeen tot hemodynamische instabiliteit kan leiden.

Hypotensieve perioden komen vaak voor tijdens een dialysebehandeling en zijn een belangrijke oorzaak van morbiditeit bij dialysepatiënten. Twee mechanismen zijn van belang bij de handhaving van de hemodynamische stabiliteit tijdens dialyse: het eerste is de plasma volume preservatie, die afhangt van de snelheid van vochtonttrekking gedurende dialyse en ultrafiltratie en op de hervulling van het plasma volume vanuit het interstitiële weefsel; het tweede is de intactheid van cardiovasculaire regulatiemechanismen bij een daling van het plasma volume.

Omdat het $60-80 \%$ van het totale plasma volume bevat, is het veneuze systeem is een belangrijke factor in de regulatie van de cardiovasculaire hemodynamiek.

Het veneuze systeem kan beschouwd worden als een twee-compartimentsmodel. Een compartiment bevat hemodynamisch actief ('stressed') bloedvolume dat actief deelneemt aan de terugstroom van bloed vanuit de perifere vaten naar het hart. Het andere gedeelte van het veneuze systeem bestaat uit hemodynamisch inacrief ('unstressed") bloedvolume, hetgeen met name een reservoirfunctie heeft. Onder basale omstandigheden is slechts $\pm 40 \%$ van het totale bloedvolume hemodynamisch actief. 
Twee mechanismen zijn van belang in de regulatie van de veneuze hemodynamiek; de eerste is de veneuze compliance, d.w.z. de volume/druk relatie van het hemodynamisch actieve compartiment, die in gezonde personen met name bepaald wordt door de passieve visco-elastische eigenschappen van de veneuze wand. Onder basale omstandigheden is de gladde spierceltonus van de veneuze wand namelijk minimaal en beïnloedt aldus de veneuze compliance nauwelijks; het tweede mechanisme is de venoconstrictie, hetzij passief of actief, die dient om 'unstressed' bloed volume naar het hemodynamisch actieve compartiment te verplaatsen. Passieve venoconstrictie wordt veroorzaakt door collaps van de veneuze wand na een daling van de flow; actieve venoconstrictie wordt veroorzaakt door een toename van de gladde spierceltonus.

Een verlaagde veneuze compliance kan de hemodynamiek tijdens hemodialyse nadelig beïnvloeden door een negatieve invloed op de plasma volume preservatie, te wijten aan een verstoring van het capillaire Starling evenwicht. Tevens, door de verlaagde volume/druk relatie, kan een relatief geringe afname van het plasma volume leiden tot een snelle daling van de centraal veneuze druk. Een verminderde veneuze compliance bij dialysepatiënten kan worden veroorzakkt door de aanwezigheid van hypertensie, frequent voorkomend bij dialysepatiënten, of door verhoogde circulerende spiegels van vasoactieve substanties, zoals noradrenaline of angiotensine-II.

Naast een verlaging van de veneuze compliance, kan ook de venoconstrictie bij dialysepatiënten verstoord zijn door de aanwezigheid van autonome neuropathie of door een afgenomen eind-orgaan gevoeligheid voor het effect van catecholaminen. Verder kan de dialysebehandeling zelf een acute verstoring van de vasculaire respons tijdens hemodialyse induceren, hetgeen ondersteund wordt door de observatie dat de hemodynamische stabiliteit beter gehandhaafd blijft wanneer vocht verwijderd wordt tijdens geïsoleerde ultrafiltratie (d.w.z. zonder hemodialyse).

Dit proefschrift is verdeeld in drie delen; in het eerste deel werden de gebruikte methoden beschreven (hoofdstuk 2 en 3 ). In het tweede deel (hoofdstuk 4-6) werd de veneuze compliance en diens hemodynamische invloed bestudeerd. In het derde deel (hoofdstuk 7 en 8 ) werd de actieve reactie (venoconstrictie) van het veneuze systeem bestudeerd.

In hoofdstuk 2 werden de methoden die gebruikt werden om veneuze compliance en venoconstrictie te meten besproken. Zowel veneuze compliance als actieve venoconstrictie werden gemeten in de onderarm met behulp van strain-gauge plethysmografie, gecombineerd met directe intraveneuze 
drukmetingen. Alhoewel de volume/druk relatie van het veneuze systeem een curvilineair verloop heeft, werd de veneuze compliance alleen gemeten in het lineaire deel van de volume/druk relatie, omdat onder deze omstandigheden de veneuze compliance alleen bepaald wordt door de ware visco-elastische eigenschappen van de veneuze wand, in tegenstelling tot de veneuze compliance in het curvilineaire deel van de volume/druk relatie, die meer bepaald wordt door de geometrische toestand van de gedeeltelijk gecollabeerde veneuze wand.

Venoconstrictie werd uitgedrukt door middel van veranderingen van de veneuze tonus (druk/volume ratio). Veranderingen in veneuze tonus na sympathische stimulatie worden alleen bepaald door veranderingen in gladde spierceltonus. Veranderingen in veneuze tonus werden bepaald bij een cuffdruk van $40 \mathrm{mmHg}$, omdat de venoconstrictie gemeten bij hogere transmuraaldrukken onafhankelijk is van veranderingen in flow; zodoende wordt alleen actieve venoconstrictie gemeten.

De veneuze compliance van dialysepatiënten kan worden beïnvloed door de aanwezigheid van hypertensie. Het is echter moeilijk om de aanwezigheid van hypertensie goed vast te stellen bij dialysepatiënten, omdat het niet goed bekend is of de bloeddruk gemeten voor- of na dialyse representatief is voor de gemiddelde bloeddruk tijdens de inter-dialytische periode. De pre-dialytische bloeddruk kan worden beilnvloed door de stijging van het plasma volume gedurende de inter-dialytische periode of door de arousal opgewekt door het begin van de dialysebehandeling, terwijl de post-dialytische bloeddruk kan worden beïnvloed door specifiek aan de dialyse gerelateerde factoren, zoals de daling van het plasma volume en de activatie of verwijdering van vasoactieve stoffen. Daarom werden, zoals beschreven in hoofdstuk 3, niet-invasieve ambulante bloeddrukmetingen gedurende de inter-dialytische periode verricht om vast te stellen of de pre- of post-dialytische bloeddruk representatief is voor de gemiddelde inter-dialytische bloeddruk. Aangetoond werd dat de post-dialytische bloeddruk een betere voorspellende waarde heeft voor de inter-dialytische bloeddruk dan de pre-dialytische bloeddruk en daarom als parameter moet worden gebruikt woor het vaststellen en evalueren van hypertensie bij dialysepatiënten. Verder werd aangetoond dat het dagnacht bloeddrukritme afgevlakt is bij dialysepatiënten.

In hoofdstuk 4 werd bestudeerd of de veneuze compliance verlaagd is bij dialysepatiënten, en zoja, of een eventuele verlaging kan worden beïnvloed door eenmalige orale toediening van een direct werkend venodilaterend agens (Nitroglycerine) of door een driedaagse orale behandeling met een $\alpha_{1}$ adrenoreceptor antagonist (Doxazosine). Aangetoond werd dat de veneuze 
compliance niet verschilt tussen normotensieve dialysepatiënten en normotensieve gezonde controlepersonen, maar verlaagd is bij hypertensieve dialysepatiënten ten opzichte van normotensieve controlepersonen en dialysepatiënten. De veneuze compliance van personen met essentiële hypertensie nam een intermediaire plaats in tussen de hypertensieve dialysepatiënten en de normotensieve groepen.

De verlaagde veneuze compliance in hypertensieve dialysepatienten kon niet worden beïnvloed door toediening van Nitroglycerine of Doxazosine, hetgeen suggereert dat structurele factoren kunnen bijdragen aan de verlaging van de veneuze compliance bij deze groep patiënten.

Daarom werd in hoofdstuk 5 de morfologie van de veneuze wand van normotensieve en hypertensieve uremische patiënten vergeleken met die van controlepersonen zonder een cardiovasculair gecompromitteerde voorgeschiedenis. De dikte van de media bleek niet te verschillen tussen normotensieve uremische patiënten en controlepersonen, maar was significant groter bij hypertensieve uremische patiënten, hetgeen mogelijk zou kunnen bijdragen tot de verlaagde veneuze compliance in deze patiëntengroep.

Ook werd een verhoogd gehalte aan glad spierweefsel geobserveerd in verschillende normotensieve en hypertensieve uremische patiënten, hetgeen zou kunnen zijn veroorzaakt door een verhoogde veneuze druk of door een effect van circulerende trophische substanties.

In hoofdstuk 6 werd de hemodynamische invloed van een verlaging van de veneuze compliance bestudeerd in dialysepatiënten gedurende geïsoleerde ultrafiltratie. De veneuze compliance bleek negatief gecorreleerd met de daling in centraal veneuze druk en de afname van het plasma volume gedurende ultrafiltratie. De grotere daling van de centraal veneuze druk bij patiënten met een verlaagde veneuze compliance wordt waarschijnlijk veroorzaakt door de afgenomen volume/druk relatie van het veneuze systeem, terwijl de toegenomen afname van het plasma volume waarschijnlijk te wijten is aan een verminderde terugvulling van plasma volume uit het interstitieel volume door een verandering in de relatie tussen plasma volume en interstitieel volume. Deze veranderde relatie kan verklaard worden door een verstorend effect van de afgenomen veneuze compliance op het capillaire Starling evenwicht.

De arteriële bloeddruk en hartslag bleven onveranderd in alle patiënten, hetgeen waarschijnlijk te wijten is aan een adequate activatie van cardiovasculaire compensatiemechanismen tijdens geissoleerde ultrafiltratie. 
In hoofdstuk 7 werd bestudeerd of de actieve reactie van het veneuze systeem op een sympathische stimulus intact was in normotensieve en hypertensieve dialysepatiënten. De studie werd verricht de dag na dialyse bij normovolemie. Het sympathische zenuwstelsel werd gestimuleerd door middel van een cold pressor test. Ook werd de functie van de totale baroreceptor reflexboog getest door middel van de Valsalva manoeuvre. Ondanks een pathologische reactie op de Valsalva manoeuvre reageerden zowell normotensieve als hypertensieve patiënten met een actieve toename in veneuze tonus en een stijging van de arterielle bloeddruk gedurende de cold pressor test. Dit suggereert dat het autonome defect bij dialysepatiënten niet gelokaliseerd is in het efferent sympathische deel van de baroreceptor reflex boog. Ook lijkt bij dialysepatiënten een afgenomen eind-orgaan gevoeligheid voor het effect van catecholamines een geringe rol te spellen.

In hoofdstuk 8 werd bestudeerd of de hemodialysebehandeling zelf de vasculaire reactie tijdens een daling van het plasma volume kan beïnvloeden. Daarom werden veranderingen in veneuze tonus en perifere vasculaire weerstand gemeten, zowel tijdens geïsoleerde ultrafiltratie als tijdens ultrafiltratie gecombineerd met bicarbonaatdialyse. Hoewel de daling van het plasma volume niet verschilde tussen beide behandelingsmodaliteiten, stegen zowel de veneuze tonus als de perifere vasculaire weerstand significant tijdens geïsoleerde ultrafiltratie, in tegenstelling tot ultrafiltratie gecombineerd met dialyse, tijdens welke zowel de veneuze tonus als de perifere weerstand niet significant veranderden. De reactie op de Valsalva ratio correleerde niet met de vasculaire reactie, noch tijdens geïsoleerde ultrafiltratie, noch tijdens ultrafiltratie gecombineerd met hemodialyse. Dus de behandeling zelf heeft een negatieve invloed op de vasculaire reactie tijdens hemodialyse. Verder kan gesteld worden dat autonome functietesten die berusten op hartslagveranderingen geen predictieve waarde hebben voor de vasculaire reactie tijdens een daling van het plasma volume.

Concluderend draagt het veneuze systeem in twee opzichten bij aan de gestoorde hemodynamische respons van hemodialysepatiënten; Ten eerste door een verlaging van de veneuze compliance bij hypertensieve dialysepatiënten, hetgeen de plasma volume preservatie nadelig beïnvloedt en tot een forsere daling van de centraal veneuze druk kan leiden. Ten tweede is de mobilisatie van hemodynamisch inactief bloed volume verstoord als ultrafiltratie tesamen met hemodialyse wordt verricht, hetgeen kan leiden tot een 'pooling' van het plasma volume. Al deze factoren kunnen de veneuze return negatief beïnvloeden en aldus leiden tot een daling van de cardiac output (zie figuur op pagina 124). 
Als de cardiovasculaire regulatiemechanismen intact zijn, zoals het geval is wanneer vocht verwijderd wordt tijdens geissoleerde ultrafiltratie, of wanneer de hartfunctie van de patiënten intact is, hoeven deze veneuze afwijkingen miet noodzakelijk tot hypotensiewe perioden te leiden, zoals aangetoond in de studies beschreven in dit proefschrift. Echter, met name in patiënten met een afgenomen compliance van de linker ventrikel of een anderszins afgenomen linker ventrikelfunctie, die sterk afhankelijk zijn van een adequate veneuze return voor de handhaving van de cardiac output kunnen afwijkingen van het veneuze systeem een belangrijke rol spelen bij het ontstaan van hypotensieve perioden tijdens hemodialyse. In deze patiënten moet het overtollige vocht verwijderd worden met een lage ultrafiltratiesnelheid of met behulp van geïsoleerde ultrafiltratie. 


\section{NAWOORD}

Met veel plezier denk ik terug aan de afgelopen jaren waarin ik gewerkt heb aan het in dit proefschrift beschreven onderzoek. Het feit dat de eerste hobbells al genomen waren bij het begin van mijn aanstelling maakte dat het onderzoek al snel tot resultaten leidde. Dat ik in staat gesteld werd deze her en der op congressen te presenteren heeft voor mij zeker stimulerend gewerkt.

In de afgelopen tijd heb ik veel interessante mensen ontmoet en heb ik met name gezien waartoe een goede samenwerking kan leiden. Steun en medewerking ondervond ik niet alleen binnen de universiteit, waar met name Sjef Wijnen en Luc van Bortel van de afdeling Farmakologie mij met raad en daad bijstonden bij het verrichten van de experimenten, maar ook daarbuiten, waar diverse diallysecentra actief participeerden in het onderzoek. Dr. W. Grave van het St. Laurentiusziekenhuis te Roermond en dr. Th. van der Wiel van het Maaslandziekenhuis te Sittard waren bereid mij hun patienten voor het onderzoek toe te vertrouwen. Prof.dr.med. H. Mann yom Kuratorium für Dialyse in Aachen, mit wem unsere Abteilung schon seit längerer Zeit eine gute Zusammmenarbeit hat, erlaubte uns in seiner Klinik Untersuchungen durchzuführen. Dabei war die Hilfe von dr.med. U. Gladziwa, dr.med. G. Böcker und von Frau J. Stiller unersetzlich.

Het patholoog-anatomische werk was voor mij het moeilijkst, omdat ik hier het minste ervaring in had. Mat Daemen en Monique Verluyten-Goessens hebben veel tijd en energie besteed om mij de technieken aan te leren terwijl Rene Wijnen zorgde voor de verzameling van de veneuze samples. Zodoende hebben ze een belangrijke bijdrage geleverd aan het hoofdstuk over de structuur van de veneuze vaatwand.

Binnen de afdeling Nefrologie heb ik met veel plezier gewerkt. De discussies met mijn kamergenoten Ton Luik en Hennie Peltenburg zorgden voor de nodige ontspannende momenten. De samenwerking met Petra Draaijer verliep steeds uiterst plezierig en was van groot belang voor het vorderen van het onderzoek. Secretariële ondersteuning kreeg ik van Desirée van Schoubroeck.

De leden van de beoordelingscommissie, prof.dr. H.A.J. Struijker Boudier, prof.dr. J.W. Arends en prof.dr. R.S. Reneman, wil ik danken voor hun kritische beoordeling van het proefschrift. I am very honoured that prof.dr. L.W. Henderson en prof.dr. E. Ritz were willing to review my manuscript.

De hulp van de dialyseverpleging van het Academisch Ziekenhuis Maastricht, het Maaslandziekenhuis Sittard, het St. Laurentiusziekenhuis Roermond en het 
Kuratorium für Dialyse te Aachen was van grote waarde bij het verrichten van de experimenten.

Mijn promotores, prof.dr. J.P. van Hooff en prof.dr. P.W. de Leeuw, dank ik voor hun constructieve bijdrage aan het tot stand komen van het manuscript.

Mijn co-promotor, dr. K.M.L. Leunissen: Karel, jouw energie en motivatie zijn bewonderenswaardig. Jij was de drijvende kracht achter het geheel. Zonder jouw stimulerende en opbouwende begeleiding was het verrichten van dit onderzoek onmogelijk geweest. Nooit klopte ik tevergeefs bij je aan voor het bespreken van problemen. Ik heb de afgelopen jaren veel van je geleerd. Bedankt!

Een klinisch onderzoek staat of valt met de medewerking van de patiënten. Daarom will ik alle dialysepatiënten die geheel belangeloos hebben deelgenomen aan de experimenten van harte danken. Ik hoop met dit proefschrift iets meer inzicht te hebben gegeven in de problemen waar zij dagelijks mee kampen. 


\section{CURRICULUM VITAE}

The author of this thesis was born on June 12, 1966 in Maastricht, the Netherlands. He graduated in 1984 from the Stedelijke Scholengemeenschap in Maastricht (Gymnasium- $\beta$ ), after which he attended the Medical Faculty of the Rijksuniversiteit Limburg. From 1987-1988 he worked as a student-assistent at the department of Surgery, Academical Hospital Maastricht. After receiving his doctoral degree in 1988 (cum laude), he received his medical degree in 1990 (cum laude).

At July 15, 1990 he started to work as a research assistant at the department of Internal Medicine, University Hospital Maastricht (head: Prof.Dr. J.A. Flendrig), during which period this thesis was completed. For the work described in chapter 3 he received the Hospal Award from the Benelux Dialysis Society.

After attending military service he will start his residency in Internal Medicine in October 1993 at the University Hospital Maastricht (head: Prof.Dr. J.A. Flendrig). 